\title{
Metachoice and metadata : innovating with environmental policy analysis in Europe
}

Citation for published version (APA):

Badkas, S. K. (2014). Metachoice and metadata : innovating with environmental policy analysis in Europe. [Doctoral Thesis, Maastricht University]. Boekenplan. https://doi.org/10.26481/dis.20141120sb

Document status and date:

Published: 01/01/2014

DOI:

10.26481/dis.20141120sb

Document Version:

Publisher's PDF, also known as Version of record

\section{Please check the document version of this publication:}

- A submitted manuscript is the version of the article upon submission and before peer-review. There can be important differences between the submitted version and the official published version of record.

People interested in the research are advised to contact the author for the final version of the publication, or visit the DOI to the publisher's website.

- The final author version and the galley proof are versions of the publication after peer review.

- The final published version features the final layout of the paper including the volume, issue and page numbers.

Link to publication

\footnotetext{
General rights rights.

- You may freely distribute the URL identifying the publication in the public portal. please follow below link for the End User Agreement:

www.umlib.nl/taverne-license

Take down policy

If you believe that this document breaches copyright please contact us at:

repository@maastrichtuniversity.nl

providing details and we will investigate your claim.
}

Copyright and moral rights for the publications made accessible in the public portal are retained by the authors and/or other copyright owners and it is a condition of accessing publications that users recognise and abide by the legal requirements associated with these

- Users may download and print one copy of any publication from the public portal for the purpose of private study or research.

- You may not further distribute the material or use it for any profit-making activity or commercial gain

If the publication is distributed under the terms of Article $25 \mathrm{fa}$ of the Dutch Copyright Act, indicated by the "Taverne" license above, 


\section{Metachoice and Metadata \\ Innovating with Environmental Policy Analysis in Europe}

Sachin Kumar Badkas 
(C) 2014 Sachin Kumar Badkas

All right reserved. No part of this publication may be reproduced, stored on a retrieval system, or transmitted in any form, or by any means, electronic, mechanical, photocopying, recording or otherwise, without prior permission in writing from the author.

ISBN 9789086663521

Published by Boekenplan, Maastricht 


\title{
Metachoice and Metadata \\ Innovating with Environmental Policy Analysis in Europe
}

\author{
Dissertation
}

To obtain the degree of Doctor at Maastricht University, on the authority of Rector Magnificus, Prof. Dr. L.L.G. Soete in accordance with the decision of the Board of Deans, to be defended in public on Thursday, 20 November 2014, at 1600 hours

By

Sachin Kumar Badkas 


\section{Supervisor:}

Prof. Dr. Michael Faure, Maastricht University \& Erasmus University Rotterdam

\section{Assessment Committee:}

Prof. Dr. Bart Verspagen, Maastricht University, chairperson

Prof. Dr. Lars Hansson, Lund University

Prof. Dr. Renee Kemp, United Nations University-MERIT

Prof. Dr. Anthony Ogus, University of Manchester 
The formulation of a problem is often more essential than its solution, which may be merely a matter of mathematical or experimental skill. To raise new questions, new possibilities, to regard old problems from a new angle, requires creative imagination and marks real advances.

- Albert Einstein

राजा पश्यति कर्णाभ्यां धिया पश्यन्ति पण्डिताः।

पशु: पश्यति गन्धेन भूते पश्यन्ति बर्बराः॥

Administrators perceive by their ears,

The wise by their intellect.

Animals perceive by scent, and fools by the past.

- Sanskrit Shloka

It is our choices that show what we truly are, far more than our abilities.

- Harry Potter and the Chamber of Secrets by J.K. Rowling 


\section{Acknowledgements}

Michael Faure is not just the supervisor for this research, he unintentionally set the topic of the research, by sparking curiosity as only the best of teachers can. I have him, Thomas Lindhqvist, Lars Hansson and Andreas Plepys from IIIEE, Lund University to thank in the greatest measure. Their lectures falling in quick succession triggered the thoughts behind this work. I cannot just thank them here though; no words would be enough.

Apart from the many teachers at school, engineering, business school and MSc, all of whom have contributed at the very least by inspiring me to take up their walk of life, I thank all the teachers from the PhD program, Jon Qvist, Denis de Crombrugghe, Eddy Szirmai and Katrin Kriz in particular. This also owes much to all on the assessment committee, for reading this and for much valued critique.

Discussions with the academic staff and debates with fellow pursuers of the doctorate have helped me grow as a researcher. For specific influences that I remember, I must thank in the fullest measure researchers at Maastricht University and UNU alike: Eddy Szirmai, Mindel van de Laar, Boris Blumberg, Marjan Peters, Stefan Weishaar, Dalindyebo Shabalala, Denise Prévost, Anselm Anders, Peter van de Bosch, Biniam Bedasso, Lutz Krebs, Julie Grier, David Rodríguez, Tatiana Skripka, Luciana Cingolani, Sepideh Yousefzadeh, Henry Espinoza, Esther Schüring, Antony Otieno, Güney Celbiş, Cheng Boon Ong, Zina Nimeh, Elvis Amoateng, Clovis Freire, Rashad al-Khafaji, François Lafond, Shuan Sadre Ghazi, Daniel Opolot, Robin Cowan, Can Huang, and Stefania Innocenti. I may also mention some from Erasmus University Rotterdam, Paris $X$ and Universität Hamburg for a memorable academic exchange: Natalia Lyarskaya, Massimiliano Gambardella and Inna Lubareva in particular. Likewise virtually all speakers in the lunch seminar series from September 2008 to October 2014; I learned nearly as much from them, if not more, as from writing this on a single topic. Just as to teachers and colleagues, I owe much to students. Those at University College Maastricht - that teaching evaluation buoyed me up for months - and those in our MPP and PhD programs. If I may single out Tomas Damerau for sharing some candid criticism of my teaching. Thank you, one and all.

It would be terribly remiss not to thank the staff at the School of Governance Susan Roggen, Mieke Drossaert, Floortje van Laarhoven-Bergmans, Janneke Knaapen, Céline Duijsens-Rondagh, Anouk Mohammed, Martin Rehm, Ana-Maria Raus , Danny Beckers, Monique Raedts; the staff at METRO - Yleen Simonis, Marina Jodogne, Chantal Kuypers, Marjo Mullers; UNU staff- Eveline in de Braek, 
Eric Engelen, Wilma Coenegrachts, Marc Vleugels, Mourik Jan Heupink, Sueli Brodin, Ad Notten, Herman Pijpers, Howard Hudson; the staff at UM - Anja Bouwers, Mayke Pothof and others. They have all at some point had a direct hand in facilitating some part of the research or related work.

Besides the interviewees named, this benefits from the advice of several other professionals not mentioned in the main text: Alex Marten of the US EPA, Andrew Jordan of the University of East Anglia, Philip Drauz of the European Parliament, Jan Teekens of the Dutch Environment Ministry, Åsgeir Helland of Xynteo, Leonardo Secchi of the Universidade do Estado de Santa Catarina. They all have my heartfelt gratitude.

Little reveals what one is made of as the challenges one overcomes and those that one does not. Tongue partly in cheek, I thank some that made this a greater challenge that one expects it to be. 
The general quality of environmental indictors across the European Union and the associated success of environmental policy is the envy of the world. The Union has led the way in stringent but market-friendly Environmental Policy and prides itself on its role as the environmental steward in the world, propagating higher standards and leading by example. The stringent regulation also gives the region an economically competitive edge, which might well become the defining differential advantage of 21st century global trade.

That lead, however, is scarcely guaranteed in perpetuity. On the one hand, the financial crisis since 2008, the subsequent Eurozone recession and a sovereign debt crisis have severely constrained the policy space across the Union. On the other, emerging economies with booming industries find themselves both with more fiscal flexibility and popular demand for policy reforms. At its core, this research work studies ways to sustain Europe's lead in environmental policy, primarily by innovating with policy analysis, and supplementary action to harness opportunities as only a leader can.

Even in policy domains less fragmented and complicated than environmental policy, no amount of effort can show a particular policy option to be indubitably better than all the others on the table and for everyone at the table. The reason that limits are drawn on the time and effort spent on making public choices is that all the expense involved comes out of the public pocket itself. To put it differently and to motivate the main idea in this proposal, the cost of a truly "rationalcomprehensive" choice is prohibitive. Hence the design and evaluation of public policy is a broad topic of increasing academic and political interest. The kinds of policy instruments both in practice and on the shelf is also rising.

Economic analysis is at the heart of all choices. Plants and animals weigh costs and benefits in careful decision even if it is by coded instinct and not voluntary or conscious. It is, after all, the simplest form of rational choice. And that is the strongest argument in support for using it and continually improving it. When someone uses it, everyone else readily understands the rationale. Whether or not they agree with all the parameters involved is quite another question, but as a chosen method, they understand it. In fact, it is precisely because they understand the basic logic, that many will be able to raise astute objections as to the finer details. That has been the fate of economic analysis of public policy, and perhaps to a greater degree, of environmental policy in particular. Though multiple forms of policy evaluation exist, in the realm of environmental policy, almost all analysis 
takes an economic form, often in the guise of Cost-Benefit Analysis (CBA) or its cousin, Cost-effectiveness Analysis (CEA).

The objective of the first part of this research is to propose, explain and study a specific analytical innovation. The new method enables a categorical scrutiny and comparison of costs of environmental policy instruments in a well-defined frame of reference. More specifically, we examine the choice of the reference frame for CEA with inspiration from another popular form of environmental analysis, Life Cycle Analysis (LCA), which attaches a great deal of importance to frames of reference.

The innovation serves several purposes. Firstly it enables a disaggregated comparison of corresponding costs, which in turn unlocks a wealth of information invaluable to the critical design of policy instruments at the analyst's level. In the European Union, the proposed method enables a comparison of costs with respect to the contextual differences between member states when transposing regulation. Proper comparison of certain categories of costs such as administrative costs would also facilitate a form of governance analysis. It will help in examining the interaction effects of costs of concurrent policies in other sectors. The matter of costs is also a significant consideration in the operationalization of the precautionary principles and the choice of an analytical frame of reference would help resolve some issues regarding perceived disproportionate costs.

The dissertation begins with the history of economic analysis and a review of relevant literature in chapter two. It covers the current practice in environmental policy and a broad overview of both older and current issues with CBA, the most common method of such analysis, of which CEA can be seen as a subset. The review is necessary to lay out the limitations and the humble scope of this thesis with regards to solving the outstanding issues, while acknowledging the major ones. That scope is defined at the beginning of the very next chapter, chapter three, with the research questions. That chapter also motivates the methodological choices made for the diverse parts of this work.

The next chapter turns to the rationale for innovating with CEA and presents the proposed adaptation itself. It lays out the inspiration behind the idea, introduces LCA, and explains the adaptation to economic analysis of environmental policy instruments. Several examples are included for illustration.

Chapter five is devoted to the analytical tests of the adapted method in the form of quantitative case studies. Each of the cases uses a different computer-based model used in actual policy making at governments, thus providing a test with realworld data and parameters. The objective is to show how the results of a typical 
CEA exercise would change if additional contextual information were to be incorporated into the choice framework using the proposed adaptation. An attempt has been to made to illustrate choice reversals, merely to emphasize the potential impact on policy decisions.

This is followed by a conversation by the ultimate clients of this research, i.e. policy analysts, in chapter six, which uses Key Informant Interviews. The discussion tries to discover information on matters ranging from the nature and degree of the use of economic analysis in practice to the typical educational background of analysts and their colleagues, and the challenges they face in their duties.

A recurring finding in that chapter concerned problems with data availability. Hence, the next chapter seeks remedies to the data shortage in light of opportunities presented by current technology and media trends. It reviews the current buzz around the promise of Big Data, and empirically investigates the potential of that promise to this particular area. The concluding chapter, the eighth, assesses how well the research meets the primary promised goals and critically assesses other values it offers. This chapter also concedes the limitations of this research and indicates avenues for overcoming them and for research to further the central ideas. 


\section{Table of Contents}

Chapter 1 The Setting ........................................................................................ 1

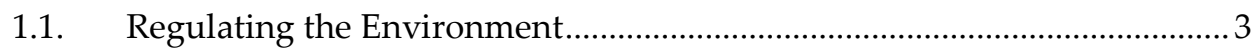

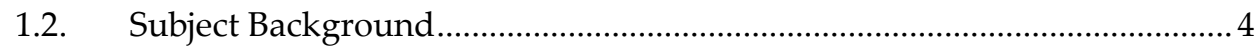

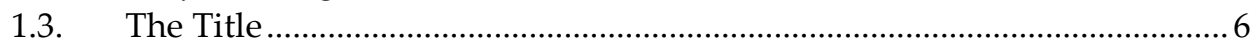

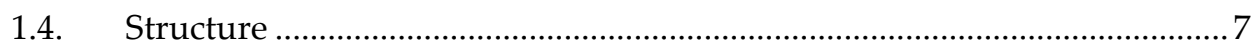

Chapter 2 Cost Benefit Analysis and its Limits........................................................10

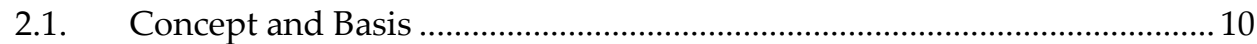

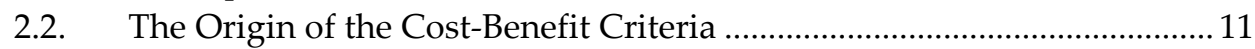

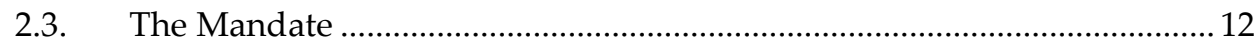

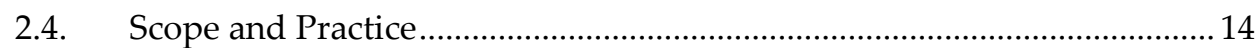

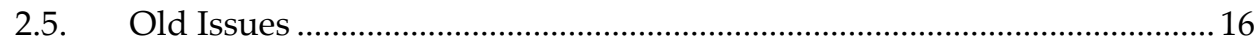

2.5.1. Fundamentals............................................................................. 16

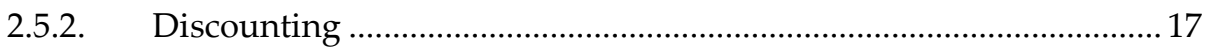

2.5.3. Values and Measurement ………………………………………...... 19

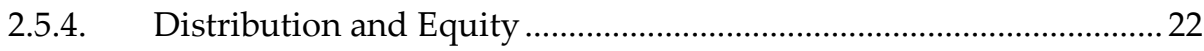

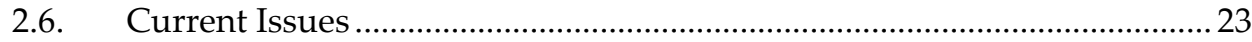

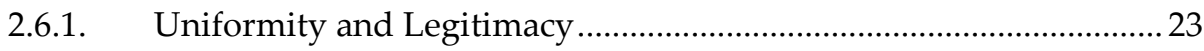

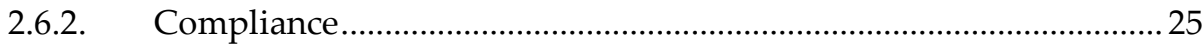

2.6.3. Uncertainty, Morality and Precaution ……………………………….... 26

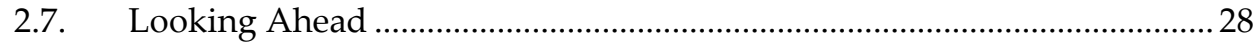

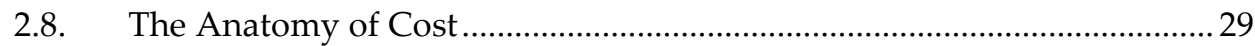

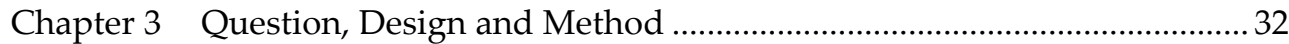

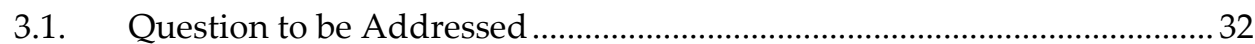

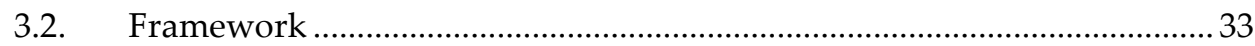

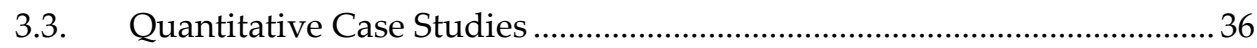

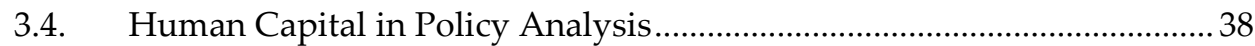

3.5. Exploring the scope of Big Data for Policy Analysis ....................................39

Chapter 4 Innovating with the Analytical Method ..................................................... 40

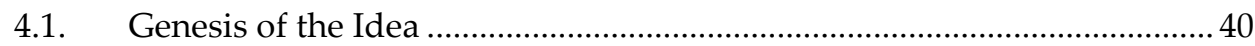

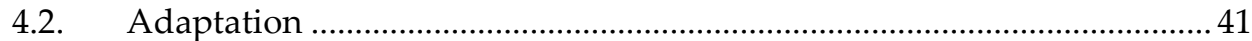

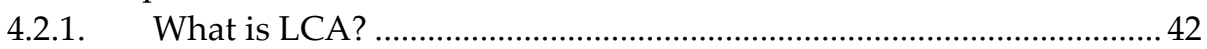

4.2.2. Contextual Equivalence a la LCA ........................................................... 45

4.2.3. "Functional Units" for Policy …………………………………………..... 46

4.2.4. Expanded Cost Taxonomy …………………………………………..... 47 


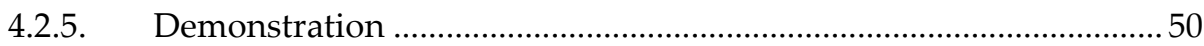

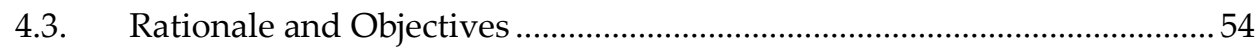

4.3.1. Equivalence for Fair Comparison........................................................54

4.3.2. Efficiency in Instruments Design........................................................... 55

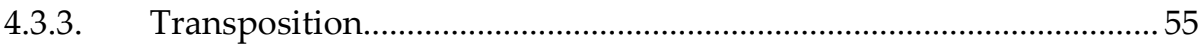

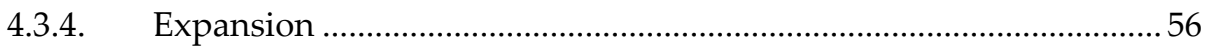

4.3.5. Governance Analysis ......................................................................... 57

4.3.6. Proportion and Precaution .................................................................... 57

4.3.7. Concurrent Costs of Other Policies ........................................................ 58

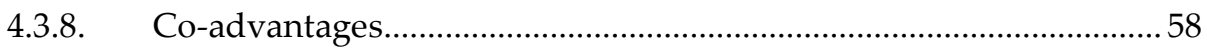

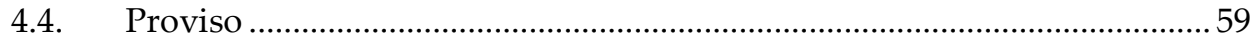

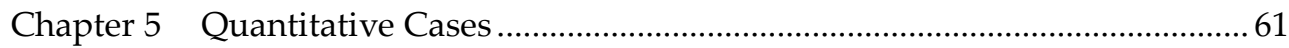

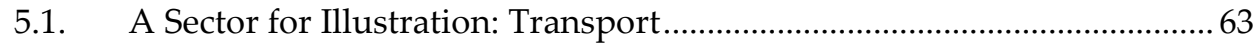

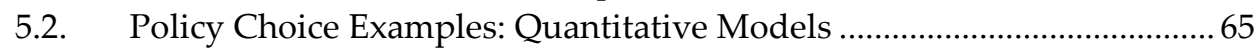

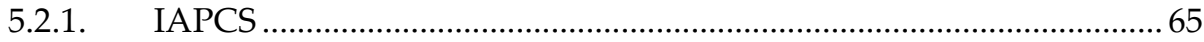

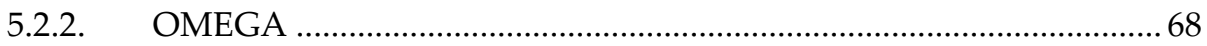

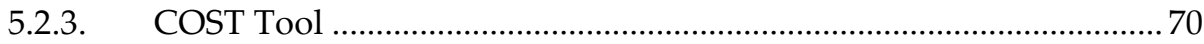

5.2.4. DEFRA Agricultural Model ............................................................ 72

5.2.5. EIO-LCA: German Economy.............................................................. 74

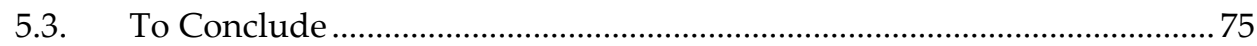

Chapter 6 Dialogue with Policy Analysts .................................................................

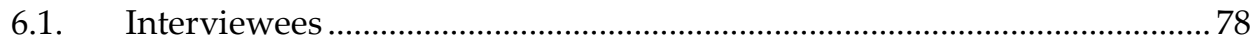

6.2. Recruitment, Profile and Position Relative to Policy-Making................... 79

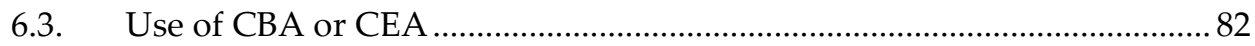

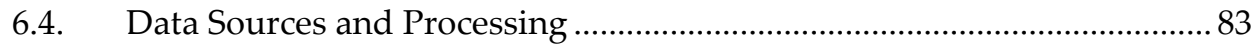

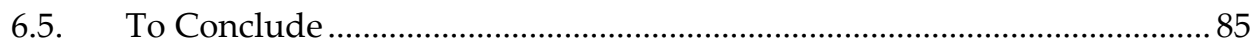

Chapter 7 A Word on Data and Analysis ................................................................... 89

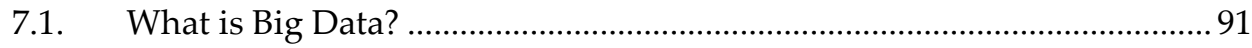

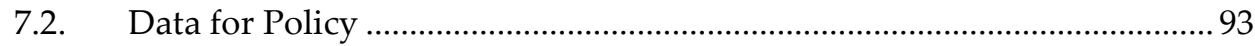

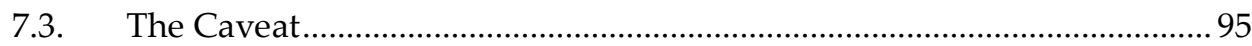

7.4. New Sources of Environmental Data ………………............................. 95

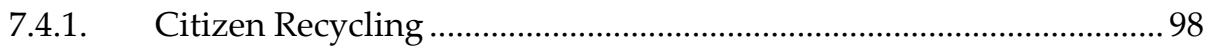

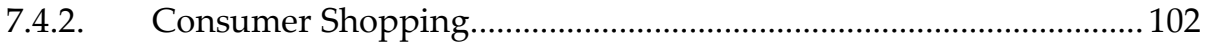

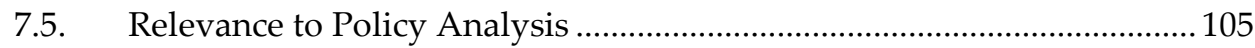




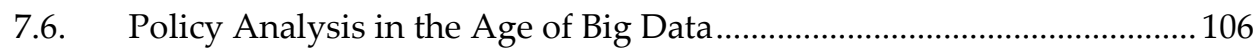

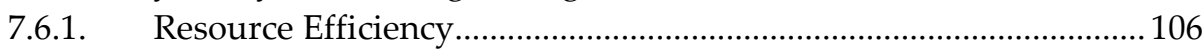

7.6.2. New Denominators for the Chapter 4 Approach................................. 108

7.6.3. Bottlenecks, Hotspots and Crises ........................................................ 108

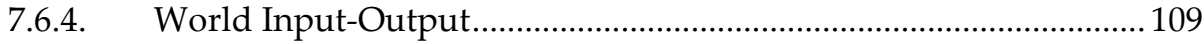

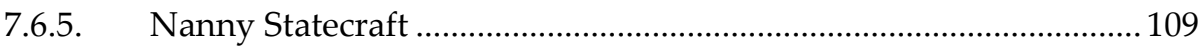

7.6.6. Uncertainty, Precaution and Discounting ............................................ 110

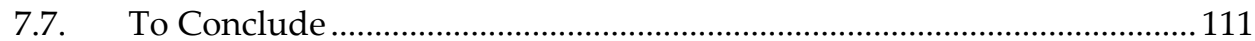

Chapter 8 To Valorise and Conclude......................................................................... 113

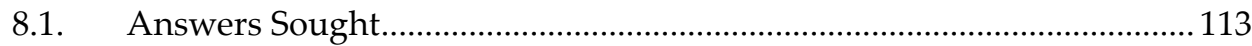

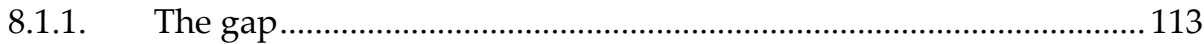

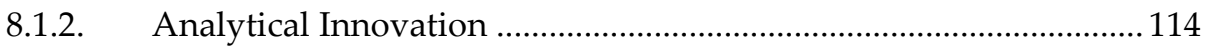

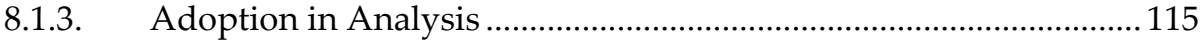

8.1.4. Promise of Big Data ............................................................................. 116

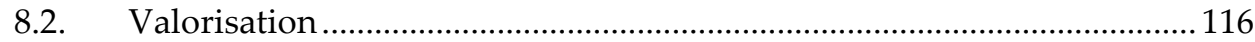

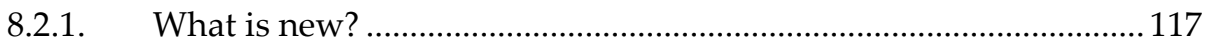

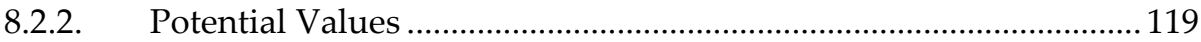

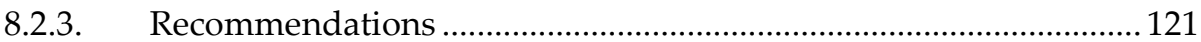

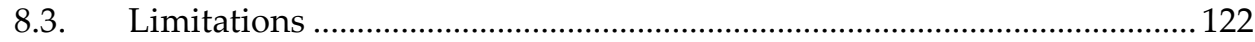

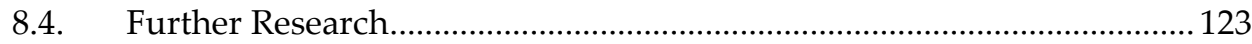

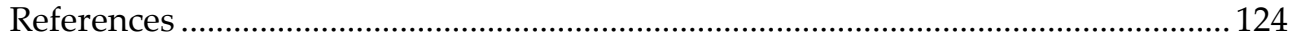

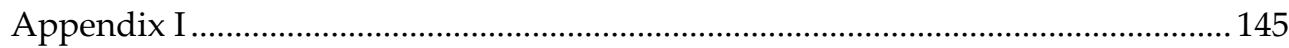




\section{List of Figures}

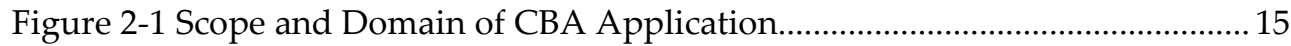

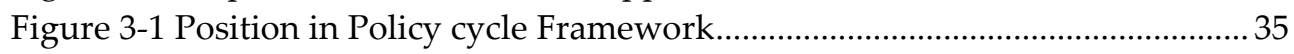

Figure 5-1 Cost Profile for a Range of Emission Reduction ............................................ 61

Figure 5-2 Cost Profile for a Range of Emission Reduction - Case 2 .........................62

Figure 5-3 Sample Visualization of Aggregated Costs of Emission Reduction......... 63

Figure 5-4 Cost Profile for NOx Reduction Technologies against Operating Labour

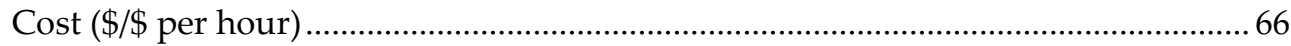

Figure 5-5 Cost Profiles for Technology and Policy Mixes for NOx Reduction against Operating Labour Cost $(\$ / \$$ per hour).

Figure 6-1 Schematic: Human Capital Sourcing and Building for Policy Analysis. 86 Figure 7-1 Correlation Between Relevant Online Search Activity and Official Flu

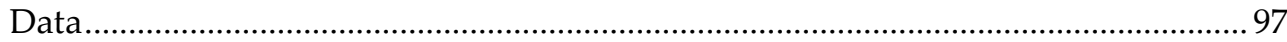

Figure 7-2 Search Popularity in \% (Y axis) vs. WEEE Collected from Households

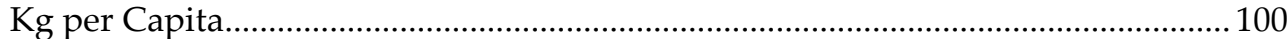

Figure 7-3 Search Popularity in \% (Y axis) vs. Total WEEE Recycled and Reused (\%)

Figure 7-4 Geographic Variation in Search Activity for the Swedish equivalent of "recycling" 102

Figure 7-5Census Data for Retail Sales of Women's Clothing vs. Online Search Activity for "Gift for mother" 103

Figure 7-6 Retail Sales of Women's Clothing vs. Normalized Search Activity for Related Terms 104

Figure 7-7Retail Sales of Men's Clothing vs. Normalized Search Activity for "travel gift" 104 


\section{List of Tables}

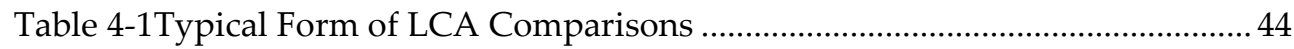

Table 4-2 Elements of an LCA Comparison ................................................................ 44

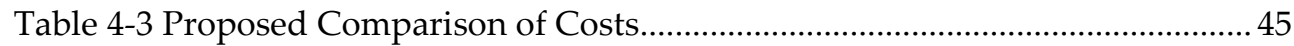

Table 4-4 Proposed Cost Comparison with Correction Factor .................................... 47

Table 4-5 Building a Taxonomy of Costs for a CEA Exercise …….............................. 48

Table 5-1 Illustration with Various Units in the Transport Sector ...............................64

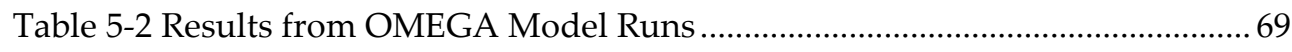

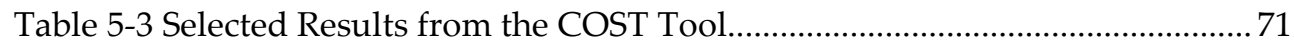

Table 5-4 CEA Choices between Selected Farm Types ................................................. 74

Table 5-5 Pollutants in Metric tons for 1 million Deutsche Marks of Output in 1995

.75

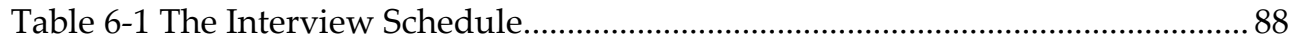

Table 7-1 Recycling: Search Term Popularity on Google and EUROSTAT Data ..... 99

Table 7-2 Correlation between search popularity and waste collected per capita. 100 


\section{List of Abbreviations}

ACCF American Council for Capital Formation

APPAM Association for Policy Analysis and Management

ASPA American Society for Public Administration

BAT Best Available Techniques

BCR Benefit-to-cost Ratio

CBA Cost Benefit Analysis

CEA Cost-effectiveness Analysis

CEB Cost Effectiveness Basis

CEPS Centre for European Policy Studies

DEFRA (UK) Department for Environment, Food and Rural Affairs

EC European Communities

EGR Exhaust Gas Recirculation

EIO-LCA Economic Input-Output Life Cycle Assessment

EPA Environmental Protection Agency

EPR Extended Producer Responsibility

EU European Union

EUCAR European Council for Automotive R\&D

GDP Gross Domestic Product

GFT Google Flu Trends®

GHG Green House Gas

GPP Green Public Procurement

GPS Geographical Position System

IAPCS Integrated Air Pollution Control System

IIIEE International Institute for Industrial Environmental

Economics

IO Input-Output (Analysis)

IP Internet Protocol

IPP Integrated Product Policy

ITC Investment tax credit

JPAM Journal of Policy Analysis and Management

LCA Life Cycle Analysis

MPP Master's in Public Policy

MPV Multi-purpose Vehicle

NAO National Audit Office

NASPAA Network of Schools of Public Policy, Affairs, and Administration 
OIRA Office of Information and Regulatory Affairs

OMB Office of Management and Budget

OMEGA Optimization Model for reducing Emissions of Greenhouse

Gases from Automobiles

RFID Radio Frequency Identifiers

RIA Regulatory Impact Assessment

SEPA Swedish Environmental Protection Agency

(Naturvårdsverket)

TAR Technical Assessment Report (of the Intergovernmental

Panel on Climate Change)

TEB Technology Effectiveness Basis

(US)EPA United States Environmental Protection Agency

VMT Vehicle Miles Travelled

VOC Volatile Organic Compounds

WEEE Waste Electrical and Electronic Equipment 



\section{Chapter 1 The Setting}

The general quality of ambient environmental indictors across the European Union and the associated success of environmental policy are the envy of the world. The Union has led the way in stringent but market-friendly Environmental Policy and prides itself on its role as the environmental steward in the world, propagating higher standards and leading by example (Jordan \& Adelle, 2012). The stringent regulation also gives the region an economically competitive edge, which might well become the defining differential advantage of $21^{\text {st }}$ century global trade.

That picture though may begin to gradually change. Europe's lead in environmental policy is threatened from several quarters - economic crises, the constrained budgets and policy space in its wake, a general climate of uncertainty and emerging economies catching up in terms of environmental technologies and relatively less constrained by budgets.

The financial crisis of 2008 and the economic downturn that followed has lasted nearly the entire length of this doctoral work. Europe too, in this duration has been under the pall of the Eurozone Recession and a Sovereign Debt crisis. Though it remains a contested move, a number of countries on the continent responded with public sector austerity, cutting down government spending across the board.

Reportedly, emerging economies, which, with their booming industries had more fiscal wriggle room to begin with, showed signs of an earlier recovery and a relatively unscathed financial sector. In a parallel development, countries like China also happen to be on a drive to clean up their industries and there is palpable renewed political will ("Red light, green light," 2014) to bring environmental policy up to par with international standards. That is certainly due in no small part to a recognition of the aforementioned potential role of technological and environmental standards in trade advantages.

This work is also motivated by the conviction that the EU, quite apart from its lead in environmental standards, is uniquely placed to inspire the world to deal with environmental problems.

Environmental problems everywhere in the world tend to span national borders. Even within a country, the various economic connections and resulting impacts of mitigation efforts on various sectors make the problems particularly intractable. 
In a different time, princes or chieftains of small estates gathered and formed a pact or adopted a charter when faced with a common threat that none could deal with alone. A state trades in a parcel of sovereignty, but that is not always at odds with its essence as a state. In fact, when the challenge is to the existence of the state itself, the trade is entered into precisely to further the sovereign interest.

That is what the EU strived to achieve with its experiment with an overarching union. The primary goal may well have been facilitating trade in coal and steel, the secondary to promote a sense of political integrity across the continent to avert further wars, but it is with the environment that the experiment has borne the ripest fruit. When confronted with environmental problems and with a political motivation to set itself apart from other economic behemoths on some value, the European Union rallied its members around a strict code of environmental stewardship. Self-acclaimed though the code might initially have been, political will from leading nations in the union forged it into reality. Regulation that would be considered too stringent at a national level in some states found a supranational back door to get formalised into binding law. There is clearly something about transacting policy beyond the arena of national politics that makes for the adoption of otherwise unpalatable solutions.

In that and less notably in other spheres, the EU has shown how jurisdictions may rise above differences and relinquish bits of sovereign space to resolve matters that essentially need exactly that. It is a profound experiment in governance to be watched closely, as globally we stumble upon more and more problems that seem to demand supranational handling.

Europe then bears the burden of responsibility to continue its lead in environmental stewardship, so that the world can stick to its model example.

Those developments then are constitute the motivation behind this research work. With the economic downturn of recent years and a focus on economic growth on one hand and fiscal austerity on the other, the pace of environmental action might slowdown in the developed world and emerging economies might pick up the baton. There are already signs of some of these countries more than catching up in the development of environmental technologies ("China leads world in green energy investment," 2011; Hargreaves, 2013). It may only be a matter of time before they catch up in environmental regulation as well.

That would be all very well for the world and everyone wishes that the emerging economies take that route, but the Environmental cause will also benefit from Europe maintaining its lead. That is of course not achieved by betting on 
stagnation elsewhere, but by building on past head start and experience. The case can also be made that maintaining that lead is also in Europe's best economic interests (European Commission, 2011; Lewis, 2013). In the same sense that Sidney Winter (2003) talks of "sustainable advantage" and "dynamic capabilities" for firms in a competitive market, states or regions may also strive to strategically maintain a sustained lead in terms of regulation.

This disquisition is an attempt to study ways in which the European Union and constituent states might go about just that. At its core, it identifies and then examines a number of ways in which Europe might maintain its lead in environmental policy. It looks at three ways, to be precise: a new analytical approach for a subset of policy choices, an appraisal of the human capital invested in policy analysis and, thirdly, exploring the opportunities in the emergent information phenomenon of this decade.

\subsection{Regulating the Environment}

Many may have touted this about their own public policy niche and many more may indeed have asserted this about this very niche too, but repetition can do little harm if it is required to set the premise of this research. Environmental policy is uniquely difficult among policy sectors.

By and large, environmental policy does not bring direct legitimate benefits (or payoffs) to any human actors or legal persons. (Since its origins, environmental policy has been championed for the effects on human health rather than the environment for its own intrinsic sake, but a possible reduction in the medical bill is an indirect uncertain benefit, unlike the tax exemption that stands out in real numbers when declared on paper.) Politicians cannot sell environmental policy the way they can some other policies, with the exception of green parties that are arguably not yet a worldwide phenomenon. There are generally no subsidies or transfers for voters en masse that would get anyone voted in. There are mostly taxes and costs that get governments voted out. Not to imply that the only motivations in electoral or legislative processes are always and purely economic (Kau, Keenan, \& Rubin, 1982), but broadly speaking, most other sectors of policy are driven by the dollar. In periods of global economic downturn, such as the duration of this doctoral work, matters go from bad to worse. What most nations do under environmental policy is not down to their legislatures; it is despite them. Parliaments and congresses do not cheer and champion environmental policy; they begrudgingly enable and allow it. 
With that in mind, all ways to make environmental policy cheaper are hence ways to sell it better. They make way for better policy in turn. All new devices that take a critical look at costs of environmental policy in a novel way are hence welcome.

The first of the three objects of this research is to enable a categorical scrutiny and comparison of costs of environmental policy instruments in a well-defined frame of reference. More specifically, we study the choice of the reference frame with inspiration from another popular form of analysis which accords a great deal of importance to frames of reference. One of the primary aims is to go beyond the customary practice of aggregation in economic analysis of policy. Official guidelines for conducting economic analyses such as Cost-Benefit Analysis (CBA) commonly involve the summation of all relevant costs on one side and all benefits on the other before a comparison is made. Enabling disaggregated comparison of like costs unlocks a wealth of information invaluable to the critical design of policy instruments at the analyst's level. Along the way, the new form of analysis offers a number of other analytical values.

\subsection{Subject Background}

No amount of effort can show a particular policy option to be indubitably better than all the others on the table, for everyone at the table. The reason that limits are drawn on the time and effort spent on making public choices is that all the expense involved comes out of the public pocket itself. To put it differently and to motivate the underpinning idea in this research, the cost of a truly "rationalcomprehensive" 1 choice is prohibitive. The bounds on rational choice are, of course, not just of the economic kind (Kahneman, 2003; Simon, 1991), but that is a matter for another day.

Evaluation of public policy is a broad topic of increasing academic and political interest. While part reason of the interest is the limit to analysis mentioned above, the other part reason is surely the fact that the kinds of policy instruments both in practice and on the shelf is rising. The losses in translation, as it were, from instruments as described in academia to the version put into practice (Lévêque, 2000), do not help the poor policy analyst either. Add to that the fact that between the text book and the law book an instrument may spend a long time on dusty shelves and the situation gets far worse.

\footnotetext{
${ }^{1}$ The 'rational-comprehensive' method is described as part of one of the commonly accepted theories of the policy process. A complete treatment of the subject appears in Weimer, D. L., \& Vining, A. R. (1999) Policy Analysis: Concepts and Practice. Prentice Hall.
} 
As the objects of evaluation multiply, the forms of evaluation analyses have themselves grown in number. The 'Magenta Book', a guiding document for policy evaluators issued by the Government Social Research Unit in the UK, presents a comprehensive list of methods (UK Government Social Research Unit, 2007). It distinguishes between:

Summative evaluation

Process evaluation

Theory-based evaluation

Experimental evaluation - Randomized Control Trials (RCT)

Qualitative evaluation

Economic evaluation

As more and more methods of analyses are peddled, the one consideration that escapes mention is whether a new evaluation method proposed is cheaper and quicker to conduct than those already known and used. Are any of the policy instruments under consideration themselves cheaper to implement? These questions rarely get asked, although given how policy processes progress, they are crucial questions.

Regrettably, analytical methods employed for cutting-edge environmental policy are often far from the cutting-edge themselves, often even ill-suited. Part of the reason may be that the two edges are far removed from each other - divided by the Atlantic, it may seem. As an academic discipline and as a profession, policy analysis has its origin in American universities closely working with or observing US government processes. Governments in Europe "imported" it from the US much later (Saretzki, 2007). It is somewhat of a paradox that while Europe has been slow in latching onto that buzz, it has emerged a clear and consistent leader in the area of environmental policy (Vig \& Faure, 2004; Vogler \& Stephan, 2007). That leadership can be strengthened if state-of-the-art tools of policy analysis are rigorously and critically applied to the recent environmental policy momentum in the EU.

Authoritative academics in the area of policy analysis have noted that for analysts, ex-ante analysis is the most problematic stage in the policy process (A. Vining \& Boardman, 2006). This is truer especially in the European context when they are faced with a befuddling choice of policy instruments previously tried with success in other member states (Halpern, 2010). Easing the choices can help maintain and even boost the aforementioned European leadership, with faster policy diffusion through EU directives. 
On the other hand, another prominent opinion is that for better policy instruments to evolve, it would help if analysts are given a greater say in the policy process (Bromley, 1990; Schmid, 1989; Turner, 2007; Viteritti, 1982) and if they take up that role. This author comes firmly from that school and the opinion is in fact one of the fundamental premises behind this research. The adaptive analytical method proposed and investigated here is to arm the policy analyst with more information and means to use that information for arguments. (This is complementary to the positioning in sections 2.4 and 3.2.) The single most important benefit sought is for the analyst to get insights into tweaking the prescribed design of instruments for his context, simply with an adapted version of analysis based on the information available.

Further along that same line of persuasion regarding the role of the analyst, the second part of the research turns the focus from the tool to the user of the tool who fits the bill as an analyst, and once recruited, the challenges they face during the course of the analytical process that is their routine work.

This is above all, research on policy analysis. To be more specific, this is research on a form of environmental policy analysis in its practical 'as-is' shape in government offices, not as prescribed in academic literature nor the theory underlying the analytical method under scrutiny. What this is certainly not, is policy-relevant research on a particular policy problem in environmental policy. Indeed, the quantitative cases traverse the breadth of the environmental sector, from NOx emissions in boilers to water pollutants from agriculture, in investigating the effects of the analytical adaptation proposed the thesis proposes. The domain expertise of analysts interviewed likewise ranges from climate change to nature conservation.

\subsection{The Title}

The keywords in the title bear some explaining at the outset.

The prefix meta is used to denote a recursive or "nested" application of a concept. Meta-search for instance, is searching within the results of various search engines, rather than the vast original sources of data. To conduct a meta-analysis is to analyse a set of analytical results to look for, say, a broader consensus on the effects across multiple studies from various contexts. Meta-choice is similarly a phrase coined to connote "the choice in the parameters of choosing", in this case, referring to the effect of the choice of reference units or 'regulatory units' for a CostEffectiveness Analysis (CEA) exercise on the choice of policy instruments. 
In economic literature, the phrase, "choice of policy instruments" invokes either the dichotomous discussion between regulation and market-based remedies (Keohane, Revesz, \& Stavins, 1996) or the equally laboured price vs. quantity line of enquiry (Pizer, 1997; Stavins, 1996). Although there are initial or occasional references to work in both camps at an abstract level, in its chosen focus this dissertation speaks in a direct way to neither. Also as the title indicates, it deals with the practice of policy analysis in the environmental sector, one analytical method in particular, and does not extend economic literature in the above two fields. By 'choice of environmental policy instruments', we mean design choices involved at the stage after the goals and means are largely set. This understanding of the scope and positioning of this research is explained in a more elaborate way in sections 2.4 and 3.2 .

'Meta-data' in the title refers to the explosion of data in recent years, a phenomenon broadly recognised under the term 'Big Data'. Technically, metadata connotes 'data about data'. For a dataset, for instance, metadata includes the sources, date, contacts etc. that apply to the entire dataset. The nature of metadata referred to in chapter 7 is slightly different from that in quantitative economic studies and explained further in section 7.1. That connotation of the term 'metadata' is itself quite the buzzword in the post-Snowden media landscape 2 . The thesis makes the case for a wider and smarter sourcing of data for policy analysis.

\subsection{Structure}

The research presented here investigates ways forward for European Environmental Policy Analysis with two of the core chapters on a new method of analysis, one describing the method and the second an empirical demonstration of its value, one chapter on the human capital employed in analysis and one chapter on the potential for utilizing the advances in Big Data for furthering environmental policy.

The history of economic analysis and a review of relevant literature are covered in chapter two. It covers the current practice in environmental policy and a broad overview of both historical and current issues with the most common method of such analysis. The core idea is an adaptation to an analytical method (CEA) used in policy choices. It is fitting to begin with a broad overview of where the adaptation

\footnotetext{
${ }^{2}$ See footnote on page 111.
} 
fits in the grand scheme of things. CEA is seen as a subset of CBA, on the shortcomings of which there is a vast corpus of literature that it would be negligent to ignore. The review is also necessary to lay out the limitations and the humble scope of this thesis with regards to solving the outstanding issues, while acknowledging the major ones. That scope is set at the beginning of the very next chapter, chapter three, with the research questions. The chapter thereafter describes and motivates the methodological choices made for the disciplinarily disparate parts of this work.

Chapter four, first of the core chapters, turns to the rationale for adapting the CEA method and presents the adaptation itself. It lays out the inspiration behind the idea, introduces Life Cycle Analysis (LCA), and explains the adaptation to economic analysis of environmental policy instruments. Several examples are included for illustration.

Chapter five, entitled 'Quantitative Cases', is for empirical demonstration of the methodological innovation proposed in chapter four. It is devoted to the analytical tests of the adapted method in the form of quantitative case studies. Each of the cases uses a different computer-based model used in actual policy making at governments, thus providing a test with real-world data and parameters. The object is to show how the results of a typical CEA exercise would change if additional contextual information were to be incorporated into the choice framework using the proposed adaptation. An attempt has been made to illustrate choice reversals, merely to emphasize the impact on policy decisions. That constitutes the first part of this work, which presents the analytical innovation to CEA, a proposition in itself, and an entirely new one.

This is followed by a critical evaluation of the role of the clients of this piece, i.e. policy analysts, in chapter six. Innovations in analysis can only go so far if not backed with the training necessary to handle such innovation. That is a qualitative chapter that goes straight to the clients of the proposed analytical method, for key informant interviews.

Given the consistent and recurring finding in that chapter, an additional chapter on remedies to the data shortage was added at a late stage. It speaks to the current buzz around the promise of Big Data, and investigates the potential of that promise to the specific domain of environmental policy. We get our hands dirty with examples of some of the most ambitious datasets typical of the definition of Big Data to look for opportunities in analysis. The concluding chapter, the eighth, takes stock of how the method fares in meeting the promised goals, the improvements that the analysis and external evaluation suggest, and recommendations that arise from the findings form subsequent chapters regarding the human resources 
invested in policy analysis and the opportunities form the emerging trends in digital data. 


\section{Chapter 2 Cost Benefit Analysis and its Limits}

\subsection{Concept and Basis}

Economic analysis is at the crux of all choices. Plants and animals weigh costs and benefits in what would seem careful selection even if it is by coded instinct and not voluntary or conscious. Humans do it from an early age and quite consciously. A child weighs the fun quotient of a prank in the moment against its gravity as perceived by adults and the expected degree of rebuke that might follow later, if caught. The thought process develops into common sense of everyday application for most people ("Cost-benefit analysis," 2009). A lot of this information is sourced from past experience. All decision making then, has some characterization of costs and benefits. In fact, not only do costs and benefits figure as criteria of decisionmaking, at a cognitive level, they also play a part in the choice among the strategies and methods of decision or choice-making (Payne \& Bettman, 1993), in metachoice, to use a coined word.

It is, after all, the simplest form of rational choice. And that is the strongest argument in support for using and continually improving it. When someone uses it, everyone else readily understands the rationale. Whether or not they agree with the details of parameters is quite another question, but as a chosen method, they understand it. In fact, it is precisely because they understand the basic logic, that many will be able to raise astute objections as to the finer details. Such has been the fate of economic analysis of public policy, and perhaps to a greater degree, of environmental policy in particular.

Though the multiple forms of policy evaluation enumerated above exist, in the realm of environmental policy, almost all analysis takes an economic form, usually in the guise of CBA or its cousin, CEA. This method of analysis of regulation is hardly new and definitive guidelines exist ${ }^{3}$. Though it is not entirely relevant here to review the entire breadth of its current usage, there is some worth in looking at its origins - the original purpose, variants of the purpose, current practice, and issues, for we may view the analytical innovation proposed in this thesis in that light.

\footnotetext{
3 The best sources are often governments - such as the US Office of Management and Budget (OMB) Guidelines (OMB, 1996) and the Magenta Book prescribed in the UK mentioned earlier.
} 


\title{
2.2. The Origin of the Cost-Benefit Criteria
}

Pearce (1998) traces the introduction of the dichotomous cost-benefit criteria to between early to mid-nineteenth century, depending on whether it was a US bureaucrat, Albert Gallatin, or a French engineer, Jules Dupuit. Pearce himself considers it just to credit the engineer at the latter date. Leroy and Crabbe (2008, p. 103) recognize Alfred Marshall, an American economist, as having formulated the concepts involved at an unspecified later time, but presumably not long after Dupuit. The newspaper The Economist, however, would pin it much further back, nearly a century back, in fact, to inventor and statesman Benjamin Franklin (Hindle, 2008). Reportedly ("Cost-benefit analysis," 2009), he wrote in 1772:

\begin{abstract}
When difficult cases occur, they are difficult chiefly because while we have them under consideration, all the reasons pro and con are not present to the mind at the same time... To get over this, my way is to divide half a sheet of paper by a line into two columns; writing over the one "Pro", and the other "Con". Then ... I put down under the different heads short hints of the different motives ... for and against the measure ... I endeavour to estimate their respective weights; where I find one on each side that seem equal, I strike them both out.... and thus proceeding I find at length where the balance lies... And, though the weight of reasons cannot be taken with the precision of algebraic quantities, yet when each is thus considered, separately and comparatively, and the whole lies before me, I think I can judge better, and am less liable to take a rash step.
\end{abstract}

It does seem like Franklin had all the basics laid out just the way they would later get standardized, including articulating issues we still face. He enumerates the benefits and costs, he assigns weights and he attempts to balance the two sides by 'cancelling' equivalents. One point to be noted is that the said engineer's more formal design of the method was, quite expectedly, for the purpose of informing investment decisions on projects such as building roads. Policy instruments are, of course, somewhat different in nature and of a broader scope than building projects. In later sections we shall see how the difference is at the root of some of the current issues with the cost-benefit criteria.

From that rather early conceptual beginning, the practical use, however, appears to have been delayed for almost another century. About that time, the criteria came to be applied in various "rudimentary" forms in assorted sections of the US Government, the first words to the clear effect emerging in the United States Flood Control Act of 1936 (Pearce, 1998). 
On the theoretical side, Vilfredo Pareto (1894) postulated a normative criterion as a test to judge whether a proposed policy change was efficient. The criterion deems it so if the change improves the lot of at least one individual without rendering any individuals worse off. It is easy to see that it is a rather strict criterion.

Subsequently, nearly half a century later, Nicholas Kaldor (1939) and John Hicks (1939) gave a less stringent version of the criterion. The variation was that even if an individual or more were worse off, a change was still considered efficient if the sum of gains for the gainers was larger than the sum of losses of the losers, thereby leaving room for compensation. Of course, the possibility of actual compensation is hypothetical, but leaving the question outside the test of efficiency simplifies matters. The test becomes more pragmatic and is rather diplomatically called 'potential' Pareto improvement. It has been claimed though that Vilfredo Pareto in his original article explicitly accorded some importance to the compensation actually occurring if such a case is considered (Kemp \& Pezanis-Christou, 1999). Nevertheless, as can be seen from the brief history of the development of the criterion, we have come a considerable distance along that line of thought.

In the second half of the nineteenth century many streams of economic scholarship gradually converged to reinforce the foundations of the criteria, among them the concepts of social costs (Coase, 1960), efficiency of regulation (Posner, 1972) and the economics of regulation (Stigler, 1971). More and more authors began endorsing it as reaffirmation of the Kaldor-Hicks criterion, which in turn was seen as the more practicable version of the by then all-pervasive Pareto criterion. Since that time, however, the efficiency rule has been questioned on theoretical and practical grounds, as we shall see in a later section.

\subsection{The Mandate}

The beginnings of high-level stipulations lie with the US Government as theirs is one of the more rigorous efforts and most consistent practice when it comes to codified economic analysis of public policy (Pearce, 2000). The earliest mandated form existed from the Reagan period (M. Adler \& Posner, 2006; "Executive Order 12291," 1981). Though it laid the foundations for a systematic review of regulatory action, it was not yet perhaps true to its name in practice (B. D. Friedman, 1995). It was President Bill Clinton who issued the order that laid out the clearest mandate for such analysis ("Executive Order 12866," 1993). The result of this order was the formulation of exhaustive guidelines (OMB 1996) on conducting CBA mentioned earlier, the most common form of regulatory analysis today. President George W. Bush amended that order with two of his own ("Executive Order 13258," 2002, "Executive Order 13422," 2007). President Obama in his turn, within weeks of joining office, revoked the Bush amendments with yet another order ("Executive 
Order 13497," 2009). The brief history in USA just goes to highlight the fact that while journal articles may go back and forth and perhaps inch forwards with the critical improvement of policy analysis methods, the analysis actually conducted in the real world has to conform to guidelines that are like political Plasticine. It is no surprise then that a prominent Philadelphia newspaper laments that administrations opt in and out of the use of regulatory analysis and its procedural details as they please rather than the requirement being mandated in a specific legislation by the congress (O'Neill \& Sinden, 2009).

While that may be evident, not all that emerges out of the White House is political whim. More recently still, President Obama has signed a memorandum that categorically enumerates and addresses several issues with mandated economic analysis (Obama, 2009). To quote:

A great deal has been learned since that time [Clinton's Executive Order 12866, September 1993]. Far more is now known about regulation-not only about when it is justified, but also about what works and what does not. Far more is also known about the uses of a variety of regulatory tools such as warnings, disclosure requirements, public education, and economic incentives. Years of experience have also provided lessons about how to improve the process of regulatory review. In this time of fundamental transformation, that process - and the principles governing regulation in general-should be revisited.

Further along in the order, the President gets downright specific and makes several points as if summarizing an academic review for this particular research:

I therefore direct the Director of $O M B$, in consultation with representatives of regulatory agencies, as appropriate, to produce within 100 days a set of recommendations for a new Executive Order on Federal regulatory review. Among other things, the recommendations should ... encourage public participation in agency regulatory processes; offer suggestions on the role of cost-benefit analysis; address the role of distributional considerations, fairness, and concern for the interests of future generations; identify methods of ensuring that regulatory review does not produce undue delay; clarify the role of the behavioural sciences in formulating regulatory policy; and identify the best tools for achieving public goals through the regulatory process.

In sections to follow, we will examine the import of all of the key phrases in the presidential quote. 
In Europe, the legal mandate or even political interest in codified economic assessment of regulation appeared late and has been slow in developing (Helm, 1998; Pearce, 1998; Turner, 2007). The EU, however remains the jurisdiction of interest here. While at the umbrella level of the European Commission, the prescription appears to be more recent and patchier, among some member states there are older and clearer landmarks pointing to the adoption of CBA or Regulatory Impact Assessment (RIA). The UK Government, for instance, has had official guidelines from the Department of Environment (DOE, 1991) and Her Majesty's Treasury (HMT, 2003). Radaelli (2004b) and Renda (2011) present a comprehensive overview of the diffusion of RIA in Europe and the spread of variation in the understanding and the practice.

\subsection{Scope and Practice}

As the practice of CBA is sketchy and anything but uniform (Hertin, Jacob, Pesch, \& Pacchi, 2009; C. Radaelli, 2009), a standard defining is both hard to come by and not likely to be very illuminating. Nevertheless, it is imperative to broadly identify the form or purpose that this research intends to focus on. The practice of CBA may be seen to have three disparate forms, or could be said to play or operate at three different levels of policy making.

One is at the stage where the policy makers consider if a certain policy objective is justified. This is the first stage in the life cycle of a policy, the first hurdle it must cross. It is hence also the stage with the most political influence (Figure 3-2) and the greatest degree of extra-governmental involvement. This is where the media and the general public will question the costs and benefit of a proposed action. A generic instrument of implementation would be assumed, if one is not already clearly described in a proposed bill. Ball-park estimates for costs and benefits would suffice for the debate and eventual decision. Accuracy of all the numbers is rarely a talking point here.

The second is for the purposes of standard setting, a more explicit use of the standard method. This stage quickly follows when there is minimum agreement on a particular policy objective. In the environmental sector, the same very fundamental and inescapable questions arise: "What level of protection do we target?" or "What level of environmental quality can we as a society afford?" Naturally, every society would want the highest standards were it not for the positively correlated costs, as in every other sector. The better the environmental quality we aspire to, the more stringent a standard has to be set and the higher the societal costs. CBA helps ascertain the point of balance or the degree of 
compromise between desirable benefits and affordable costs. Relatively more effort is poured into getting hard data and good estimates.

The third is the form where the instance of application is perhaps the rarest and least clear, the stage for the choice of instruments. Presumably, or at least ideally, the objective and the level of regulation have been decided before this point. The degree of political influence is therefore relatively limited at this stage. The instances are not rare. Under the chapter on Paternalism in Law, Ogus (2006) gives several examples. It is now up to a Policy Analyst or equivalent executive official to finalize and justify the choice of instrument and the finer details of its design, including the terms of implementation. Research or studies may be commissioned to determine the precise cost and benefit curves across a range of parameters. Procedurally, this has to occur just before the instrument is codified.

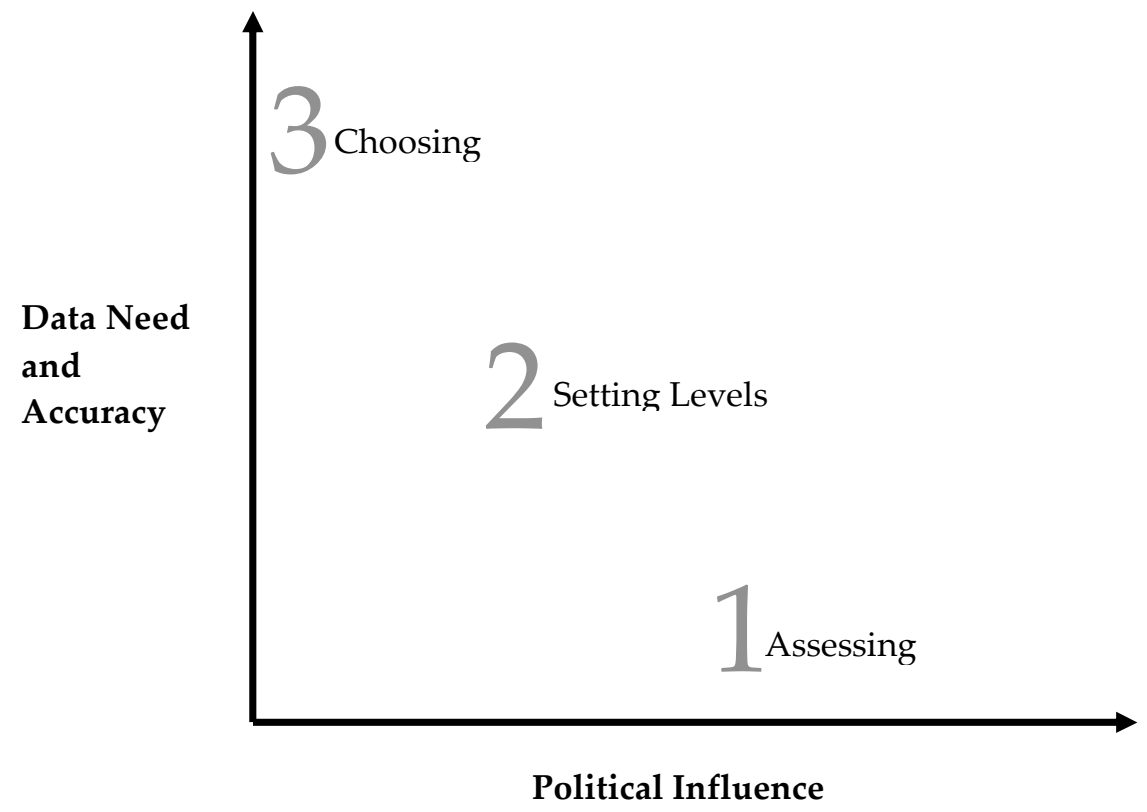

Figure 2-1 Scope and Domain of CBA Application

The analyst has recourse to a wide range of methodology when it comes to the choice between instruments. The choice as to the criteria is also open and may include more than economic efficiency. If, however, efficiency is one of the prominent considerations, cost-benefit criteria offer a good test to compare instruments with, although here it more closely approaches the cost-effectiveness paradigm. This third application sets the bounds of the sandbox for this research. 


\subsection{Old Issues}

It is a daunting task to write a critical review of a subject as beaten as CBA all over again. Journals have devoted entire issues ${ }^{4}$, and authors a lifetime's worth of publications ${ }^{5}$ to the topic. It is difficult to cover the entirety, but quite useful to systematically compartmentalize the discussion. For the purpose of outlining the scope of this research, the issues with CBA can be seen in two parts - those that have plagued the discipline since early days and those that have emerged more recently and continue to be under current attention. Then we can revert to what the method can offer with and without entirely remedying all of the issues.

\subsubsection{Fundamentals}

The oldest criticisms address the very heart of the original basis - the Kaldor-Hicks criterion. How robust are the fundamental concepts? How does the policy maker arrive at the decision of what is good for the society? Even before that, how does the analyst infer what is good for an individual?

There is a broad philosophical discourse on the operationalization of individual well-bring (Elster \& Roemer, 1993) and choosing a one school will always receive critique from others. The common rebuttal is that views on individual well-being that go beyond individual preferences are at least slightly paternalistic (Kopp, 1993) and economists would not have that. Some question the validity of aggregating individual preferences and welfare to give a measure of societal welfare. Adler and Posner $(2001 ; 2006)$ present a range of critical views on such matters.

A more technical issue is that usually the aggregation in CBA takes the form of a simple summation of individual preferences. In cases that show a diminishing marginal utility of income or where individual utility depends on the overall income distribution, public choices that meet the potential Pareto improvement test may not actually increase the overall well-bring in a society and vice versa (Revesz $\&$ Stavins, 2007). There appears to be some consensus though that neither the Kaldor-Hicks criterion nor the distilled CBA standard be seen as either necessary or sufficient rules for "designing sensible public policy" (Arrow et al., 1996). The authors nevertheless recommend its use in environmental regulation.

\footnotetext{
${ }^{4}$ The Journal of Legal Studies, Volme 29, Special Issue 2

${ }^{5}$ The late David W. Pearce of University College London prominent among those in the environmental sector
} 


\subsubsection{Discounting}

Future streams of costs and benefits need to be discounted to bring them on a comparable footing at any selected point in time. But at what rate?

This choice is also a distinguishing parameter between private and socio-economic considerations: A private firm fixes the discount rate by the opportunity cost of capital, i.e. is by the next best rate of return the same capital could have generated, or the interest rate applicable if the same amount of capital had been raised by debt. For a governmental project, they may use the rate at which the government borrows from, say, the federal (central) bank, in some countries also called the Treasury Bond Rate. Or, if the government borrows from a private firm, then the discount rate to be used is that firm's rate of return before tax. Since the tax is paid back to the society, the total value to society is represented by the returns before tax. Alternatively, one may use a weighted average of the private pre-tax and aftertax rate of return, because part of the government's revenue comes from tax on interest from foregone consumption of individuals. The after-tax rate of interest comes from the opportunity cost of the forgone consumption for these individuals. This weighted average is not seen much in practice as it is difficult to arrive at the weights.

Another choice is what is called the Social Discount Rate. This is the rate at which society accepts the tradeoff between consumption today and consumption tomorrow. This is different from the private or public rates of return since commercial ventures are concerned with a particular project or firm over its life, but the society cares about its future generations. Hence, concern for our future generation should make us value the future more than we otherwise would. They do not trade in markets of the present day, but we must give them standing nonetheless. This premium on the future, however, holds more strongly in some societies than in others. Different preferences may exist within societies as well.

However, the concept of the social discount rate, or rather, how to arrive at the number in practice, is fraught with complications and controversy (Hanke \& Anwyll, 1980). The market does not provide a good indication because of factors such as the distributions of taxes, risk, liquidity and information distort what is reflected in rates prevalent on the market. Various approaches such as exponential, hyperbolic and time-declining rates have been suggested based on empirical indications (Revesz \& Stavins, 2007).

In several matters of public policy, and more so in environmental policy, either costs or benefits or both may accrue far out in the future, beyond the lives of the 
current generation of citizens. That presents a peculiar problem to the discipline of economics, that of determining preferences. What is to guide our imagination in the exercise? Whether we assume the preferences will remain unchanged or that they will change along a specific trajectory, either assumption necessitates substantial information regarding the future world. The other complication is that the future world would in part be shaped by the decision at hand. When confronted with complex relationships with cyclic interdependencies, we fall back on models.

Models do a shabby job of predicting aspects of the natural world on those time scales, given the complexities involved in aspects such as the climate. They are likely to help even less in predicting the socio-political values of the time in response to those natural aspects that far in the future. As the periods of time involved are large, small immediate effects of the current decision or tiny errors in estimating them can cause the course of future impacts to deviate greatly from prediction.

To aggravate the issue, the future generations of mankind do not get to cast their vote in matters currently facing policy makers, though the decision will definitely affect them. In an ironic twist, our human descendants are just as voiceless and just as dependent on others to make their case in environmental matters, as non-human species are today. The likelihood that their concerns will get undervalued or deprioritised in current decision making is hence quite high. The assessment of the preferences of generations not yet born and guarding against an undervaluation of even the assumed preferences is a matter of much discussion.

Lind (1982) gives an exhaustive theoretical commentary on the issues involved, updated along with several other illustrious names in a recent volume (Robert C. Lind et al., 2013). Others have assessed the implications in practice over time (Boardman \& Greenberg, 1998; Kolb \& Scheraga, 1990; Moore, Boardman, \& Vining, 2013; Moore, Boardman, Vining, Weimer, \& Greenberg, 2004; Turner, 2007). The bulk of such literature deals with the choice of discount rates in various scenarios as guidance to policy analysts.

Applying an appropriate discount rate is critical, since within a range of possible values, the decision may be positive at one discount rate and negative at another. For this reason, the decision makers usually run a sensitivity analysis to evaluate benefit-to-cost ratio (BCR) for a range of rates, and observe how the BCR changes with respect to the discount rate. This helps in choosing a realistic and relevant discount rate. The range too, however, would need to be carefully chosen with the purpose in mind. Weimer and Vining (2005, p. 406) suggest reporting the largest 
discount rate at which the benefits exceed costs. The client can then make the choice comparing the discount rate they have in mind.

Then on the flip side, there are those (Summers, 1992) who do not buy into all the discussion around providing for future generations or see the worth of calculating special discount rates. The 1992 article met with immediate rebuttals (Adey, 1992; Clements, 1992), of course, and on and on the talk drags.

Regardless of the theoretical deadlock, what rates, then, are used in actual practice? Revesz and Stavins (2007) suggest that the numbers lie in a very "large range", specifically between 7 and 2 per cent. The U.S. Office of Management and Budget (2003) used to ${ }^{6}$ recommend 3 per cent where the question of future generations does not arise, although that is almost invariably unlikely in environmental policy. A general good practice is to conduct a sensitivity analysis of the CBA results with a range of rates on either side of the chosen rate. In simpler terms, the analyst would repeat the analysis, successively using each in a range of recommended or applicable values for the rate, and report the results of all the analyses.

\subsubsection{Values and Measurement}

Several disparate issues fall under this catch-all heading.

CBA requires monetization of costs and benefits. Each unit of both then has to be expressed as a tradable good. How are values assigned to each unit? Market prices are directly used in case there are no market imperfections such as externalities, monopoly or unemployment.

Broadly speaking then, for costs, robust methods exist for the cases of efficient and inefficient markets, with or without significant price effects (Weimer \& Vining, 2005, pp. 385-390). It is on the benefits side where things are not straightforward. Not everything is traded directly or at all in markets. As is commonly known, most societies use environmental services without paying for them. Ironically, we pay when we lose them (Black, 2010; Judson, 2009; “Nature loss 'to damage economies,'" 2010).

\footnotetext{
${ }^{6}$ The recommendations are periodically updated or refined as tailored for specific purposes, for instance, by a recent OMB memorandum (Burwell, 2014) which suggests a range from 1.0 to 3.9 per cent for lease-purchase and cost-effectiveness analysis varying with project duration.
} 
Shadow prices ${ }^{7}$ are one way to go. The shadow price represents the marginal social cost of a good. Others methods include Revealed Preferences. This method is used when something does not have an explicit market, but an equivalent economic choice exist. For example, the value of time can be taken to approximate the income per hour for persons who are self-employed and work in flexible timings. Hedonic Pricing is typically used when valuing changes to the environment that can be assumed to reflect in, say, real estate prices. Lastly, when there is no market price and no available revealed preference alternative, we use Contingent Valuation ${ }^{8}$. In this case, people are asked how much value they attach to things and that involves all the shortcomings of surveys.

For even items that can be readily valued, there are problems with accounting these values. Often, secondary benefits are counted but secondary losses are not. At times, some benefit streams are double-counted or two equally probable but mutually-exclusive streams are counted. For example, one may count the increase in the value of a tract of land from some intervention and also the present value of the increase in income from the current form of land use. Ideally, only one of them should be counted, because the landowner either sells the land or retains ownership and gets a steady income under the current land use.

Some values are considered incommensurable; life, liberty, wellbeing and so forth among them (Ackerman \& Heinzerling, 2002). However, these values at least show a more or less direct effect on humans. Environmental benefits, on the other hand, may not even directly accrue to humans, as noted right in the introduction. When they do, they involve challenging mathematics with too many uncertain variables that economists try to engage with all the more as a challenge! The actual algorithms of measurements by the methods mentioned above have received substantial attention (Christie, 2001; Forbes \& Calow, 2006; Heyde, 1995; Knetsch, 1995; Kopp, 1992; List, 2007; Rosenthal \& Nelson, 1992).

The types of values included and their measurement have also consistently been raised (Driesen, n.d.; Sen, 2000; Zerbe Jr., 1998) with the focus often on indirect values such option values or purely non-values such as existential values. An example of option value would be the potential worth of a known or unknown species of Himalayan herb or Peruvian tuber for which no current medicinal use is known. The argument is that we will surely see newer diseases or disorders in the future or could find better cures for known ailments. Whereas the value an average

\footnotetext{
${ }^{7}$ An overview appears in (Boardman, Greenberg, Vining, \& Weimer, 1997)

${ }^{8}$ An overview appears in (A. R. Vining \& Weimer, 1998)
} 
West European attaches to the mere existence of Olive Ridley turtles ${ }^{9}$ although they may never plausibly encounter them either in Costa Rica, India or even in an aquatic entertainment park closer home, would be classified as existential value.

The operational methods to measures these are not universally accepted. Some believe that measurement in 'Willingness to Pay' or 'Willingness to be Paid' treats the preferences of citizens the same as those of consumers. Sagoff (2008) discusses the distinction and the reasons thereof from a philosophical standpoint at length.

Then there are the costs of measurement. The more there is disagreement or discussion about what to measure and how to measure it, the higher are the costs of undertaking the measurement exercise itself. There are those who worry if in some cases the CBA procedure would itself pass the CBA test (Swanson \& Kontoleon, 2004, p. 194)! Studies relying on Contingent Valuation and so forth tend to be protracted and involve expensive experts, and that does not always ensure that the numbers they produce would be incontestable. More Kronor are then spent in revising the numbers.

At this point, an important proviso is in order. By 'cost' the dissertation concerns itself largely with compliance costs and other direct costs of regulation, such as administrative costs. To be even clearer, the disquisition in this chapter and the premise of this research treats the term 'costs' to mean those that are explicitly accounted for, literally, meaning that they appear in the books of accounts of either the regulator or the regulated party. Naturally, given the nature of CBA, socioeconomic assessments may be called for on the cost side of the equation, for instance, when the damage from a prospective project is in terms of the loss of an environmental service. This section and section 2.8 merely mean to highlight the distinction in the very nature of costs and benefits, in that for a large section of costs, the magnitude is readily available simply because they are tangible, immediate and accounting rules require their quantification for the core purposes unconcerned with environmental policy or goals.

\footnotetext{
${ }^{9}$ The traditional example in lierature is commonly that of polar bears, but the author feels they have lost the instructional value (pun not intended). Firstly, they have become the ubiquitous posterboys of all things green. Secondly, like most charismatic carnivorous mammals, they are quite prominent in zoos including in Western Europe, as the celebrity of Knut the polar bear at the Berlin zoo bears out. The species has lost the type of remoteness essential to the concept of existential value.
} 


\subsubsection{Distribution and Equity}

As earlier mentioned, the simple decision rule in CBA is that aggregate benefits exceed aggregate costs. The aggregation is done over the entire population and conventional CBA does not account for the divisions across which costs and benefits respectively befall. The costs and benefits may accrue to different sections of the population or may be apportioned inequitably. The Kaldor-Hicks reasoning is met so long as there is scope for potential gainers to compensate potential losers and still retain some surplus for themselves. Whether or not that compensation actually occurs as part of the project or policy under consideration is outside the concern of the CBA decision. Indeed, even if such compensation was attempted, there are doubts about the sufficiency of compensation (Sen, 2000) expressed in terms of willing to pay or accept. The common alternative used is assigning weights to costs and benefits depending on who pays/receives them. The next question then is - how to pick the weights? ${ }^{10}$

A problem common to valuation and distribution, is uncertainty. To get around uncertainty, probability figures are used to arrive at expected values. That turns the problem into one of risk and can be dealt with in standard decision-making algorithms. We then move from the language of assessing net benefits to 'net expected benefits'. However, we know well that people feel varying degrees of aversion to risk that arises out of uncertainty (P. Slovic, 1987; Paul Slovic, 2000). The expected values need adjustment for risk-aversion. The assumptions for the degree of risk-aversion and the ways to reconcile it with the choice of discount rate is again a matter long waiting to be resolved (M. J. Bailey \& Jensen, 1972).

The mutually related issues of distribution, fairness and standing too have received considerable press (Richardson, 2000; Trumbull, 1990; Turner, 2007; Zerbe Jr., 1998). Kaplow and Shavell (2002) tackle the more fundamental issue of whether non-utility values implied in the interpretation of fairness can be factored in without seriously compromising the Pareto criterion itself.

Some foreseeable undesirable outcomes can be avoided in theory by alternative design. For instance, tradable permits which are popular instrument can arguably lead to so-called "pollution havens", but the problem can be mitigated if the permits are pegged relative to ambient standards (Revesz \& Stavins, 2007, p. 47). However, that would almost always imply higher transaction and enforcement

\footnotetext{
${ }^{10}$ A fascinating paper on reconciling efficiency and fairness (Dekker, 2008) came out at this very university though, the implications of which one hopes may some day address some of this. The paper mathematically explores how allocations would be different if the basis was a measure of relative desert (what someone deserves) rather than unqualified efficiency.
} 
costs. Moreover, not all distributional concerns may be that apparent without considerable study.

Pearce (1998, p. 50) laments that the distribution issue was "never fully resolved". The fact is, many of those covered under "old issues" remain unresolved (Turner, 2007). Some defenders of the old method assert that the delay in such resolution need not necessarily preclude the application of CBA in public decisions (Posner, 2000). Others go further to say they would rather leave the distributional corrections required necessitated by environmental or other regulation to be handled by parallel instruments under the income tax regulation (Kaplow \& Shavell, 2002) because it is better equipped.

At any rate, the distributional impact of a proposed policy is never free from the political web. Analysts can leave the concerns to the politicians to resolve and factor the subsequent into the instrument design. If we were to take the positive rather than a normative outlook, in most jurisdictions, it is rarely within the prerogative of analysts what they may "leave to" politicians. The latter would usually wrest all questions of a political bearing into their control and preemptively define the constrained space for analysis.

The majority of the above are "contentious normative or empirical" issues, to quote Adler and Posner (2009), who also choose to skirt them. So we too move on to more current issues that emerged as problems grew in complexity and policies progressed in design and seek simple, technical improvements.

\subsection{Current Issues}

As a broad observation, one could say that the issues presented in this section are somewhat less of a technical nature and rather more procedural or methodological, although when it comes to remedies or solutions, the distinction will not substantially matter.

\subsubsection{Uniformity and Legitimacy}

One of the major issues under discussion in present day is decidedly the lack of clarity, despite or due to exhaustive guidelines, on what CBA connotes and entails (Crandall, 1981; Hahn \& Litan, 2005). State actors and agencies across the world have applied varying versions of the analysis (C. M. Radaelli, 2005) and the variation appears to be ad-hoc. In fact, the differences in understanding are seen 
not just between governments. Even within governments, different actors may perceive the standard differently (Boardman, Vining, \& Waters, 1993). Though politics or economic constraints are often cited as the obvious causes, they may not be the only causes. In noting the reasons for divergence in environmental policy between US and the EU, Krämer (2004, p. 68) notes that the US considers policy discussions in EU as scientifically unsound because CBA does not play a great role there. The interesting European counter-view Krämer (2004, p. 69) cites is that the US Congress does not really consider CBA either; it is the individual agencies that are required to apply it at their level. The EU does not have "federal" agencies like the Environmental Protection Agency in the US (USEPA or EPA) that could apply CBA. An honourable mention must be made here of the Best Available Techniques (BAT) reference documents, otherwise called BREF documents, adopted under the European Directives on Industrial Emissions Directive (IED, 2010/75/EU) and Integrated Pollution Prevention and Control Directive (2008/1/EC) which require a CBA for environment-friendly or mitigation technologies, though by the European's Commission's own admission, the directive proved too "weak" to achieve the desired "level of application" (European Commission, 2007).

There has been a wider belief largely in the public sphere that CBA "crowds out" flexibility (Pearce, 2000, p. 71) in terms of policy choices and implementation. Indeed, there are clarion voices out there calling for more "pluralistic" approaches in Europe to such ex-ante assessment (Radaelli, 2004) if only to allow for cultural or institutional diversity. By contrast, Hahn and Litan (2005) would prefer a more centralized guidance on the practice in the EU through a directive.

A concern mentioned earlier is relevant here. Aggregation obscures the information of the relative sizes of costs, compared across categories in one context and of identical categories across contexts. More information on relative magnitudes of costs would offer a greater flexibility of the smaller choices involved in policy design. That promise is at the crux of this research and as such is further developed in the next chapter.

A lingering question concerns the degree to which the criterion of economic efficiency can hope to approach democratic mandates, where the votes of individuals reflect their moral, ethical, political or even psychological inclinations (Bryne, 1987; Turner, 2007).

Even where it is regularly conducted, and by the book (any book), the outcome of CBA may not always correspond or contribute to actual policy choices (Pearce, Atkinson, \& Mourato, 2006, p. 49). That is hardly a surprise, given how democratic governance is organized. Repeated reports have expressed concern over considerable political influence on the application of the CBA standard (Driesen, 
n.d.; B. D. Friedman, 1995; Schmid, 1989). Though that sounds scandalous, one would find on some reflection that political influence is not a bad thing in itself. As many have observed, goals of public policy are wider than efficiency alone (Pearce, 2000 , p. 71) and forces other than analytical rationale come into play in realizing those goals. In some cases, policy makers may have distributional concerns in mind that override the efficiency criterion (Bromley, 1990; Weimer \& Vining, 2005) and in others, they may have a paternalistic outlook (Ogus, 2006, p. 220) that preempts the choice of instruments available to the analyst. Efforts are underway to construct methods where the inevitable compromises are more explicit. While that is not among the goals of this research, the method proposed here does intend to broaden the scope of the efficiency criterion itself. A wider set of choices within and under the rubric of efficiency will make the trade-offs with other criteria more transparent.

\subsubsection{Compliance}

Of the competing forces that influence public policy, one of the stronger ones is business. Much of the emphasis on the intensive scrutiny of costs of regulation is of-course with business at home in mind. It is after all, 'economic' analysis and most progressive governments have an eye on the performance of their domestic economies, more so in these times ${ }^{11}$ than ever before.

Optimizing the costs of regulation has been a popular agenda with progressive governments. As much as 60 per cent of private firms in the UK, for instance, perceive the level of regulation in the country as an obstacle to the success of their business (UK National Audit Office, 2007).

Businesses may be the best sources of compliance data in one sense, but they may not always cooperate. Private actors will always have one eye on their bottom-line. Even in the few countries where the private sector receives regulation warmly, compliance costs are only met grudgingly. These players stand to gain from blowing up ex-ante estimates of compliance cost if they can help it and that, indeed, has often been found to be the case (ICS, 2004).

A related difficulty is that of correctly determining additionality - discounting measures that the industry would have taken regardless of the policy in question. That is industry-insider information with a price tag attached to it. The game between the regulator and the regulated plays out as a tug of war between higher standards and higher compliance costs. Haq et al. (2001) speak of this game of pre

11 Post 2008-2009 financial crisis 
and post-regulation negotiations and the difficulties arising from the discrepancies between the cost estimates from the two periods. MacLeod et al. (2006) and Bailey et al. (2002) present a somewhat elaborate review of the reasons for the disparities, which can be of some help in working around them.

A very prominent concern specific to the EU remains with the transposition of EU Directives into national legislation. Home-grown businesses often see these as foreign-imposed burdens. National governments in member states have to try harder to make transposed legislation seem leaner rather than gratuitously "goldplated" (UK National Audit Office, 2007).

The National Audit Office (NAO) also seems to suggest that governments also strategically pursue the ability to achieve common EU goals at the minimum administrative costs of compliance to give their own businesses an edge over their competitors in other member states. Businesses all over Europe are subject to same or similar policy goals. If your regulator manages to design regulation to meet the same goals such that your costs to comply are significantly lower than the competitor across the border, the government is likely to be that much more popular.

Moreover, if Porter's Hypothesis (Porter \& van der Linde, 1995) holds, more or better regulation at less cost would also give an edge in innovation. The pressure to innovate is there but the direct costs associated with the pressure could be differential across countries. The Less is More report commissioned for the UK government testifies much of this rationale (UK Better Regulation Commission, 2005).

Businesses may, of-course, have reasons to reject the whole premise (Keohane et al., 1996). The U. S. Chamber of Commerce (n.d.) calls the guidelines issued by OMB guidelines cited earlier inadequate and calls for more "dynamic" models of analysis. Its other grievances include the lack of data consistency between different government agencies and the absence of any post-facto validation of ex-ante analyses. These too, are not insurmountable.

\subsubsection{Uncertainty, Morality and Precaution}

The residual issues with CBA concern moral responsibilities, uncertainties and the precautionary principle ${ }^{12}$, all of which are especially relevant to the environmental

\footnotetext{
${ }^{12}$ For an overview, see the section 'Precationary Priciple and CBA' in (Faure \& Niessen, 2006)
} 
sphere. Though the underlying issues are quite intractable, the basic premise is quite simple to follow. In fact, because it is a recurrent theme in public debate on a variety of topics, we all understand the essence of the principle.

One need not look far back to see how topical the whole concept of precautionary principle and disproportionate costs is. Thomas Friedman (2009) likes to point out at every opportunity on print and screen that the US Government has displayed a rather hypocritical stance on the precautionary principle - it explicitly and strongly cited in its response to the threat of global terrorism but rejects it downright on environmental issues, climate change being the case in point. Indeed, Cass Sunstein (2004) went so far as to suggest that the adherence to the principle is the primary difference between the European and American approaches to the environment. It was certainly the crux of the debate across the world media for over two weeks in May 2010 when Eyjafjallajökull, the volcano in Iceland, infamously erupted resulting in a complete deadlock over European skies. Millions of travellers were stranded and airlines lost billions of dollars. Everyone asked everyone else on round-the-clock news channels if the huge cost was justified and whether the regulators had sufficiently considered all scientific evidence when closing the airspace for reasons of public safety. In view of uncertainty, 'justification', 'sufficiency' and 'evidence' are all key words.

In the environmental field, one of the first formulations occurred on the international stage, as principle 15 in the Rio Declaration (UN, 1992):

Where there are threats of serious or irreversible damage, lack of full scientific certainty shall not be used as a reason for postponing cost-effective measures to prevent environmental degradation.

The choice of words makes it clear that uncertainty is the reason precaution is invoked, as it does the fact that costs will remain a central consideration. It also inextricably links science and scientists to policy.

Christoforou (2004) gives a historical overview of the emergence of the precautionary principle in environmental regulation; Raffensperger and Tickner (1999) look at application in a number of cases across sectors and contexts. Some actually consider the underpinnings of the precautionary principle and those of the economic analysis incompatible (Bernstein, 1999; Pearce, 1994). Others find it imperative that the two be reconciled (Sunstein, 2005), at least in practice.

The reconciliation would indeed be difficult if governments had unequivocally called for benefits to 'outweigh' costs. For evidence, we must go back to the 
guidelines that governments release for practitioners. The chosen wording in the British interpretation of RIA is particularly telling, however: the impact assessment form states that the benefits "justify" the costs (C. M. Radaelli, 2004b), not 'outweigh' them, which would be the more common objective and normative interpretation of the economic principles underlying CBA mentioned earlier regarding its origin. That incidentally is also the word used in the Clinton mandate cited earlier ("Executive Order 12866," 1993), which was a shift from the use of "outweigh" in the Regan mandate ("Executive Order 12291," 1981). The choice of the word 'justify' almost certainly imparts some political leeway, but on the other hand, also reflects the ideology behind precautionary policies.

In practical terms, of course, the degree of uncertainty in estimating costs of environmental damage can itself be factored in or out by fiddling with the assumptions and choices of what impacts to include. A recent study on the social cost of carbon (Moyer, Woolley, Glotter, \& Weisbach, 2013) offers a particularly good example: they test the effects of including the direct effects of climate change on productivity in models that estimate the economic impacts. The uncertainty of the magnitude of economic impacts is modulated by the 'academic uncertainty' as to whether or not climate change affects productivity and the debate over whether or not to account for it in the modelling. That is a second tier of uncertainty - does an impact occur at all (should it feature in the analysis), versus, what the best estimate of the magnitude is.

It all boils down to answering this: how much does a society value what extent of protection? Words like "unjustified" or "disproportionate" (Turner, 2007) signify only that the society cannot afford a certain level of protection. Usually, they do not signify that those higher levels of protection are not desirable. What one may ask though, and many have, is whether humans as a single species have a moral obligation to consider benefits to other inhabitants of the planets and bear a portion of the implicit costs they impose of them. If they do, the size of costs that might appear unjustified from a human standpoint might be a pittance in the view of a random global inhabitant. But that is philosophy and questions that call for deep personal reflection. Any analytical tool, then, that helps put the proportions of cost in relative perspective is hence welcome. That is the limited extent to which this investigation will deal with the issues of scientific uncertainty and precaution.

\subsection{Looking Ahead}

Despite the many issues, it is clear that while the CBA standard is far from being shelved in favour of an alternative, several concerns around it are growing in 
prominence on the public agenda. It is only prudent then, for academics who believe in the standard and labour on improving it to make it easier to integrate those concerns in the future design and application of the standard.

The words "benefits" and "costs" will be repeatedly thrown around in every discussion on regulation (Lipton, 2010). Due to the very nature of the discipline, public policy is a matter that receives continual public commentary (in the press) aside from academic examination. Also, due to its nature, both voices are equally competent or at least noteworthy. Increasingly, the public mouthpieces too have been calling for alternatives. As recently as May 2009, The Philadelphia Enquirer wondered if president Obama's nominee for the "regulatory czar", the head of the Office of Information and Regulatory Affairs (OIRA), will rely on CBA, modify the process, or abandon it in favour of a better method. The Center for Progressive Reform, an independent think-tank of university-affiliated academics, advocates a critical review of CBA practice and use ("Center for Progressive Reform: OMB and Cost-Benefit Analysis," n.d.).

Despite the exhaustive commentary on support or criticism that CBA has been consistently subject to, the discourse has stalemated. What is by far more interesting to note, is that a great majority of the above authors cite examples from environmental policy and regulation to illustrate the issues. Until relatively recently, however, critics have stopped short of giving viable, saleable alternatives, except for sporadic works redressing it under various names such as Monetized Net Benefits Analysis, Revenue-Expenditure Analysis, Qualitative Cost-Benefit Analysis, Embedded Cost-Benefit Analysis and so forth (Hajkowicz, 2008; A. Vining \& Boardman, 2006). There have also been attempts to bring in geographic information into the fold. Clearly, these have not assuaged the criticism and it is only in the year 2008 that radical alternatives have begun emerging (Shapiro \& Schroeder, 2008) ${ }^{13}$. That is mixed news. It incontestably settles the rationale for the research currently proposed here, but also lends this research an air of urgency.

\subsection{The Anatomy of Cost}

Commonly, in an ex-ante situation, after the preliminary aim of a particular policy is decided, the policy maker chooses one from the variety of instruments available. The choice instantly commits the state exchequer and regulated parties to a certain amount of costs. Though many models of ex-ante and ex-post evaluations of instruments are available, none of them looks exclusively at costs. In fact, MacLeod

\footnotetext{
${ }^{13}$ The authors have, however, gone so far in pursuing an alternative that they have sidelined the economic basis of analysis in favour of a more "pragmatic approach".
} 
et al. (2006) document in detail the cost categories that the mandatory Regulatory Impact Assessment (RIA) in the UK usually does not take into account. Hitherto, 'Total Cost Assessment' has been a term variously applied to either a general business tool for comparing investments or - even in the environment sector - a decision support device for agencies implementing projects and programs, not in choosing policies. That kind of cost analysis completely lacks the complications of aggregating costs that accrue to multiple actors, let alone the fact that in the policy arena, one of the actors exercises the choice of imposing them on all concerned. The first suggestion of broadening the scope of costs attributed to an instrument of policy was perhaps the relatively recent one from Cole and Grossman (2002), which, of-course, they concluded by lamenting the unavailability of data.

Some of the issues with CBA from the discussion cited earlier are relevant here. While on the cost side, measurements can usually not be faulted, on the benefit side, many issues remain unresolved (Christie, 2001; Forbes \& Calow, 2006; Heyde, 1995; Knetsch, 1995; Kopp, 1992; List, 2007; Rosenthal \& Nelson, 1992). Costs are often easier to quantify than benefits (Susskind, Jain, \& Martyniuk, 2001, p. 114). Costs get meticulously recorded in books of accounts; benefits require subjective and ironically, costly - studies to be commissioned. Moreover, cost are certain, benefits are not. As we often hear, "Nothing is certain, but death and taxes"14. In the environment sector, more than in others, measurement of benefits is often moot. Even in cases where cost uncertainty may exist, it is thought to matter much more than benefit uncertainty in the theoretical choice between price and quantity instruments by and large (Stavins, 1996). Moreover, distributional aspects - another common issue with CBA - are much easier to resolve on the cost side than on the benefits side (Ashford, 1981).

Another set of reasons for a spotlight on costs in the proposed method, is that it enables analysis of several other aspects of policy design at the analyst's stage. We know, for instance, that institutional design choices involved in implementation mostly get ignored (Bressers \& Klok, 1988; Weinter, 1992) and these can have nontrivial influence on costs of a policy. Further, costs of instruments under consideration may interact significantly - and what is more important, differentially - with costs of pre-existing policies (ACCF, 2007; Goulder, Parry, Williams, \& Burtraw, 1999), thereby directly affecting the instrument choice. This becomes all the more important in the light of the fact that ever more, policy gurus advocate policy 'mixes' or packages over singular instruments for greater efficacy (Faure, 2008; OECD, 2008). Rousseau and Proost (2005) agree that including a wider set of costs into the analyses significantly alters the cost-effectiveness of

\footnotetext{
14 The entry at a popular online repository of English phrases and proverbs is available at http://www.phrases.org.uk/meanings/death-and-taxes.html. Retrieved on 11 January 2008.
} 
policy instruments under consideration, and hence, can significantly influence the ultimate choice. Incidentally, a European think-tank also seems to be working along these lines (Humbeeck, 2006).

As might show from the citations, articles on CBA methodology from the Journal of Policy Analysis and Management (JPAM) form the bulk of the body of literature that the research proposes to build on and contribute to, drawing only occasional pointers from journals such as Evaluation and Journal of Legal Studies. Thus the approach is from the perspective of aiding the professional policy analyst, more than from a legal standpoint. For the same reason, this work also takes into account directives and guidelines from governments that may have a bearing on an analyst's direct work. Nevertheless, this work does not continue any single line or school of work. Rather, it forks out from the discussion around CBA alternatives and improvements into a line of its own.

As noted in an earlier section on the origins, the most common form that ex-ante analysis takes is Cost Benefit Analysis (CBA). While a single CBA procedure is designed to gauge or justify the merit of implementing a single policy option, when choosing between one or two, the simple extension is to conduct a CBA of both and compare. That being so, this work stems from the conviction that when thus extending the application of CBA to analysis of choice, it is not sufficient to merely copy the method as designed for its original purpose and build up on it wherever the whim strikes. The ideal approach to adaptation of methods is to build the most comprehensive design of the method suited for the new purpose. There will definitely be constraints to its application. Yet, the better analyst starts with the new comprehensive method at the time of application, so they may dumb it down from there subject to constraints and remain well aware of precisely what information is lost or compromised. Chapters to follow reinforce the rationale for a slight adaptation to CBA for a specific stage of policy analysis by way of CEA and LCA. 


\section{Chapter 3 Question, Design and Method}

\subsection{Question to be Addressed}

It would be a tall order to take on any of the current issues with CBA and attempt to give the last word on the resolution. As conceded in the very introduction (section 1.1.), this research is a more humble undertaking.

Here, our interest is to innovate with policy analysis in a limited way and explore ways to maintain the pioneering lead in analysis and policy design. More formally put, the key question is:

\section{By what means can Europe maintain its relative advantage in environmental} policy?

On the way to answering that, we will begin by exploring the effects, benefits and challenges of treating a CEA enquiry like an LCA exercise, in a narrow set of specific contexts that allow for it. (Examples and application will elaborate on the limitations of the approach when we come to them.) We will take a measure of the stock of skills engaged in analysis and the challenges in the profession. Lastly, we will scrutinise the topical phenomenon of Big Data and explore every avenue and opportunity it presents for environmental policy. For the purposes of structuring research design and drawing on various research methods, the key question may be broken down to ask, in sequence:

- Could a framework inspired by LCA help adapt CEA for instrument design choices in environmental policy?

- What would the analogous equivalent of a 'functional unit' look like under a CEA paradigm?

- What are the demonstrable effects of trying multiple 'instrument units'?

- Are the skills required for similar analytical innovation available in the human capital devoted to policy analysis?

- Does Big Data offer the potential to revitalize Environmental Policy Analysis? In what way? 
In the very next chapter, we examine and attempt to improve CEA, which has been described as a subset of CBA (Johannesson, 1995). The following quote from Cellini and Kee (2010, p. 493) best covers CEA as treated here:

[CEA] is a technique that relates the costs of a program to its key outcomes or benefits. [CBA] takes that process one step further, attempting to compare costs with the dollar value of all (or most) of a program's many benefits.

[CEA] seeks to identify and place dollars on the costs of a program. It then relates these costs to specific measures of program effectiveness. Analysts can obtain a program's cost - effectiveness ratio by dividing costs by what we term units of effectiveness. Units of effectiveness are simply a measure of any quantifiable outcome central to the program's objectives.

To exemplify, in cases where stakeholders are all agreed that NOx is an environmental bad and its emissions must be brought down, analysts can choose between policy instruments targeting such reduction based on the criteria of least cost for achieving one unit reduction, without hankering about how best to precisely quantify and measure the societal benefits of NOx reduction.

This portion of the thesis could be said to contribute to literature on the application of CEA to environmental problems where the benefits are difficult to quantify, but can be implicitly accounted for by comparing the cost profiles for two options to achieve the same level of benefit (Vo $\beta$ \& Schmid, 1991). Much of the literature on the effects of contextual heterogeneity on the results of CEA though appears to be in the health sector (Garber \& Phelps, 1997; Johannesson, 1995; Lord, Laking, \& Fischer, 2006).

To match up to the innovative nature of this work, we draw on research methods from fields as diverse as engineering, operations research, product design and journalism. That is quite fitting as the methodological origins of policy analysis itself are said to have been outside the sphere of public administration or political science, and owe a great deal to engineering and operations research (Dunn, 2007, p. 41).

\subsection{Framework}

To position this research in a framework, we must go back to the theories of public policy and policy analysis. Policy Analysis may be seen as a stage in the Public Policy process. In his popular textbook, Dunn $(2007$, p. 45) credits Lasswell (1956) as the seminal influence that shaped later conceptions of a policy cycle. Essential 
elements of the policy cycle are presented in Figure 2-1 to illustrate the position and scope of the analytical innovation proposed. As seen there, it spans or bridges two phases of the policy cycle, namely, problem definition and policy analysis.

The idea quite simply is that, by casting analysis as a revisionist and iterative process, it can be extended to overlap with the preceding stage of problem definition. That overlap facilitates some of the values the innovation seeks to deliver, as elaborated in section 4.1.

To look at another way of framing it, policy analysis comes in flavours. Dryzek (1982) presents an illuminating description of policy analysis being manifested in five modes:

- Policy evaluation: Identify a problem, relevant criteria, a set of policy options, assess the options on the criteria, choose and recommend the option based on a weighted sum of the criteria.

- Policy Advocacy: Choose a client, identify their strategic interest, assess options towards serving that interest, offer evidence and arguments in support of the option.

- Single framework: Adopt one of many frameworks from social science, learn the range of policy instruments it offers, interpret a policy problem against the framework, determine how best to apply the instruments to the case.

- Social choice: Choose criteria to judge institutional performance, identify a set of alternative social choice mechanisms, assess the alternative against each criterion, advocate the mechanism based on some weighted sum of the criteria.

- Moral philosophy: identify a moral framework, interpret the policy problem at hand in the light of this framework, develop a general set of principles to inform public policy in this problem area.

In the typology as laid out above, we are firmly rooted between the first and second modes of policy analysis - between evaluation and advocacy. Both modes are commonly encountered in environmental policy. Positioning in this frame is important to understanding the premise of this research. While evaluation is the prerogative of the policy analyst, advocacy brings in the perspective of his boss, the policy maker. It is at this juncture that the methodological innovation seeks to offer its worth. As Tversky and Kahneman (1981) postulated over three decades ago, frames of reference have a direct bearing on preferences and that that is a "significant concern" for the matters of rational choice. The proposed method attempts to adapt the analyst's procedurally algorithmic handling of CEA to 
accommodate the interests and associated preferred frames of policy makers and relevant stakeholders.

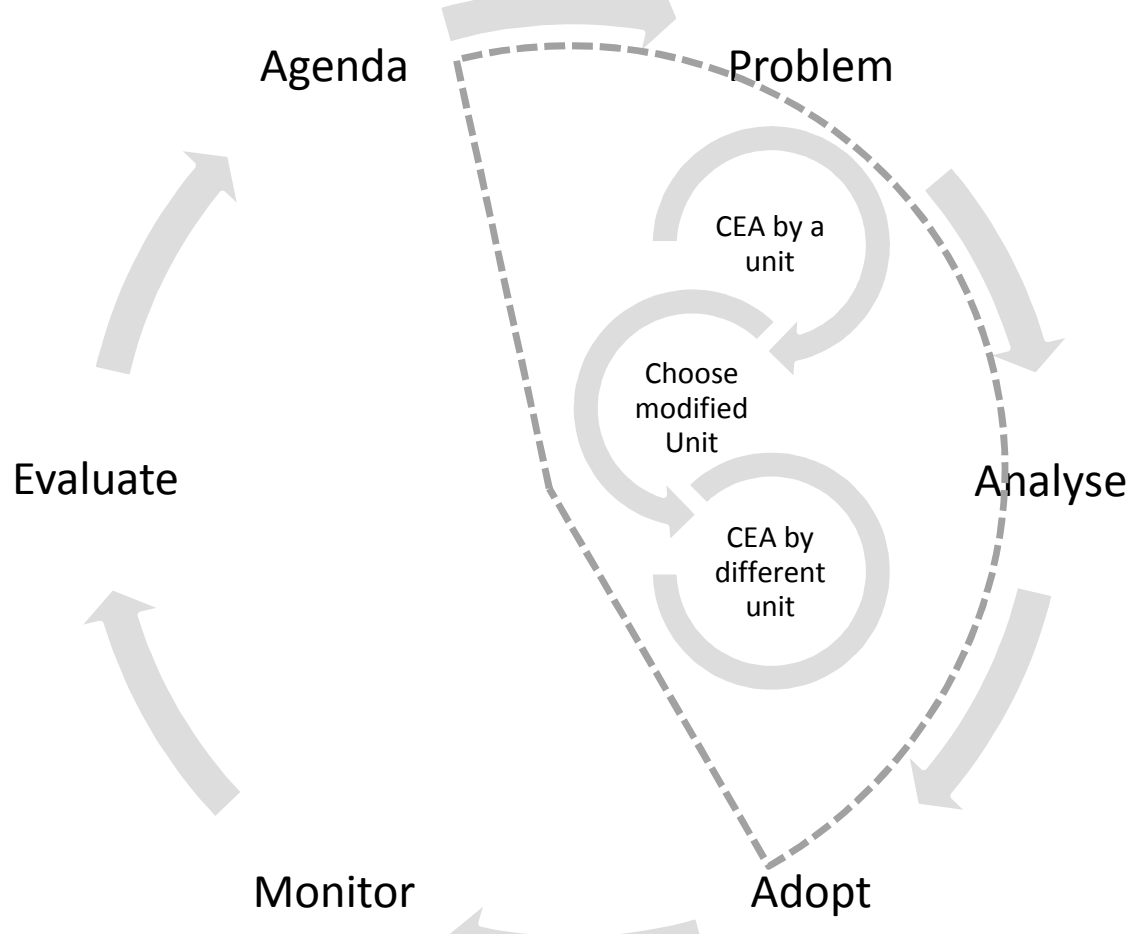

Figure 3-1 Position in Policy cycle Framework.

At that position, several streams of literature converge and contribute. Role of analysts (Bromley, 1990; Turner, 2007; Viteritti, 1982); an instrument design focus in policy analysis (Linder \& Peters, 1984); the exercise of selecting, defining and revising policy objectives themselves - or the "relationship between policy choice parameters and policy target variables" (Ho, 2000). One aim of positioning the research at that juncture is to speak to those disparate but very relevant streams of literature.

The research design is structured in four parts:

- Analysis Method Innovation - outlining the new design (Chapter 4)

- Proof of concept - Empirical testing of the design and claims (Chapter 5) 
- Understanding the Human Capital Invested in Policy Analysis (Chapter 6)

- Exploring the scope for Big Data in Policy Analysis (Chapter 7)

\subsection{Quantitative Case Studies}

Quantitative case studies are regularly used in medicine (Hopkins, 2008) and in operations research or engineering. As the use in this thesis is closer to the latter, we turned to engineering journals for prescriptions. Zelkowitz and Wallace (1998, p. 25) lay out the different approaches towards experiments that are paraphrased concisely below:

- Scientific method: A theory to explain a phenomenon is developed. A given hypothesis is proposed and then alternative variations of the hypothesis are tested.

- Engineering method: A solution is developed and tested. Based upon the results of the test, the solution is improved.

- Empirical method: A statistical method is proposed as a means to validate a given hypothesis. Unlike the scientific method, there may not be a formal model or theory describing the hypothesis.

- Analytical method: A formal theory is developed, and results derived from that theory can be compared with empirical observations.

The second, the engineering method, appears to most suit our purpose. We have here a proposed improvement to a tool of analysis, in essence, a new tool that we must test. As an engineer by training, the author is quite at ease with the approach.

They proceed to enumerate numerous methodologies - the title of the paper is 'Experimental models for validating technology'. One the methods listed is Case Study. The reason that method is of particular worth over others such as Field Study, Dynamic Analysis or Project Monitoring, is that this research is not about tackling a specific policy problem. The wider the use-case scenario that can be demonstrated as worthy, the more credible the innovation proposed. The keyword, in fact, is right there: use-case. A variety of case studies can be employed to illustrate use-cases. However, as we seek variety and not depth, these are not to be case studies of the kind more common in the social sciences or business management literature, where the emphasis is on an ethnographic exploration of 
the 'why' and 'how'. As the analytical tool proposed is essentially a quantitative exercise, the case studies we develop are also quantitative.

While the definition of the engineering method above sets apart the approach from others, and helps justify the choice, the Zelkowitz paper does not give specific guidelines for any of those methods, including Quantitative Case Studies. Quantitative case studies may be seen as a subset of the Case Study method, described well in Yin (2003). And yet, Quantitative Case Studies for the engineering method are distinct enough from the practice common in the social sciences that we need to look elsewhere for suitable practical guidelines.

Kitchenham and Pickard (1998) give comprehensive and contextualised guidelines. The main benefit of Quantitative Case Studies, they say, is that they allow "the effect of new methods and tools to be assessed in realistic situations" (p. 24). Borrowing from Pfleeger (1994), they further elaborate key elements of adapting the scientific method for evaluating tools in engineering research:

"Response variables are those factors which are expected to change or be different as a result of applying the treatment. The difference between a formal experiment and a case study is in the use of what are known as 'state variables'. State variables are factors that characterise your case study project(s) and can influence your evaluation results."

In keeping with their framework, we could say our main 'response variable' is the effect of the choice for a CEA exercise. 'State variables', on the other hand, include the policy sector and country context. As they recommend, we try to sample our cases over the state variables, attempting to build quantitative cases across diverse areas of environmental policy and different contexts, from gaseous industrial emissions in the US to land use in the UK.

For constructing the cases, data was generated with the help of publicly available computer models used by government agencies for their own analysis. Some of these cases are built with accounting models designed specifically for the purposes of cost-effectiveness studies, others are available as extensive spreadsheets that presents results from models used for evaluation purposes. In the latter case, only the spreadsheets and not the models are in the public domain. Results from each of the models required many runs with varying parameters. For each of the model presented, on an average two others were tested equally exhaustively. The cases presented were chosen for the ease of illustration. While that is a commentary on the amount of effort these results took to produce, it is also a proxy indication of the probability of real life cases where the demonstrated results might manifest. It is a non-trivial one. 


\subsection{Human Capital in Policy Analysis}

Among the paradigms we are following here, it is often the case with engineering solutions, product design and even software technology, that research stops at evaluating the tool from a technical perspective. The designer is very clear about the design goals and sets about the task of ascertaining the value of the new tool in terms of those goals. However, even the most staid engineers know that ultimately there will be a human involved, and that human's experience at the interface matters a great deal and may have a direct bearing on the instrumental goals themselves. The importance of user experience and feedback is not lost on researchers in information technology (Davis, Bagozzi, \& Warshaw, 1989), the sector that suggested the methodology for the previous chapter. In fact, the industry regularly stumbles upon product improvements drawing on the immense quantities of feedback from the close tabs it keeps on users (Agichtein, Brill, \& Dumais, 2006). Naturally, when adopting their research framework to a social science, we could hardly be done after evaluating a new analytical method. It is after all Policy Analysts who are the 'clients' of this work, to extend the analogy. The next natural step is to run it by them for an assessment.

This gives scope for the qualitative part of this research work. When it comes to qualitative research, one cannot but agree with Denzin and Lincoln (1994, p. 11) who say in their 'Handbook of qualitative Research': "An embarrassment of choices now characterizes the field of qualitative research. There have never been so many paradigms, strategies of inquiry, or methods of analysis to draw upon and utilize." That was 18 years ago. Willis (2007) also finds it one of the more interesting ironies of qualitative research that although qualitative researchers are "far less" preoccupied with choosing the right research method than quantitatively inclined, the field has produced an "unbelievable number" of research methods.

Thankfully, our purposes here are fairly straightforward as laid out above and directly point to one method: in-depth interviews with key respondents. We see policy analysts as clients of the proposed innovation in analysis and expect to glean from them pointers as to its worth and feasibility, rich with contextual details and benefits of their experience. A journalistic style of investigatory interviewing might come in handy for parts of the questionnaire.

Gubrium and Holstein (2002) provide an updated and cross-disciplinary guide to interviews. With respect to in-depth interviews they note ( $p$ 676):

"[Researchers] explore and examine research participants' concerns and then further develop questions around those concerns, subsequently seeking participants whose 
experiences speak to those questions... ... In-depth qualitative interviewing fits grounded theory methods particularly well....An interviewer assumes more direct control over the construction of data than does a researcher using most other methods, such as ethnography or textual analysis. Grounded theory methods require that researchers take control of their data collection and analysis, and in turn these methods give researchers more analytic control over their material."

As we shall see later in chapter 6, the particular method of interviewing turned out to be an apt choice, because it allowed for the question schedule to learn from previous interviews and gradually adapt the direction of enquiry. As it became clear form the very first interviews that the analysts might not be entirely equipped to gauge the feasibility of the proposed analytical adaptation, given its distance to the current practice, the interviews that followed dwelled longer on the causes and explanation for that distance instead. The target of data collection and analytical focus itself shifted from the first interview to the last.

\subsection{Exploring the scope of Big Data for Policy Analysis}

This part of the research was added entirely as an afterthought, but the relevant sections will hopefully show that it was a fortuitous thought, given the extremely pertinent findings. While the interviews disappointed to the extent that their focus had to be altered, the one consistent and valuable piece of information they did yield concerned data limitations in the environmental sector. It seemed rather defeatist to keep mum on the matter after hearing the data lament over and over, from country after country. The period also coincided with a lot of buzz in the media around the term Big Data. It was a natural step to investigate if any of that buzz held a promise for the clients of this research.

That part, Chapter 7, relies largely on demonstrating quantitative predictive relationships by way of correlation and graphical juxtaposition. The chapter gathers data from both conventional and authoritative sources (EuroStat and US Census Bureau) and a typical Big Data source (Google) and tests if correlations exit where they might be expected. As an indication of the future course of this work, within the scope of this thesis, it relies partially on heuristics. Which is to say, it merely seeks to establish that in the vast troves of Big Data that are rapidly becoming available on the public domain, there is policy relevant data which is worth testing for analytical exploitation. Data was generated manually from open online repositories such as Google Insights for Search ${ }^{\circledR}$, Google Trends ${ }^{\circledR}$, and Google Correlate®. Correlations were examined using open source statistical package PSPP. 


\section{Chapter $4 \quad$ Innovating with the Analytical Method}

We dwelled on the problems in the chapter 2. That is a cumbersome exercise and would be entirely empty if it did not instruct us on what to look for in solutions what needs solving, where past remedies have been found wanting, what can be remedied and what aspects can be improved while others toil on perfecting those remedies. It is now time to look at solutions and improvements, albeit, given the scope of this work as set out in sections 2.4 and 3.2, within the confines of a narrower focus.

Analysts cannot wait for resolution of all issues with the only methods they have at their disposal and Weimer and Vining (2005, p. 405) would agree. While one set of researchers attempts to work on one set of issues, that should not stop another researcher to advance the method towards other potential values that method promises. As it is the best method available and for want of comparable alternatives, analysts will continue to employ it and any improvements will only benefit everyone concerned. This section describes some of the values that adaptations to CEA potentially hold and then the adaptations themselves.

\subsection{Genesis of the Idea}

It was in a lecture on law and economics at the International Institute for Industrial Environmental Economics (IIIEE) at Lund University that the thought first struck the author. That particular class was peppered with mentions of CBA. The first year of the same M.Sc. program had included an in-depth course on Cost-Benefit Analysis (CBA). The lecture had followed another on the Life Cycle Analysis (LCA) methods at heart of Integrated Product Policy (IPP) instruments. With the salient bits of all those courses overlapping in memory, it was only natural to come to wonder: "CEA compares costs referenced to a unit, LCA compares impacts referenced to a unit, but LCA seems to invest much more attention to the choice of the functional unit. Why not expand a typical Costs-effectiveness Analysis (CEA) to more than one "reference" unit too? Why always the dollar-per-ton paradigm? Could we not try out with policy instruments what we do so exhaustively with products?...".

This is, at the end of the day, the work of a chemical engineer who went on to do a master's degree in business management before being appointed Policy Analyst at the environment ministry. That was, in turn, before the second master's program 
taught partly at the IIIEE. Sitting in those classes, insights from the previous education chased each other helping the author see connects between various subjects e.g. technical issues in containing NOx emissions, business compulsions when considering an investment in equipment or an alternative supplier and the universal travails of a government analyst in the midst of all the politicking. The collection of related research questions in this project offers a way to bring the three sources of insights to a synergetic benefit.

\subsection{Adaptation}

The numerous issues with CBA are only compounded by aggregation and comparison of aggregates. As a model for choice between policy instruments, costeffectiveness comparisons make much better sense, but conducted in a format that heavily resembles CBA, they retain all of inherent issues. Many of the issues can be overcome or tackled by a design better suited for comparison.

This chapter presents two methodological adaptations to the CBA prescription. The first is to adopt a framework to facilitate comparative equivalence, and the second to capitalize on the new comparative framework to intensify the cost focus of the analysis.

The comparison of equals requires a bit of tweaking the original simple CBA analysis. Also, as one of the aims is to help factor in the policy context and the jurisdictional context, the tweaks can be borrowed by inspiration from other methods of analysis that aim at comparison of equivalence in varying contexts. One such method, known to most who work with environmental policy, is Life Cycle Analysis (LCA). LCA specialists spend a great deal of time and effort in testing and arriving at reference units precisely suited to their analysis and that is where we will draw our inspiration.

Why LCA, one might ask? The main reason is as noted above: like CEA, LCA is also a framework for choices. Apart from that main reason, consider the origins of the CBA standard as described in chapter 2, specifically section 2.2. We find that the early formulations drew form assessment of projects. One wonders if policy is not more like a product than a project. (As we shall see in the very next section, the primary use of LCA is for product design choices.) Compare this quote from an illuminating treatise on the subject of economic analyses by Anthony Ogus (2006, p. 283). 
Law-making is not a "project" in the sense that it does not necessarily lead to a desired outcome; rather it principally involves changing the incentives of the actors in the hope that they will induce the desired outcome. This difference forces the parameters of project analysis to be extended.

Not to stretch the analogy, but as a tool when used by the government, LCA too aims at giving incentives to firms to incorporate environmental considerations into their products at the design stage itself.

\subsubsection{What is LCA?}

Life Cycle Assessment has gained increased prominence with the emergence of Integrated Product Policy (IPP), particularly in Europe. It is worthwhile to set the introduction to LCA in a background of IPP. The author's first introduction to IPP was in an eponymous graduate level course taught by Thomas Lindhquist ${ }^{15}$. The class began with a discussion on the need to focus on products, whereupon the author recalls having said something to the following effect:

Development is the most persistent pursuit of mankind. The world has evolved into a system where all development is delivered through products and services. When we, ordinary citizens of the world, wish to improve our lives, we draw cash or a card out of a pocket and we go ahead and buy something.

That may sound like a rather post-modern, materialistic outlook. Yet as increasing bulks of populations move into urban settings, even the most non-materialistic, modernity-averse pleasures such as time spent in wilderness involve buying things ranging from travel to outdoor accoutrements.

The entire global society is organized around economy which in turn is nothing but production and sales. All interaction we have with our planet, which for the most part takes the form of environmental impacts, is associated with some sector of the global economy, which contributes at some level to a product eventually sold in some market. Hence, it makes sense to trace the impacts back to the original purposes - the products themselves. Our interactions with the planet are mapped to our interaction with products.

\footnotetext{
${ }^{15}$ At IIIEE, Lund University, one of the forerunners in research on the subject.
} 
LCA, as the term implies, is that means of mapping the impacts to stages that products pass through - their design, their production, their use and their disposal. Definitions abound in literature, but given the purposes here, it is best to refer to practitioners in the public sphere themselves. To quote the USEPA:

LCA is a technique to assess the environmental aspects and potential impacts associated with a product, process, or service, by: compiling an inventory of relevant energy and material inputs and environmental releases; evaluating the potential environmental impacts associated with identified inputs and releases; interpreting the results to help you make a more informed decision (USEPA, n.d.).

The European Commission lays more emphasis on the nature of product life cycles:

LCA is a structured, internationally standardised method and management tool for quantifying the emissions, resources consumed, as well as environmental and health impacts that are associated with goods and services (products). LCA takes into account the product's full life cycle: from the extraction of resources, production, consumption and recycling up to the disposal of remaining waste (European Commission, n.d.).

What aspects of Life Cycle Assessment can inspire the adaptation of CEA? Given the nature of LCA, the concept of analogous comparison can help a policy analyst reference costs to unitized objectives, sensitive to the context.

Life Cycle Assessment compares rival products or services on a common footing, called the 'Functional Unit'. In many cases, the common measure is easy to stipulate. E.g. when comparing packaging options - a carton, a glass bottle or a plastic decanter-the function to be served and the basis for comparison can be something like "carrying one litre of milk" (Table 4-1). 


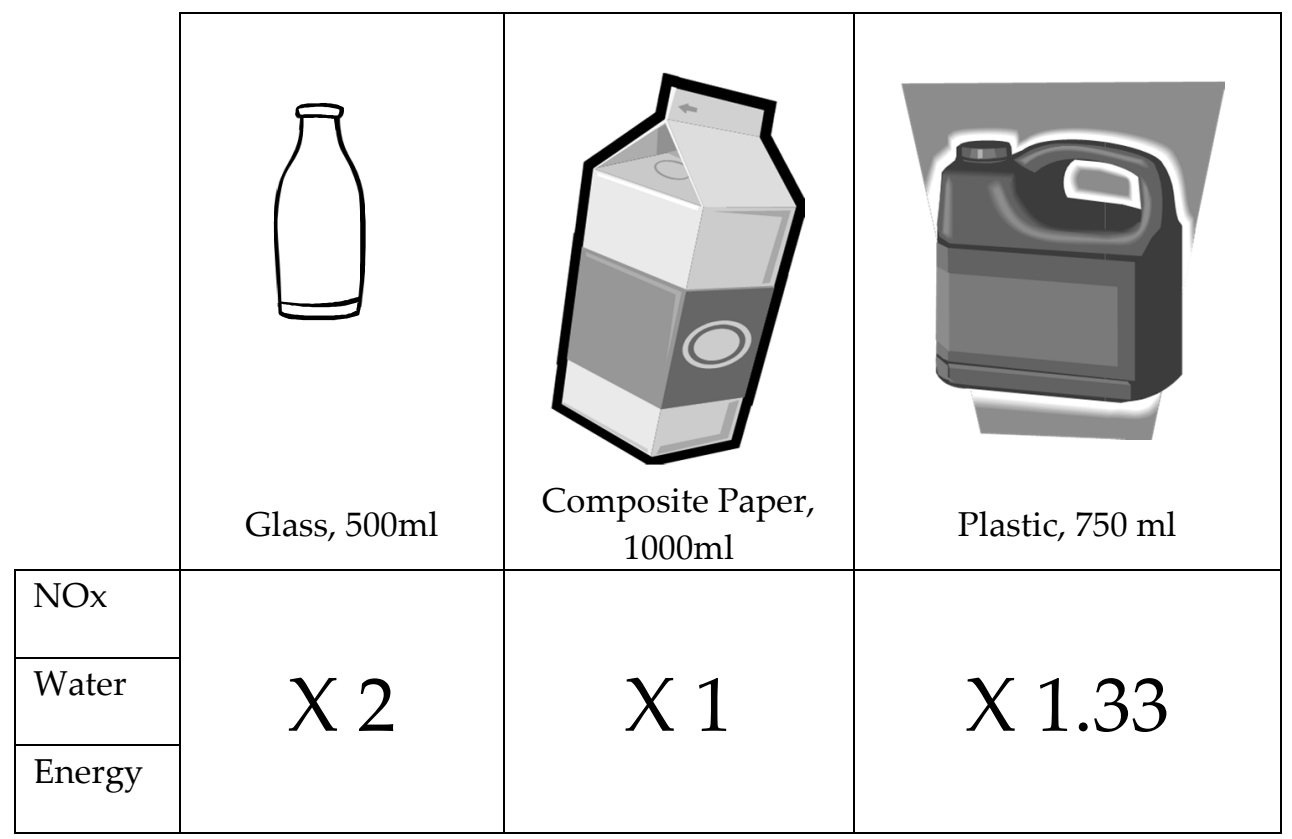

The table 4-1 above enumerates NOx emissions, water and energy consumption as the environmental impacts associated with each of three packaging option for milk as a product. As each kind of packaging carries a different amount of milk, the quantum of environmental impacts is multiplied with the corresponding factor to achieve an equivalent comparison. Table $4-2$ presents a more generic view of the elements in an LCA analysis.

Table 4-2 Elements of an LCA Comparison

\begin{tabular}{|c|c|c|c|}
\hline & $\begin{array}{c}\text { Design Alternative } \\
1\end{array}$ & Alternative 2 & Alternative 3 \\
\cline { 1 - 2 } $\begin{array}{c}\text { Environmental } \\
\text { Impact 1 }\end{array}$ & & $\begin{array}{c}\text { X Correction } \\
\text { Factor }\end{array}$ & $\begin{array}{c}\text { X Correction } \\
\text { Factor }\end{array}$ \\
\cline { 1 - 2 } Impact 2 & & & \\
\hline Impact n & & & \\
\hline
\end{tabular}




\subsubsection{Contextual Equivalence a la LCA}

Thus, a rational comparison of alternatives involves defining fair units. The same can and should be done for instruments of policy. To analogously adopt the framework, products are now replaced with policy instruments, and where we earlier had environmental impacts, we now have the costs of the achieving the given policy objective through the respective instruments (Table 4-3).

Table 4-3 Proposed Comparison of Costs

\begin{tabular}{|c|c|c|c|}
\hline & Instrument 1 & Instrument 2 & Instrument 3 \\
\hline Cost 1 & & X Correction Factor & $\begin{array}{c}\text { X Correction } \\
\text { Factor }\end{array}$ \\
\cline { 1 - 2 } $\operatorname{Cost} 2$ & & & \\
\hline Cost $\mathrm{n}$ & & & \\
\hline
\end{tabular}

As a first step, what we learn from LCA is that comparisons do not have to be postponed until after aggregation. The analysis is far richer if details are retained and like is compared with like i.e. the scope for comparison between like cost categories is retained. The richer information would help the fine-tuned design of instruments to match a context.

Let us refer back to the example in Table 4-1. This is a relatively simple example in the product related environmental comparisons. The only variables are packaging material and container capacity. However, often under Integrated Product Policies where LCA is most routinely applied, products and product-service systems can get much more complicated than that.

With a more complicated comparison, usually when services are involved, the functional unit gets more complex to enable a fair comparison.

E.g. when comparing technical designs of washing machines, the unit may be something like "removing a stain from $1 \mathrm{ml}$ ink from a 1 sq. meter white towel and drying it to $10 \%$ moisture". However, if the comparison includes a product-service system such as a communal washing facility, the unit may have to additionally account for the frequency and number of persons or households served. That illustrates how the definition of a functional unit involves some art and science 
which eases the comparison of disparate systems with respect to their environmental impacts.

\subsection{3. "Functional Units" for Policy}

In the case of policy instruments, by 'fair', we mean fair given the context and the limitations associated with the context. Authors such as Albrecht (2006) have stressed that for instruments such as environmental taxes to be optimal, ideally they should be "differentiated according to the different pollutants, the mix of pollutants, the sources of pollution and their location, the amount of pollution and the timing of the pollution". Others have observed the importance of choosing appropriate units for economic analyses (Litman, 2001). For instruments to be suitably differentiated to meet the context, of-course, they should be dynamically designed and chosen.

While instruments of environmental policy are frequently adopted from foreign sources, the geo-economical context can vary greatly across jurisdictions. The north of Sweden is likely to significantly differ from the French coast in the capacity to absorb and clean out, say, Sulphur Dioxide, and the susceptibility to direct or indirect harm. Normally, such science does inform the standards at the initial stage of their formulation. However, thereon, the standards make their way into federal or European standards and get transposed to a wider set of member states or get diffused to other continents. For a better comparison between instruments, costs could be pegged to desired goals such as reduction emissions but in a framework set by the determinants of local absorption capacity (rainfall, edaphic factors and so forth).

The second context that figures even less in policy formulation and instrument design is the local economy context. Smelters or petrochemical industry may be concentrated in one corner of a continent or a country. Local economy and emission numbers would inform the likelihood of "cocktail effects" in combination with other pollutants. For instance, North Europe largely has chemical industry and food processing industry is concentrated in Southern Europe ("Europe Industrial Center," n.d.). Environmental regulation needs to be aware of the zones of production. Businesses will appreciate environmental policy that takes into account production trends and imposes costs in a fair way.

To transfer the LCA logic, we need to arrive at some form of "functional units". The above discussion indicates 'units' such as the following: 
- One unit reduction per $\mathrm{ml}$ of average annual rainfall (geographic)

- One unit reduction per ton of rubber produced in a region (economic)

Interestingly, in a policy context, the units of comparison do not necessarily need to be solely functional. For the sake of pragmatism, they can be instrumental or a hybrid. E.g., Unit emission reduction per MW generated. Table 4-3 shows how these units could be devised by the introduction of conversion factors.

Table 4-4 Proposed Cost Comparison with Correction Factor

\begin{tabular}{|l|l|l|l|}
\hline & Instrument 1 & Instrument 2 & Instrument 3 \\
\cline { 1 - 2 } Cost 1 & & \multirow{2}{*}{$\times \mathrm{E}_{2} \times \mathrm{G}_{2}$} & $\mathrm{x} \mathrm{E}_{3} \times \mathrm{G}_{3}$ \\
\cline { 1 - 2 } Cost 2 & & & \\
\cline { 1 - 2 } $\mathrm{Cost} \mathrm{n}$ & & \\
\hline
\end{tabular}

Where G denotes the Geographic Context Parameter, or factor of correction And E denotes the Economic Context Parameter, or factor of correction

When comparing two instruments for the same jurisdictions, different cost categories will have different nature of relations to the context parameters. In some cases, the cost category may not be a function of the parameter at all.

When comparing the same instruments in two different jurisdictions, the same cost category will get divided by different values of the context parameters, giving widely varying values between the contexts.

\subsubsection{Expanded Cost Taxonomy}

The adaptation proposed to the analytical method helps arrive at equivalence of comparable categories of costs for a more meaningful and comprehensive comparison. That modification would significantly benefit from another improvement to CBA itself more broadly that has been proposed earlier by others (mentioned below Table 4-5). It concerns the taxonomy of costs themselves, in response to some of the issues with CBA cited earlier.

When applied to a particular case, when a particular policy problem is taken up and the policy choices are determined, in other words, when all the specifics are known, the cost associated with a policy can be broken up into the real numbers against the corresponding sub-heads as shown in the Table $4-5$ below. It includes 
several categories of costs commonly neglected but the inclusion of which can yield crucial information especially in conjunction with the first proposed improvement (contextual equivalence).

Table 4-5 Building a Taxonomy of Costs for a CEA Exercise

\begin{tabular}{|c|c|c|c|c|c|}
\hline Actors & & & & $\begin{array}{l}\text { Instrum } \\
\text { ent } 1\end{array}$ & $\begin{array}{l}\text { Instrume } \\
\text { nt } 2\end{array}$ \\
\hline \multirow[t]{10}{*}{ Regulator } & \multirow[t]{3}{*}{ Formulation } & Consultation & & & \\
\hline & & $\begin{array}{l}\text { Decision } \\
\text { making }\end{array}$ & & & \\
\hline & & $\begin{array}{l}\text { Baseline } \\
\text { studies }\end{array}$ & & & \\
\hline & \multirow[t]{5}{*}{$\begin{array}{l}\text { Implementatio } \\
\mathrm{n}\end{array}$} & \multirow[t]{3}{*}{$\begin{array}{l}\text { Monitoring } \\
\text { Instruments }\end{array}$} & $\begin{array}{l}\text { Documentati } \\
\text { on duty }\end{array}$ & & \\
\hline & & & $\begin{array}{l}\text { Notification } \\
\text { duty }\end{array}$ & & \\
\hline & & & $\begin{array}{l}\text { Audits and } \\
\text { Inspection }\end{array}$ & & \\
\hline & & $\begin{array}{l}\text { Administratio } \\
\mathrm{n}\end{array}$ & $\begin{array}{l}\text { Establishing } \\
\text { new } \\
\text { institutions } \\
\text { Wages }\end{array}$ & & \\
\hline & & $\begin{array}{l}\text { Communicati } \\
\text { on }\end{array}$ & $\begin{array}{l}\text { Publishing } \\
\text { Advertising }\end{array}$ & & \\
\hline & \multirow[t]{2}{*}{ Enforcement } & $\begin{array}{l}\text { Enforcement } \\
\text { Instruments }\end{array}$ & Fines & & \\
\hline & & $\begin{array}{l}\text { Dispute } \\
\text { Settlement }\end{array}$ & & & \\
\hline \multirow{5}{*}{$\begin{array}{l}\text { Regulated } \\
\text { Parties }\end{array}$} & \multirow{5}{*}{$\begin{array}{l}\text { Compliance } \\
\text { Costs }\end{array}$} & \multirow[t]{2}{*}{ Preparatory } & Information & & \\
\hline & & & $\begin{array}{l}\text { Interpretatio } \\
\mathrm{n}\end{array}$ & & \\
\hline & & \multirow[t]{3}{*}{ Abatement } & $\begin{array}{l}\text { Tests } \\
\text { Capital Costs }\end{array}$ & & \\
\hline & & & $\begin{array}{l}\text { Operational } \\
\text { Costs }\end{array}$ & & \\
\hline & & & Certification & & \\
\hline
\end{tabular}




\begin{tabular}{|c|c|c|c|c|c|}
\hline & & \multirow[t]{4}{*}{ Monitoring } & $\begin{array}{l}\text { Measuremen } \\
\mathrm{t}\end{array}$ & & \\
\hline & & & $\begin{array}{l}\text { Documentati } \\
\text { on }\end{array}$ & & \\
\hline & & & Reporting & & \\
\hline & & & $\begin{array}{l}\text { Audits, } \\
\text { Inspection } \\
\text { and } \\
\text { Maintenance }\end{array}$ & & \\
\hline & & \multirow[t]{2}{*}{ Legal Costs } & Licenses & & \\
\hline & & & Litigation & & \\
\hline & \multirow[t]{5}{*}{$\begin{array}{l}\text { Associated } \\
\text { Costs }\end{array}$} & \multirow[t]{2}{*}{$\begin{array}{l}\text { Transitory } \\
\text { Costs }\end{array}$} & $\begin{array}{l}\text { Disrupted } \\
\text { Production }\end{array}$ & & \\
\hline & & & $\begin{array}{l}\text { Management } \\
\text { Diversion }\end{array}$ & & \\
\hline & & \multirow[t]{3}{*}{ Indirect Costs } & $\begin{array}{l}\text { Product } \\
\text { Substitution }\end{array}$ & & \\
\hline & & & $\begin{array}{l}\text { Discouraged } \\
\text { Investment }\end{array}$ & & \\
\hline & & & $\begin{array}{l}\text { Unemploym } \\
\text { ent }\end{array}$ & & \\
\hline & Negative Costs & & & & \\
\hline & Wages & & & & \\
\hline & $\begin{array}{l}\text { Costs of } \\
\text { Inadequate } \\
\text { Compliance }\end{array}$ & Enforcement & Fines & & \\
\hline \multirow[t]{2}{*}{ Society } & $\begin{array}{l}\text { Loss of } \\
\text { Consumer } \\
\text { Surplus }\end{array}$ & & & & \\
\hline & $\begin{array}{l}\text { Loss of } \\
\text { Producer } \\
\text { Surplus }\end{array}$ & & & & \\
\hline \multirow[t]{2}{*}{$\begin{array}{l}\text { More } \\
\text { Transaction } \\
\text { Costs }\end{array}$} & & & & & \\
\hline & & & & $\Sigma_{1}$ & $\Sigma_{2}$ \\
\hline
\end{tabular}


Table 4-5 above builds up on the varying treatment of costs in OMB (1996), Rousseau and Proost (2005), MacLeod et al. (2006) and (Eroglu \& Goodrich, 1998). Given this exhaustive list, it is fairly obvious that each of the categories of cost may not apply to both instruments in consideration, and neither may all of them at once apply to any single instrument. Moreover, some of the categories of costs mentioned may involve all the disadvantages of tedious studies that this method hopes to avoid. In such cases, such costs may only be considered as an item on a checklist, a consideration to compare between the instruments, but not in exact quantity. Also, socio-political values on the public agenda may call for distributing weights between the categories of costs.

Another potential issue concerns the distributional aspects of costs that the above enumeration will not bring out. Though less thorny to deal with here than on the benefits side as pointed out earlier, there may nevertheless be cases where even on the costs side, differences may be too significant to ignore. In comparisons where this is not simplified as a checklist option, that is, where distribution aspects are significant for both the instruments, these will have to be dealt with separately and as such are not within the scope of this investigation. It must be reiterated, however, that this method is aimed at the policy analyst. Major imbalances in distribution are normally a political or value decision resolved at an earlier stage of policy processes. The policy analyst often enters at a later and lower level in hierarchy, after the choice of instruments has been considerably narrowed down after due consideration and political screening. In most cases then, it can be safely assumed that the instruments facing our analyst have passed the higher test of the erstwhile agenda and the choice is now a technical matter left to the analyst to justify.

The advantage of constructing a frame of reference and including more costs can best be realized if the two adaptations are used in conjunction. The next sections attempt to demonstrate the advantages and enumerate the values that the adaptation offers.

\subsubsection{Demonstration}

To demonstrate the advantages of the method, let us examine as an example the Swedish charge on NOx implemented since early in the 90s, followed by applicability. 


\section{NOx Charge in Sweden}

As acid rain is a major threat given the specific geography and geology of Sweden and overall climatic systems in Europe, the precursors of the problem are among the primary targets of environmental policy in the country. Besides acid rain, nitrogen oxides (NOx) also contribute to the formation of tropospheric ozone, which directly effects human health, besides plants and animals and eutrophication in soils and on sea beds. Reducing emissions of nitrogen oxides is part of 15 Swedish environmental quality objectives, such as "Natural acidification only" and "Zero eutrophication" (SEPA, 2000).

Hence, in 1985, the Swedish Parliament agreed to a resolution mandating the reduction of ambient levels of NOx by 30 per cent compared to 1980 levels by the year 1995. Accordingly, a charge on emissions of nitrogen oxides from energy generation, mostly applying to combustion plants was introduced from 1 January 1992 (under the Act 1990:613). It was hoped that putting an economic instrument in place would help to bring down emissions faster and more cost-effective than the existing regulations.

\section{The Charge}

Under the Act, a charge was levied for emissions of nitrogen oxides from boilers, stationary combustion engines and gas turbines with a minimal annual energy production of $25 \mathrm{GWh}$. The majority of facilities that fell under this criterion were boilers. The act stipulates that charge was to be based on data of recorded emissions at a rate of SEK 40 per $\mathrm{kg}$ of NOx emitted. The SEK 40 level was determined based on evaluations of costs of abatement investments for electricity power stations and district heating plants. The estimate ranged from 3 to 84 $\mathrm{SEK} / \mathrm{kg}$ NOx reduced (SEPA, 2000). The average of that range at $40 \mathrm{SEK} / \mathrm{kg}$ was hence thought to be a reasonable level.

\section{Assessment of the Payment}

For the financial calculations involved, two parameters are needed for each plant NOx emissions and the energy produced. For reporting emissions, the plants had a choice between two alternatives: they could either pay a flat charge based on presumptive levels of emissions (between $250 \mathrm{mg} / \mathrm{MJ}$ and $600 \mathrm{mg} / \mathrm{MJ}$ ) or install equipment for measurement and pay by the actual measured levels. As the presumptive levels were on the higher side of the average, most plants preferred actual measurement. For the energy output, each plant naturally had measurement instruments already installed for other obvious purposes. 


\section{Refund}

The other half of the policy instrument was that the entire amount collected under the charge was then returned back to the boiler units. The beauty of this particular instrument lies in its 'feebate' nature and the reasoning behind the refund. While avoiding any market distortion in the industry due to the introduction of the system, the charge was devised as a means for the inefficient plants to subsidize the abatement of the efficient ones.

This was achieved by returning all the collected revenue less administrative costs back to the plants, only this time, the payment was redistributed not in proportion to emissions but proportional to the energy produced. That way, inefficient plants i.e. those with higher emissions relative to their energy output were net payers to the system and efficient ones were net gainers.

\section{The Numbers}

Given the design of this instrument, some of the costs involved are of greater interest:

Administrative Costs - The administrative costs of SEPA in the year 2003 were SEK 4155000 which was just $0.7 \%$ of the total charges collected that year (SEK 633 426 360). Perhaps a better figure to compare to would be the corresponding private costs.

Private Costs - According to the mechanism and numbers described above, a sample plant that emitted $14600 \mathrm{Kg}$ in generating $37500 \mathrm{MW}$-h of power would pay around SEK 200000 due to the instrument whereas another that produced 550 $000 \mathrm{MW}$-h while emitting just $110000 \mathrm{Kg}$ of NOx would have earned (negative cost) about SEK 760000 !

To put this further in perspective, in 1996 SEPA estimated that the average cost of abatement measures was near SEK 7 per $\mathrm{Kg}$ of NOx reduced. Even allowing for that to have inflated to SEK 10 by 2003, this plant would have cut emissions with substantial gains. SEPA (2000) found that nearly a third of the plants subjected to the charge achieved reductions at negative costs.

Monitoring Costs - As we saw above, most plants chose to install measurement equipment for NOx emissions. In 2000, the initial investment into the measuring equipment was between SEK 250000 and 300000 with continued operating expenses of about SEK 100000 (SEPA, 2000). The other part of the data that the instrument requires came at no additional costs as the energy output was already 
being measured. This would immediately stand out as a difference with another policy instrument as an avoided cost of data necessitated.

\section{Application}

Now to compare an alternative design with a similar objective - a French instrument applied to a wider set of pollutants including NOx. Even the idea behind the instrument design is similar, to subsidize abatement costs through the charge. However, in terms of costs, the design is crucially different in two ways. The charge itself is at a much lower level and the mechanism of refund involves applications from individual firms that have invested in abatement (Harrington, Morgenstern \& Sterner, 2004). While this does nothing to reduce monitoring costs, the transaction and regulation costs would be expectedly higher, with each firm filing applications and the regulator reviewing them all in turns.

Now to think of the equivalent of a functional unit, or the "regulatory unit". Given the design of the instrument, an obvious choice would be:

\section{(Cost for the Reduction of) $1 \mathrm{Kg}$ of $\mathrm{NOx}$}

This simple unit in itself will help in comparing the level of charge. Also with respect to design variation, it will illustrate very well the impact of a different refund mechanism. However, that unit does not account for the differences in context. Neither will it reflect the reasons for the variation in instrument design. Good news is, those and considerations can all be factored in just by playing around with the 'regulatory unit'.

If we wish to give precedence to a certain economic sector, as policy makers negotiating policy options with each other in the legislature often have to, an alternative unit could be:

\section{$1 \mathrm{Kg}$ NOx reduction per $€ 1000$ turnover}

Section 5.2.5 gives a quantitative case that exemplifies such a unit. If we wish to emphasize the health effects instead, it could be:

\section{$1 \mathrm{Kg}$ NOx reduction per 1000 cases of an associated ailment}

As in LCA, several of these considerations could be combined into the definition of a unit. By extension, more complicated objectives and instrumental options could be dealt with by analytically arriving at a fair 'regulatory unit'. 
Thus, characterizing costs methodically as described above will not only help the policy maker compare with a rival instrument in a more informed manner, it would also give valuable guidance in refining the details of design of the instrument ultimately chosen. What the proposed form of the analysis additionally facilitates is to reference the cost differentials to unit reductions of the target pollutant, while factoring in the French and Swedish contexts in terms of geography and economy.

While the case of two similar instruments in the EU gives a teaser, the chapters to follow will elaborately explain the application, dealing with separate categories of costs.

\subsection{Rationale and Objectives}

The primary audience of the research are policy analysts working for national governments - policy analysts who identify a list of instruments for their bosses (or are handed such a list) and then are required to inform and justify the final choice. While the thesis is of immediate use to analysts in member states of the European Union and those working for "federal" institutions such as the European Commission, the applied aspects can potentially aid any jurisdiction in the world that takes environmental policy seriously. Indeed, most common aims of environmental thought are likely to fail at the global level unless all nations of the world think and act on common principles, there or thereabouts. At the academic level, the thesis speaks to researchers concerned with policy analysis, not just in the area of environmental policies, but wider public policy in general.

Where are the main advantages likely to be seen? Some of the immediate values this research promises and examples from literature of the promised benefits are given below:

\subsubsection{Equivalence for Fair Comparison}

The method will help to construct equivalence between types of instruments for better comparison. For instance, ecolabels, emission standards or a technology standard could be used to achieve the same objective, but which types of costs are common to all of those and which are not? Which costs make a significant difference in what context? The method will indicate the cost categories that stand out, cost types that are common and their equivalent amounts for a proper comparison. 
More significantly, the method enables incorporating contextual variables at the point of comparison. As explained in section 4.1.2 above, the very exercise of defining a reference unit appropriate for the policy question at hand allows for incorporating contextual peculiarities, especially when adopting an instrument known to have been successfully applied elsewhere. In the case of some policy instruments, and in some political contexts, economic and geographical differences between regions may be of paramount significance. Accounting for and incorporating geographical factors, for instance, is neither an arbitrary goal nor a trivial one. Arguably, end emissions are directly and significantly affected by metrological or topographical factors and by the very design of the policy instruments under consideration, that will likely affect the efficient allocation that economic analysis aims at ("Technology-Based Emission and Effluent Standards and the Achievement of Ambient Environmental Objectives," 1982, p. 798).

\subsubsection{Efficiency in Instruments Design}

Once the method takes hold, the experienced analyst is expected to arrive at quicker decisions, cheaper decisions and more flexible decisions. In select scenarios, the method might eliminate tedious studies on measuring and monetizing benefits of a policy, especially with regards to finer design matters of an instrument, relying instead on secondary data and theory regarding the generation of the benefits and their relations to contextual parameters. The 'flexibility' of decisions refers to the additional negotiation space opened up by an extra variety in regulatory units. The multiple units make room for more concerns of stakeholders to be accommodated. Depending on the final selection, some of them will be incorporated better than others, but the initial choice is wider.

\subsubsection{Transposition}

In many federal systems, a national policy often translates into a national legislative framework within the bounds of which states governments are then directed to design laws or instruments for their jurisdictions, making design adjustments for contextual variables. In large federal democracies such as India or the United States, the constituent states are typically very diverse in terms of economy, demographics and climate and, in the case of India, even language and culture! The resulting variety of transposed instruments is bound to range in a broad spectrum with regards to several key parameters, costs being the most prominent among them. 
Closer home, the model has been replicated in Europe ever since certain policy portfolios fell under the organized European Community and policies began to be adopted at the supra-national level. It is quite plain that even more so in the environmental sector, environmental policy that originates in one member states may diffuse across the continent via Brussels. To quote Halpern (2010) from the abstract:

EU environmental policy is primarily structured by its instruments. ... [It] is populated not by new or innovative policy instruments, but by instruments mainly derived from the member states or other international organisations.

Even for a single instrument, variations in costs under certain categories such as enforcement, compliance, monitoring and so forth, can significantly alter its attractiveness as a policy measure. That is tantamount to suggesting some kind of a sensitivity analysis hinged on certain key costs when comparing instruments, and why not? This should, in fact, be a recurring consideration in the transposition of EU directives in member states. For example, the versions of the Waste Electrical and Electronic Equipment or WEEE directive interpreted by EU countries drawing upon (then) article 175 of the then EC Treaty are expected to lead to a vast cost spread for compliance by producers (Magalini \& Huisman, 2006) as well as calculable differences in operational efficiencies (Stevels, 2003). In future assessments, environmental analysts may do well to pay special attention to this issue for European directives adopted under (then) article 175. The very design of the method would help an analyst narrow down on and control critical design factors in the design of policy instruments, specifically for each generic type of instrument.

\subsubsection{Expansion}

A slightly different issue related to transposition in the EU, but nonetheless one that strongly supports the emphasis on hard tangible costs of introducing new policy, arises in areas that progressively fall under the ever-expanding union. For Lithuania, in 2003, the year before its accession, it was estimated that the cost of matching 15 European directives in the environment sector alone would cost the small economy $3.5 \%$ of it GDP, the average for OECD countries then being near $2 \%$ (Bluffstone, Semeniene, \& Jantzen, 2003). The authors stress that the right choices when transposing the directives would benefit immensely from a "careful comparison of costs". 
Here is a government, obliged to introduce new instruments, the skeletal frameworks for which were designed long ago. If the total costs under any one sector in a new acceding member are higher in relative terms as proportion of GDP or budget, it stands to both political and economic reasoning that the policy makers would feel responsible to bring it down regardless of the relationship to benefits, at least in the short term. When that sentiment is appreciated and expressed at the highest levels of government, it will likely trickle down to all levels of decision making.

When faced with (and allowed to make) the more intricate choices in the design of instruments, when it comes down to stipulations for reporting requirements or penalties on non-compliance etc., they need a method that helps them minimize the abrupt, accumulative burden on their economy. Hence, apart from the efficiency gains for individual member states, the methods will speed up policy diffusion in the EU.

\subsubsection{Governance Analysis}

The combined improvements to the CBA design provide scope for integrating governance analysis into routine policy analysis: regulation costs such as handling forms, monitoring, wages etc. will reflect on governance structures and help gauge their effect on the potency of policy instruments. Given the enhanced comparative equivalence, analysts can use the method to benchmark cost categories against other countries. In the case of the Swedish charge on NOx, for instance, (SEPA, 2006), the instrument restricted the size of the emission units under purview of the charge specifically to curtail monitoring costs. An analyst in another country could check, ceteris paribus, how monitoring costs in their jurisdiction compared to Sweden. A method geared for the purpose can prove vital in estimating the "distortionary effect" of enforcement costs (Pearce, 2000), for instance. Whereas the connotations of the term 'governance' remain somewhat fluid (Levi-Faur, 2012, p. 3 ), if the term is extended to 'governance analysis', this would be among the kinds of questions it would cover.

\subsubsection{Proportion and Precaution}

The constructed equivalence (as explained in section 4.1.2) could serve as a first step to resolving the discussion around "disproportionate costs" (Turner 2007). The concept of proportional costs is tied to the issues and arguments around the 'Precautionary Principle' dealt with earlier in section 2.6.3. When one wishes to be 
cautious, [Cost $<=$ Benefit] may no longer be the chosen 'rational-choice' decision rule. By what factor costs are allowed to exceed measureable benefits is an expression of the degree of precaution. That factor assumed in the decision rule has to counter the claims of disproportionality. A proper frame of reference will go a long way in helping tackle these questions and arm the analyst with justification to cite for the choices.

\subsubsection{Concurrent Costs of Other Policies}

Similarly, the method will also aid analysis of the effect of interaction between divergent policy sectors. For example, consider this illuminating case from a recent paper (ACCF, 2007): an economic instrument that promotes energy-efficiency in manufacturing. All investments are subject to varying depreciation rules. One government may supplement the instrument with preferential rules for investments in energy-efficiency, but in another country, the stand-alone instrument is likely to fail if the rigid depreciation rules there are seen as a competitive disadvantage. That kind of information is normally lost to analyst simply aggregating costs and comparing them to aggregated benefits. Unless the taxonomy of the costs included is significantly broadened and properly referenced to the context, an analyst cannot design instruments that are fairer and easier to comply with and for those reasons, easier to sell to local industry.

\subsubsection{Co-advantages}

There can be other advantages from this method apart from the direct, intended ones. Juxtaposing costs thus throws lights on other rational choices and bring some unapparent advantages.

For instance, in some future replication of the Swedish NOx charge (SEPA, 2006), the policy maker would look at such data to make an informed judgment about which side to burden with the bulk of the costs of monitoring - if a formula is used for calculating emissions, periodical audits would be called for. Instead, if the actual emissions are to be measured, the industry has to install measuring instruments. The Swedish EPA probably opted for the latter, given the unique design of the policy where the revenue is collected in proportion to the disamenity, but is redistributed to the polluters in proportion to the amenity. This would make room for a perverse incentive if calculation was left to firm data. As it was, the firm stood to gain directly by being cleaner. It was thus quite justified to shift the cost burden of measurement towards them. 
In other cases, the government itself may have a significant influence on private costs associated directly or indirectly with compliance. Such costs may be limiting the uptake of environmental initiative in the industry, as the American Council for Capital Formation (ACCF) in the US found was the case with adverse tax rates and depreciation rules for energy investments (ACCF, 2007). It might be argued that capital costs or the avoidance thereof may have also had or will have a bearing on trade with other countries where the tax rules are more favourable. These are certainly aspects of governance no prosperous economy would like to ignore.

\subsection{Proviso}

At the conclusion of this chapter, after promising a number of values of relevance to public policy, it seems pertinent to candidly admit the limited scope of this research enterprise, earlier set in sections 2.4 and 3.2.

The idea of "regulatory units" inspired from LCA-type functional units is not being proposed for every policy problem and every corresponding choice from an array of policy instruments. The thesis stems from the humble premise that in some contexts, for a narrow set of policy choices, an inspired adaptation to CEA might help policy analysts incorporate additional contextual information into the design of the instrument in consultation with relevant stakeholders and fine-tune it (e.g. sub-rules of a regulation). Such adaptive policy-making has its rightful place and advocates (Viteritti, 1982; Walker, Rahman, \& Cave, 2001). In several conceivable cases of broader policy choice though, particularly in case of large environmental problems with multiple co-benefits or multiple sources for the same pollutant ("joint production"), for a large jurisdiction, or when policy is being formulated for the apex policy level (parliament or congress) for the first time, the proposed method would be grossly inadequate and inappropriate.

The modified method has only a very limited application both horizontally - in the coverage of diverse policy questions - and vertically - at the lower levels of decision-making, but not the highest. At the highest level of analysis, all the impacts, all costs and all benefits must generally be considered within the bounds of rationality and resources constraints. For our purpose, the level of interest is where the broader objectives of the policy may have been set and the difficult broader (more theoretical) instrument choices may have been made high up and several years ago - either by policy makers or a more thorough analytical report or both. At the policy analyst's level though, in cases where they have the discretion, and when small sub-rules come up for revision, the analyst may tweak the finer points of the rule based on whatever is on the agenda at the time. After all, such 
ad-hoc policy-making is not unheard of in Europe. In fact, EU Environmental Policy-making itself at large has been described as an ad-hoc "issue network" structure (Bomberg, 1994, p. 47).

The quantitative cases in the next chapter attempt to exemplify this narrow scope of application with a range of cases. 


\section{Chapter 5 Quantitative Cases}

In a typical CEA situation, the analyst is faced with two sets of cost figures, one for each instrument under consideration, for a given level of benefit. In a finer analysis, he may have cost functions that vary with levels of benefit or a standard.

In a case such as that shown in Figure 5-1, the decision is clear. For the entire range of a feasible standard, one instrument is costlier than the other. In fact, the one on the right is costlier at the low end of the standard that the one of the left is at the higher end. Policy choices are rarely that clear.

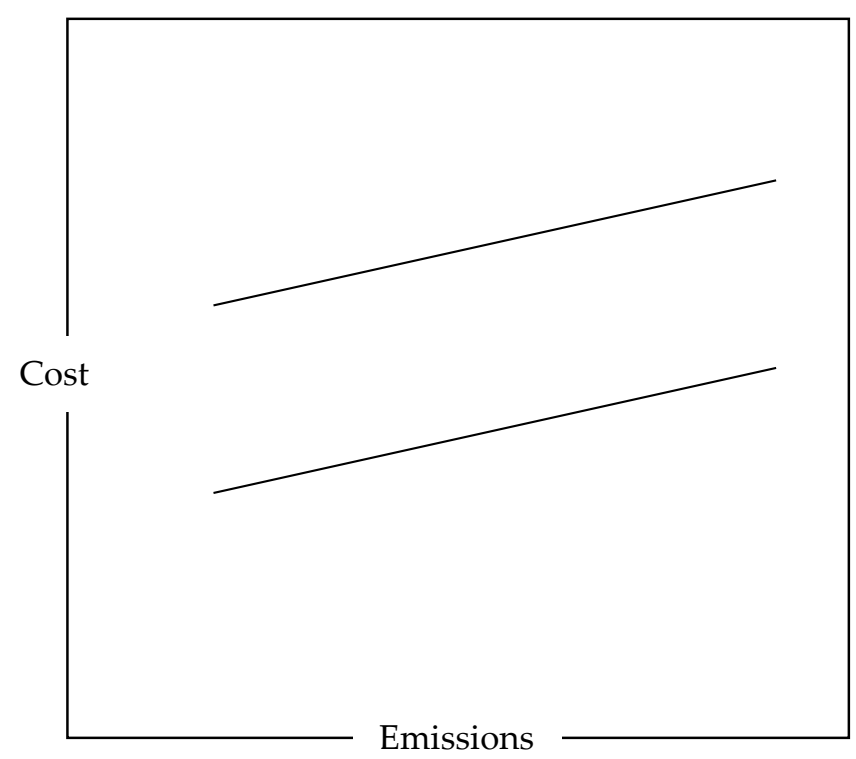

Figure 5-1 Cost Profile for a Range of Emission Reduction

In a slightly more challenging and more likely case, as in Figure 5-2, the choice depends on the level of the standard. A low level of abatement indicates one instrument whereas a higher level indicates another. The challenge to the design of the instrument becomes more apparent: the case calls for additional thought because the policy maker cannot hope to go with one instrument and aim at incremental changes in the aspired environmental quality. As the regulation becomes more stringent, i.e. less and less emission is allowed, the cost picture changes and the efficient policy option involves a switch to another instrument. To make matters really interesting and worthy of note, the switch itself generally implies non-trivial costs that the graph obviously does not capture. 


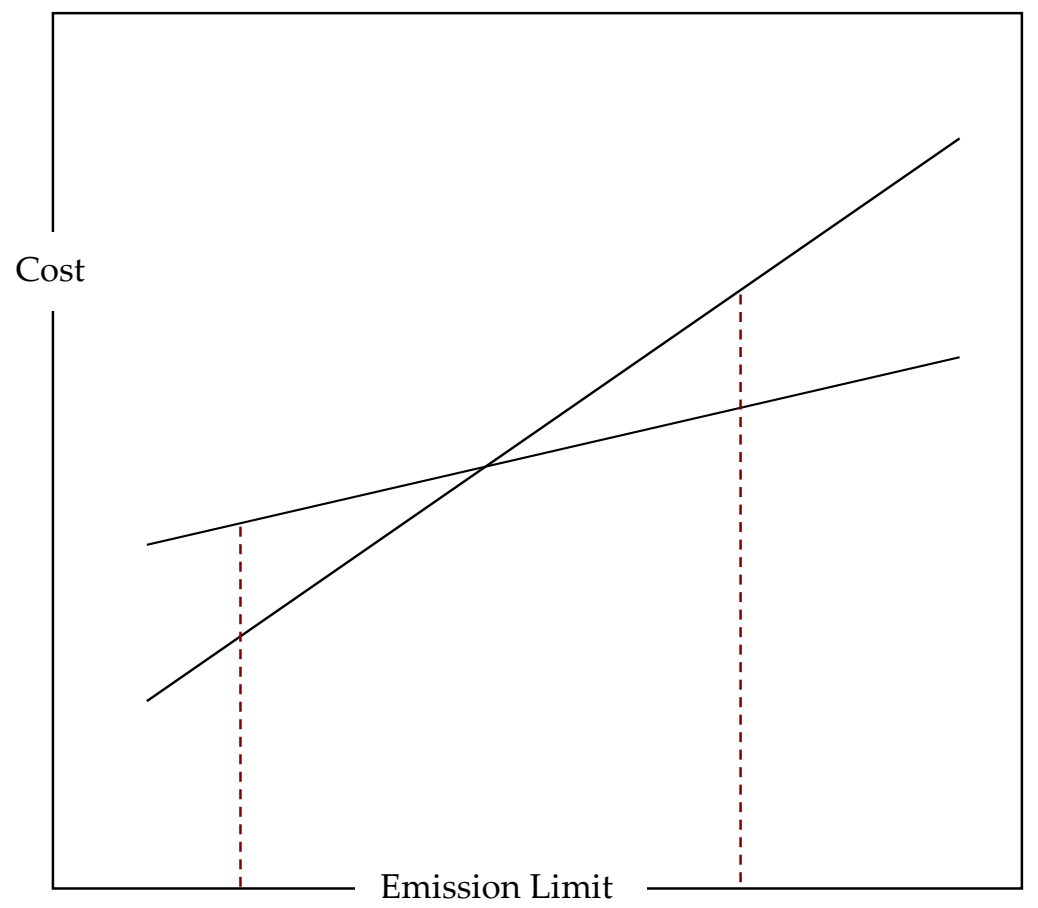

Figure 5-2 Cost Profile for a Range of Emission Reduction - Case 2

This far in the story, we have analytical tools at our disposal to inform a decision. However, the complexity above is not the whole picture and does not give the entire range of the present and future cost considerations involved in the decision at hand.

Models such as EUCAR (Denis \& Koopman, 1998), give a good picture (Figure 5-3) of what cost profiles for typical policy instruments in the transport sector look like. 


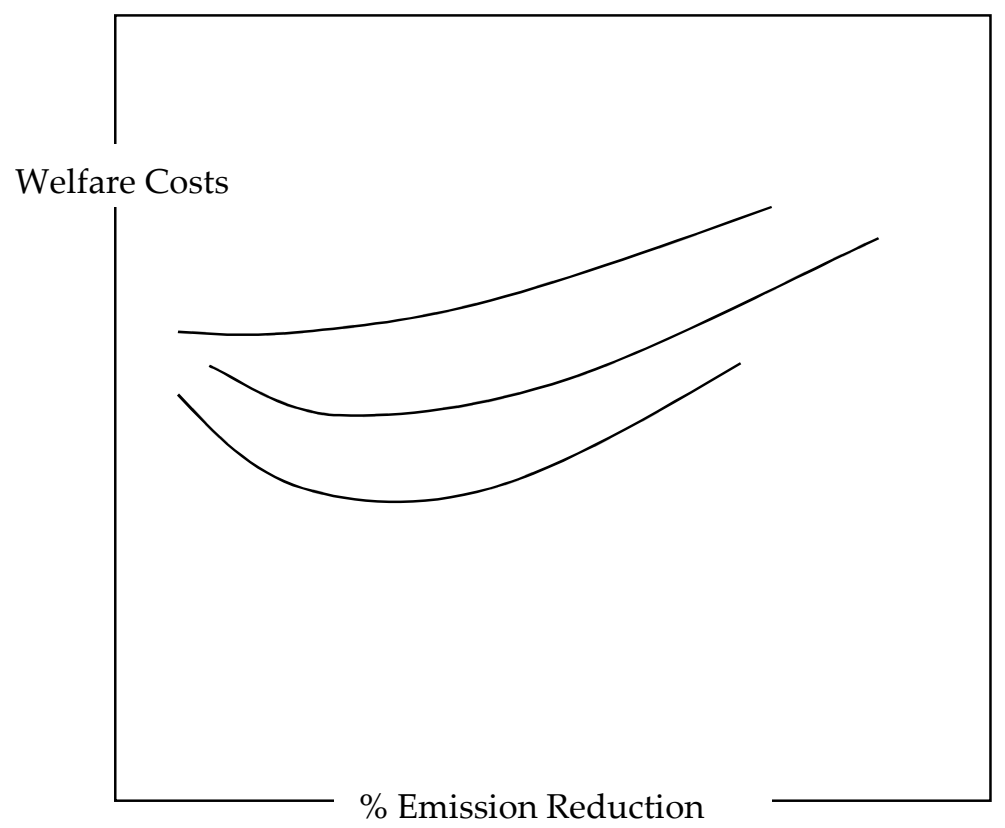

Figure 5-3 Sample Visualization of Aggregated Costs of Emission Reduction

Note the vertical axis - the cost function that the model estimates is total costs, not referenced to any of the units involved. With a view back to the preceding chapters, that does not help frame equivalence for the purposes of benchmarking (comparison across jurisdictions), instrument design, proportionality and interaction between costs of concurrent policies.

This research seeks to introduce a further layer of challenge into the choice, so as to make the eventual choice even better informed and more robust. That layer has to do with the units at the base of the very comparison.

We start with a hypothetical but plausible constructed quantitative case.

\subsection{A Sector for Illustration: Transport}

Consider a typical instrument for reduction of emissions from transport. The likely target units of the policy from the environmental view are likely to be quantitative measures of substance e.g. grams of NOx emissions or their flowrates e.g. grams 
emitted per unit time or slightly more contextualised and complicated units such as grams per second per unit power delivered.

If we look at the broader sector itself from a policy view, other units are likely to dominate discussion, in this sector viz. person-kilometres.

Table 5-1 Illustration with V arious Units in the Transport Sector

\begin{tabular}{|l|l|l|l|}
\hline Persons & Kilometres & NOx grams & $\begin{array}{l}\text { Cost of another } \\
\text { policy }\end{array}$ \\
\hline & & & $\begin{array}{l}\text { (may be a } \\
\text { function of any of } \\
\text { the three) }\end{array}$ \\
\hline & & & \\
\hline
\end{tabular}

That gives a number of potential units: $\mathrm{kg}$, $\mathrm{kg} /$ person, $\mathrm{kg} / \mathrm{km}$ and $\mathrm{kg} /$ personkilometre - each with expectedly a completely different cost response.

Only the first and the last involve common units - quantitative metric units of substances are common in environmental policy and person-kilometre is the standard unit in discussions of transport policy. The other two are just mentioned for examples of potential units but are not entirely devoid of meaning. $\mathrm{Kg} /$ person is quite relevant when the policy discussion concerns emissions per capita, which is hardly uncommon in the global climate change negotiations. On the other hand, bringing in the geographical distance dimension might invalidate comparisons between constituencies. Similarly, when the sole policy matter on the table is something like automobile design, $\mathrm{kg} / \mathrm{km}$ might be relevant, as the number of occupants may not have a significant bearing on emissions.

If we were to look at interactive costs of concurrent policies, we run into a higher level of effects. That cost stream could be a function of any of the potential units or of their parts in case of composite units such as kg/person-km.

It is conceivable that the more comprehensive the unit, the more complex the cost function is likely to be. What we now see in addition is that the choice of units is also associated with the discourse and objectives at hand. A well thought-out unit can bring to light a wider set of policy-relevant considerations. 


\subsection{Policy Choice Examples: Quantitative Models}

Having visited the idea in concept, let us explore it with the help of data and tools from the real world. What better way to test a method meant for policy analysts than to use the data processing tools used by policy makers themselves? Five examples follow, each of which represents an actual fine-tuning level of choice among various alternatives that a policy analyst could plausibly use for policy design. The data in each case is the actual data the public agency in question uses for the said policy design choices.

\subsubsection{IAPCS}

For the first example, we use a computerised accounting model routinely used for choice analysis purposes at the EPA. The Integrated Air Pollution Control System (IAPCS) is a model developed at the EPA (Kaplan, Soderberg, Pickett, \& Meyers, 1994). It can be used to predict costs of 16 pollution control technologies applicable to coal-fired power plants ranging in capacity from 300 to 1600 MWe. For any of these technologies or combinations thereof, the model can calculate material balance, emission summary, capital cost estimate, and annualized cost estimate (including capital charges and operation and maintenance expense) for implementing them on the factory floor. In several ways, the model is ideal for generating cost profiles and to runs tests against number of parameters that are included. We could see the cost profiles for a combination of technologies against a number of different unorthodox units for our purposes.

The acronyms on the graph stand for the permutations of various technologies. For instance, PFBC stands for 'Pressurized Fluidized Bed Combustion'. The full forms of all the abbreviated technology options with brief explanations are available in the aforementioned journal article (Kaplan et al., 1994).

As a Chemical Engineer, the author appreciates the acronyms and understands what the underlying technologies involve physically at the plant. An important aside here is to reiterate in context that such multi-disciplinary insight is among the motivations behind this dissertation. Exhaustive technical descriptions would be extraneous to this section though, as the focus here is on the relevance to analytical methodology rather than the specific pollutants and technologies involved, the industrial process in question or even the particular industrial sector.

The technology options chosen would stand in for policy instruments, or, more precisely, the regulatory nitty-gritty in the rules entailed, the policy-design 
nuances referred to in earlier sections. At any rate, technology mandates are a potential policy instrument in themselves. In addition, given that the model accommodates a number of economic factors such as tax rates on capital investment, we could run tests to compare cost profiles for plausible designs of policy mixes, which is the core objective and nature of the policy-analytical innovation presented in the previous chapter and exemplified by quantitative cases in this one.

Let us first consider simply a range of alternative technologies. The model directly gives us the cost of reducing emissions per unit weight (Particulates, $\mathrm{SO}_{2}$ and $\mathrm{NOx}$. We focus on NOx.) We are interested in studying the effects of additional units so let us arbitrarily choose one of the important ones - labour cost. That is a category of cost that often shows significant variation across countries and can be assumed to have a direct effect on compliance cost.

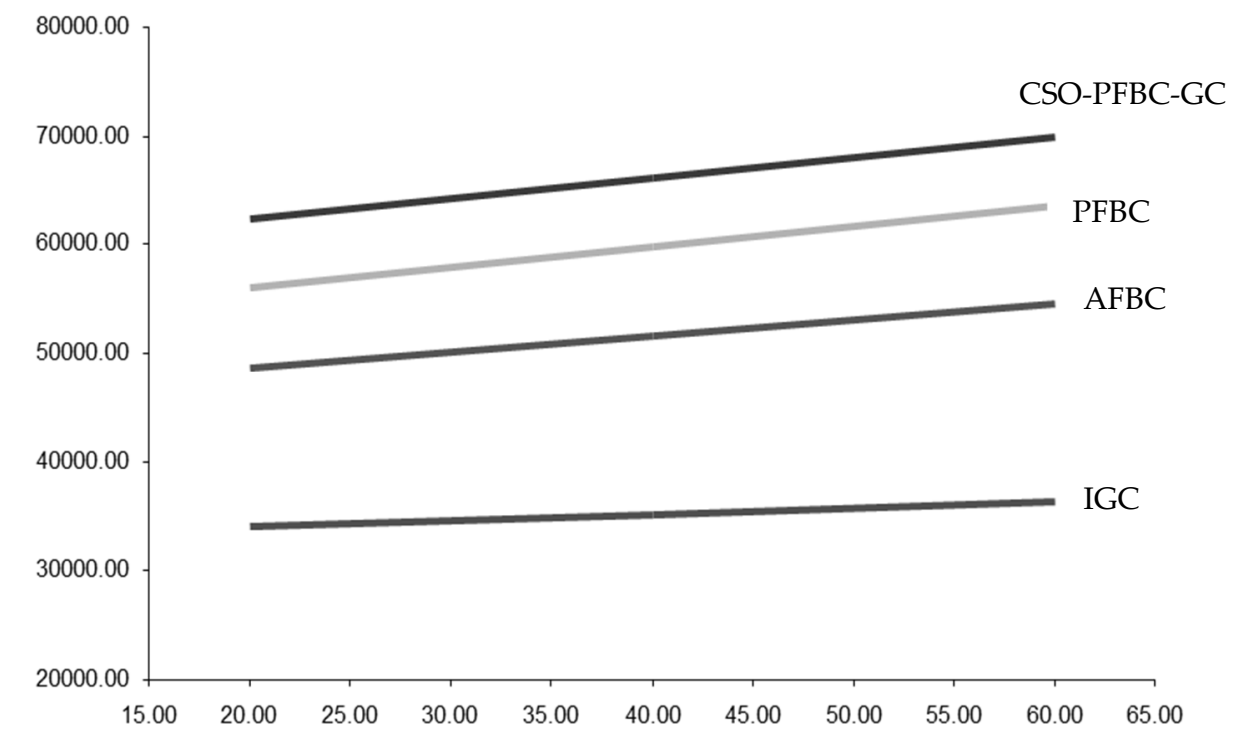

Figure 5-4 Cost Profile for NOx Reduction Technologies against Operating Labour Cost (\$1 \$ per bour)

The table 5-4 above shows the cost profiles for a unit NOx reduction for a set of technologies, generated by the author using the model. As is immediately obvious, the situation appears to resemble that of Figure 5-1. Across the entire range of operating labour cost, there is no question as to the choice of the technology. At each level of labour cost, the relative cost-effectiveness ranking between the instruments hardly changes. 
Now, as we have argued before, to go for a more complex instrument. In this case, we ask the model to create a policy mix with a technology mandate coupled with an investment tax credit (ITC), applicable to investments in environmental abatement.

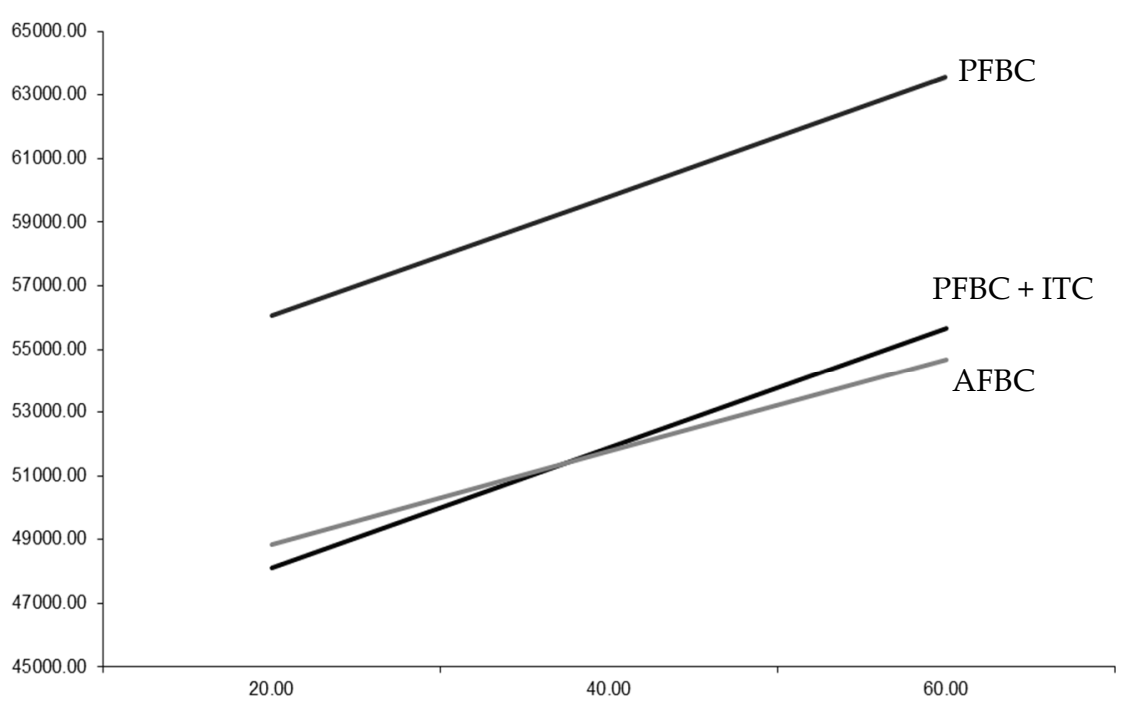

Figure 5-5 Cost Profiles for Technology and Policy Mixes for NOx Reduction against Operating Labour Cost $(\$ / \$$ per hour)

What we see now is revealing and instructive: One of the technologies is far more expensive than the other. However, for one of any number of possible reasons, a jurisdiction may prefer it over the cheaper technology. It hence brings in an investment tax credit (ITC) fixed at $x$ percent. That percentage can be adjusted and it is one of the parameters in the model. There is a value of $x(23 \%)$ at which we enter the situation of Figure 5-2. For a range of labour cost, another parameter that is likely to vary significantly across EU member states, the coupled policy mix is the more cost efficient choice, whereas after a threshold, the choice reverses. The threshold appears close to an operating labour compensation of about $\$ 40$ an hour. In this scenario, labour cost clearly becomes a determining factor. 
The key point to note is that the nuances of the impacts of choice on a relevant contextual variable are only revealed on introducing a modified 'regulatory unit'. What seems like a simple choice of the Figure 5-1 variety reveals itself to have a Figure 5-2 aspect only when the resolution of choice is sharpened to include a different aspect. That demonstrates that in this demonstrative case built on realworld data, the analyst would do well to at least test a different regulatory unit for CEA comparison and this modified analytical approach provides a way of doing so.

\subsubsection{OMEGA}

The second example attempts to recreate the application of multiple units to a question of policy choice in the transport sector with the help of a model regularly applied at the USEPA (2009) for rule-making - the OMEGA model (Optimization Model for reducing Emissions of Greenhouse gases from Automobiles).

Furthermore, this particular quantitative case tries out newer units such as engine size and technology type which have been suggested and studied earlier (Fullerton \& West, 2002).

The model helps predict the cost to car manufacturers of abatement technologies for cutting down greenhouse gas emissions for their entire fleet on the market, particularly for light-duty motor vehicles. In the taxonomy described earlier, these costs would be classified as compliance costs. In general terms, the model virtually applies a selection of abatement technologies to a chosen description of a vehicle fleet until a specified emissions reduction target is met. When that target is met, the model reports the attendant costs and benefits. Crucially, OMEGA is an accounting model rather than an engineering model which would use mechanical and chemical dynamics to predict fuel consumption. It is also not an economic simulation model that responds to market parameters such as sales for the purpose of achieving said targets. That is to say, sales values can be set exogenously, but do not respond to the technology changes or resulting price variation. (A future version of the model might include such options.) Among the most important input variables is a vehicle's baseline emission level, the initial level of abatement technology, and the vehicle's "type," which indicates the set of feasible options for technological improvements. The effectiveness of technologies can be specified, and the technological "packages" can be applied iteratively to a varying proportion of sales for a fleet, both of which can vary over time. Further details of the various scenarios are explained in Appendix I.

More interestingly for our purpose of demonstrating a variation in analytical method, along with the input data, the model files provide information on a range 
of parameters not included in the calculations. Some of this information can help formulate compound units for cost-effectiveness comparisons, and hence the model offers a way to test the proposed method.

The author used the model to generate a wide range of response variables. The table below gives the total cost of compliance to two selected manufacturers, viz. BMW and Chrysler, for a number of selected scenarios (let us call them A1, A2 and A3). For our immediate purposes, the model scenarios might be considered alternative designs of the same instruments that vary in fine detail, which in this case is the target rate of annual reduction in emissions of automobiles in subsequent design cycles.

\section{Table 5-2 Results from OMEGA Model Runs}

\begin{tabular}{|r|l|r|r|r|r|r|r|r|}
\hline & & \multicolumn{1}{|c|}{ Cost } & HP & CO2 & CO2 Cut & Cost/CO2 & Cost/HP-CO2 \\
\hline A1 & BMW & Chrysler & $779,736,991$ & 288 & 246.54 & 53.46 & 14585428.19 & 50643.85 \\
\hline & & $1,212,852,961$ & & & & 21676390.37 & 81474.12 \\
\hline & & & & & & & \\
\hline
\end{tabular}

The table 5-2 gives total cost, a proxy measure for the average engine size for the fleet of each manufacture (HP or Horsepower), the target emission achieved, the estimated reduction in emissions ${ }^{16}$, cost relative to the reduction, and lastly, costs relative to the combination of unit reduction and unit engine size. If we compare the totals for A1 and A3, there is barely any difference in the total cost, a slightly more appreciable difference in the referenced cost and an even greater relative margin in the costs referenced to a combined unit. (If the model parameters are tweaked to get identical figures in the first column, the last column still gives significant differences.)

Horse-power is a characteristic that denotes the size of the engine or by, proxy, the target market segment. The modified regulatory unit in the last column anticipates a situation where car manufacturers grumble about a potential new regulation to

\footnotetext{
${ }^{16}$ As the model documentation gives no indication as to the level of reduction, we assume a level of 300 units as the baseline emissions which was to be reduced in each case.
} 
be brought in. In this case, a new unit that takes into account the varying engine sizes available on the market gives the analyst the chance to design a policy that differentiates across various market segment. The policy maker could consult the business association and agree to differentiated thresholds or market segments for which a particular piece of the policy shall not apply. The new modified regulatory unit allows the analyst to make such a case.

The simple and obvious point here is that the more complex the unit, the easier it is to differentiate cases on the basis of reference costs. This is for a routine estimate of compliance costs by the standard methods used at EPA, where the data required to try out a combination of different units is readily available.

\subsubsection{COST Tool}

Control Strategy Tool (CoST) is yet another of EPA's models and its chief function is to estimate the emission reductions and costs associated with control strategies applied to sources of air pollution. The Control Strategy Tool was developed as a replacement for the AirControlNET (ACN) software tool which was earlier used for a similar purpose. To quote from the accompanying documentation: "It was determined in 2006 that it was an appropriate time to replace the ACN software with newer software that could provide improved effectiveness, functionality, and transparency to support current and upcoming needs. A prototype version of the Control Strategy Tool was developed in 2006 and a fully functional version was developed in 2008." Sample results of the model were released publicly on the EPA website late in the year 2010 (US EPA, 2010).

The model uses simple cost factors to calculate the cost of the control measure when applied to a specific source, and attempts to also account for engineering costs such as operation and maintenance.

The following table presents data from the sample results, more specifically two of the columns of particular interest viz., Cost per ton of pollutant (NOx) reduced and the ratio of capital costs to annual costs, for each of the control measures listed in the first column (denoted by abbreviations).

Note: The actual data contains the calculations for nearly 6000 control measures applied to various types of sources. The entirety of the data was treated to extract the cases that display a particular property. The table 5-3 below presents a selection from that subset of interest. 
Table 5-3 Selected Results from the COST Tool

\begin{tabular}{|l|l|l|l|l|l|l|l|l|l|}
\hline Control Measure $^{17}$ & $\begin{array}{l}\text { Cost per } \\
\text { ton } \\
\text { reduced } \\
\text { (A) }\end{array}$ & $\begin{array}{l}\text { Capital } \\
\text { cost to } \\
\text { annual } \\
\text { Cost Ratio } \\
\text { (B) }\end{array}$ & A/B & & & & & &
\end{tabular}

We calculate a simple ratio from the data in the fourth column.

If we as a public agency were to be making a decision on the basis of a typical CEA paradigm, all the information we need is in the first two columns. With that, we may proceed to formulate some design of a policy that attempts to minimise the total costs of bringing down a target tonnage of NOx emissions in a given period. Granted the models are capable of much more complicated analysis in aggregation, taking into account distributions by various parameters and so forth. But if we just wish to make a simple modification to our CEA goals, the idea of a different reference unit comes in handy. Consider column B. The control measures

\footnotetext{
${ }^{17}$ The first column in Table 5-3 gives an abbreviation that denotes a technological measure used to reduce a pollutant, NOx in this case. For instance, N-LNBFSPSP stands for 'Low NOx Burner and Flue Gas Recirculation; Steel Production; Soaking Pits'. Each of the entries is likewise a measure highly specific to the source, process, technology etc. Exhaustive supplementary documentation is publicly available online from the US EPA (2010).
} 
under consideration appear to vary significantly with regards to their capital cost burden. That is not a trivial observation for a policy maker. Especially in these troubled economic times, giving a special attention to the initial capital burden of a control measure might be a very legitimate and, indeed, imperative consideration. In which case, we could very easily slightly modify the CEA reference unit to internalise that information. The fourth column attempts that, again in the simplest way by taking a ration of $A$ to $B$. There could obviously be more sophisticated ways of accounting for the differential cost burden using the values in column B. This is just to illustrate the worth of a minor analytical innovation.

When we look in reference to that new and modified unit in column 4 , several of the choices we would have made based simple on column 2 are reversed. That is again, just to show that the choice of an instrument can switch depending on the choice of reference units. The pairs that demonstrated this are marked by shaded boxes to the right. (In the thin vertical columns to the right, two boxes shaded in the same column mark such a pair). Demonstrating this result is a fairly simple matter, even with a very large set of cases. The above list was generated by picking cases using the simple 'Conditional Formatting' function in MS Excel. That is to say, the demands on the Policy Analyst's skillset from this new form of analysis are often minimal, though that would partly depend on the platform used for the original modelling and the file formats that the results can be obtained in.

\subsubsection{DEFRA Agricultural Model}

Now to move to an entirely different sector of the economy, to a different environmental medium for pollutants, and to Europe proper. A project at the UK's environmental agency DEFRA (short for Department for Environment, Food and Rural Affairs), presents a framework to model the cost-effectiveness of various measures to bring down the pollutant load from agricultural activity.

The DEFRA's Nutrient Management Programme targets emissions of agricultural pollutants to air and water manage. It aim to regulate the balance of chemicals in the ecosystem by maximising the efficiency of the nutrient cycle on farms. As a key part this effort, the programme pursues a quantitative understanding of the impacts that potential mitigation measures may have on multiple pollutants.

Under one DEFRA project (WQ0106), ADAS, a British environmental consultancy, developed a model framework to assess the impact of farm pollution mitigation measures on nutrient and sediment loss. The targets for the reduction of diffuse pollutant losses to air and water varied by pollutant. Achieving these targets 
would require catchment specific and wide ranging reductions in pollutant loads from the agricultural sector. There was a need to develop and apply a modelling framework for calculating the national cost and effect of mitigation methods for controlling multiple diffuse pollutants from agriculture.

Details of the project, the targets, the mitigation measures, the farm types and the country-wide results appear in the Project Report (Gooday \& Anthony, 2010) and ancillary documents (Cuttle et al., 2006; Newell-Price et al., 2011), all publicly available online. To quote an explanation of the mitigation measures from the Executive Summary:

\begin{abstract}
The mitigation methods investigated generally represented potential for improved practice within existing farm systems rather than adoption of novel systems or technology. A total of 77 methods were investigated, each characterised for their impact on nitrate, phosphorus, sediment, nitrous oxide, methane and ammonia emissions. The effects of the mitigation methods were estimated from literature and represented as a percentage reduction against a specific source type, area and delivery pathway on representative model farms. Baseline pollutant losses from the farms were calculated at field scale using a range of existing policy models and scaled nationally using agricultural census data, to provide outputs for Water Framework Directive river basins and farm types.
\end{abstract}

The extensive model computation workbooks also available at the project website (DEFRA, 2010) were studied at length to construct this case. The table 5-4 below shows the comparison of CEA choices. The third column shows the comparison of the "dollar-per-ton" type costs of reducing the Nitrogen pollutant load on two representative types of farms. However, if, in a certain political context, the number of cattle on a farm becomes a sensitive matter, then the policy maker might be interested in a different view of the functional unit.

Of course cattle are not the only source of the pollutant. Note that this is being proposed for the stage of analysis where a public agency is negotiating this particular regulation with a group of local stakeholders. If we suppose that over and over, it becomes clear that the size of the herd is an important distinction to the farmers in terms of how they perceive equity. Or, for the government, on this occasion, in this policy cycle, cow heads are an important concern, perhaps for reasons related to another policy area. Or, for technical or other constraints, the other contributing sources of the same pollutant are not up for attention at this particular time. The adapted method allows the policy analyst to design a sub-rule of the policy in a way that is easily justified and readily explained to the stakeholders immediately concerned. 
So for that sort of context, if we use the unit 'pound per kilo ton per head of cattle', the picture reverses. The farm type that appeared to be cheaper (cost half as much) in terms of pollutant reduction by the first simple unit, now costs twice as much.

Table 5-4 CEA Choices between Selected Farm Types

\begin{tabular}{|l|l|l|l|l|l|}
\hline Farm Type & $\mathrm{N}(\mathrm{kt})$ & Cost $(£)$ & Cost/N & $\begin{array}{l}\text { Cow } \\
\text { Heads }\end{array}$ & $\begin{array}{l}\text { Cost/N- } \\
\text { cows }\end{array}$ \\
\hline Dairy & 14.79 & 809.55 & 54.73 & 827 & 0.067 \\
\hline Mixed & 11.96 & 257.13 & 21.50 & 173 & 0.125 \\
\hline
\end{tabular}

As stated above, these numbers come from far corners of the numerous worksheets that contain the model results. That only goes to show that when we invest in modelling capabilities, the information generated is potentially worth more than the original intent. When juxtaposed in a right framework, it can lead to insights that may be interesting in certain scenarios.

Once again, we see that the relative choice of a policy option relies entirely on the definition and choice of the functional unit. The functional unit can always be defined to suit the political context at hand. There is a case to be made that, when it is necessary for selling of the policy, it should be.

\subsubsection{EIO-LCA: German Economy}

The Economic Input-Output Life Cycle Assessment (EIO-LCA) is a method to tabulate and analyse the materials and resources consumed in an economy and the associated environmental emissions and impacts. Wassily Leontief (1970) developed the method in the 1970s furthering his earlier Nobel-worthy inputoutput work from the 1930s.

This last demonstration case uses EIO-LCA data compiled online ${ }^{18}$ by the Green Design Institute at the Carnegie Mellon University (2013). Selected data for the German economy in 1995 is given in Table 5-5 below.

\footnotetext{
18 At http://www.eiolca.net/
} 
Table 5-5 Pollutants in Metric tons for 1 million Deutsche Marks of Output in 1995

\begin{tabular}{|l|l|l|l|l|l|l|}
\hline Industry & $\mathrm{SO}_{2}$ & $\mathrm{CO}$ & $\mathrm{NOx}$ & VOC & Lead & PM \\
\hline Textile & 5.78 & 8.5 & 1.15 & 0.685 & 0.017 & 1.33 \\
\hline Plastic & 0.812 & 1.03 & 1.14 & 0.323 & 0 & 1.98 \\
\hline Paper & 0.459 & 1.11 & 1.3 & 0.834 & 0 & 1.18 \\
\hline
\end{tabular}

What is remarkable in the data is that all the pollutants loads are given for exactly the same size of economic output, i.e. one million Marks worth of products, so in those terms they can be said to be comparable.

The total cost of NOx reductions across Germany for each industry would of course be proportional to the relative size of the industry in the economy and if we use the price of the products then we could calculate those costs. But suppose the policy makers wish to propose a new measure and requires the backing of the industry leaders to pass that measure. They could persuade the industry by framing the new measure as equitable in terms of each industry's relative contribution in the national economy. A candidate regulatory unit would be 'NOx emitted per million Marks output'.

If the typical cost of reducing NOx emissions in German manufacturing was $\mathrm{X}$ per ton, then the burden of the NOx regulation would be about the same for the textile and plastics industries $\left(\sim 1.15^{*} \mathrm{X}\right)$, but significantly different for the paper industry $(1.3 * X)$.

As the values in the table suggest, a policy to curb $\mathrm{SO} 2$ on similar terms would mean an even wider spread of relative burden on each industry.

\subsection{To Conclude}

The quantitative cases should go some way in demonstrating the value of the new approach. Secondly, they should also demonstrate that this way of framing the policy option has a place in constrained contexts but across many different sectors and even levels. By constrains we mean, when the focus is a narrow environmental target, where the complications from co-benefits or joint production (of pollutants) or distribution and the like do not have a significant bearing on the choice at hand. With that proviso, whether the analyst is looking into the nitty-gritty, at the point of refining a the technical detail in a rule which is part of a vast regulation or drafting a brief policy memo for a preliminary discussion of policy makers at the 
highest macro level, thinking in terms of a 'regulatory unit' makes for clearer framing. It puts more options at the table but in a simple manner and helps streamline policy-making.

This analytical approach thus offers a new simple way of formulating, packaging and reasoning policy in the market for regulation. 


\section{Chapter 6 Dialogue with Policy Analysts}

The chosen methodology is borrowed from the paradigms of engineering and product design. As described earlier, in that paradigm, after the design problem is described, solutions are presented and tested on their technical merits. The technical tests check if the specifications required are met. However, product design does not end there. Meeting technical specifications is one kind of check. The second equally important check is through consumer surveys. The former is usually a quantitative enquiry and the latter a qualitative one. The former ensures that the product is technically feasible and efficient in manufacture; the latter ensures that the product is satisfactory and efficient during use-that it will likely sell well.

This work takes a very pragmatic look at some of the problems of choices in environmental policy. Hitherto, we have looked only at ways of improvement in the analysis from practical viewpoints. To retain the product design analogy, after checking the technical solutions, we were to turn to the end-users of the analytical methods, the analysts.

At least, that was the idea when this work began. The interviewees were all sent a brief explanatory note giving the background of the research, the design of the proposed analytical approach with a simple illustrative example and an overview of what the interview would cover. As explained in the methodological choice in section 3.4, the first couple of interviews indicated that it might be difficult to attain a good assessment of the analytical adaptation because of a general disconnect between their day-to-day contact with economic analysis and the elements central to this study, e.g. LCA or CBA, the former in particular. The extent of use of CBA in real offices was itself one of the key pieces of information, so the drawback still informed that part, elaborated in section 6.3 below. However, the question schedule was adapted mid-project and mid-interview to cover the reasons for the disconnect between the prior expectation of familiarity with the common form of analysis in the textbook sense on the one hand and actual practice on the other. The target of data collection and analytical focus itself shifted from the first interview through to the last. In the later interviews, a greater focus was on the professional background of the analysts, how they came to be recruited to their positions and what constraints they face in the analytical part of their job profiles, which too appeared to be somewhat broader than the author had a priori assumed. 
Regardless, as with everything in public policy, the context will always hold details that alter the balance of decision. As the eventual 'user' of the methodological innovation, the analyst would still be the best informed authority on whether or not the proposed adaptations are feasible. We need their assistance to gauge what challenges analysts face when using existing methods and what additional burden the adaptation might pose. Also, as one of the motivations for the adaptations would suggest, the challenges too may vary with the context. Hence we interview policy analysts from across the jurisdiction of interest, the European Union. A copy of the interview schedule appears at the end of this chapter.

What follows is a discussion of the information uncovered in the course of the interviews, regarding the professional background of the analysts, the recruitment process, their familiarity with and use of LCA, CBA and other methods and tools, and the challenges of their job.

\subsection{Interviewees}

Seven interviews were conducted with experts associated with the European Commission, the European Parliament, and governments in Belgium, Sweden and Germany. Given their prior experience, the experts at the European level were also able to comment to some degree on their respective home countries that included Italy and Spain. Their profiles are as below:

Europe: Dr Renda, a senior consultant at Centre for European Policy Studies (CEPS) based in Brussels and Rome. He offered an interview in Brussels on 4 May 2011.

Europe: Three analysts with the official designation of Policy Advisor at the European parliament, each of whom is attached to a committee or political group concerned with environmental policy. The interviews were held at the European Parliament in January 2012. Due to the nature of a portion of their comments, they wish to remain anonymous.

Belgium: Dr van Humbeeck, a senior analyst at the Social Economic Council of Flanders (SERV), a public agency that acts as an advisory body and regularly conducts analyses of environmental policy for the Flemish government. He also trains civil servants in RIA. The interview was conducted in Brussels on 6 June 2011. 
Sweden: Ms Ahlroth is the head of the environmental economics division at the Swedish Environmental Protection Agency (SEPA), called 'Naturvårdsverket', in Stockholm. The author met her there on 26 September 2011.

Germany: Mr Schweppe-Kraft is an economist at the Federal Nature Protection Agency in Germany. The interview took place at his office in Bonn on 26 June 2012.

Each interview took several iterations of emails and phone calls to arrange. The effort invested in identifying, pursuing, snowballing and further pursuit did not always meet success. Interviews with the Dutch environment ministry in The Hague and the European Environment Agency in Copenhagen were each twice arranged and cancelled at the last minute.

To the credit of Sweden and Germany, though it took time too, the interviews were identified not through personal contacts or snowballing, but through a general purpose contact form on the website of the ministry. For this research, the ideal sampling was for the government to have pointed out an individual they considered best suited for the stated purpose. The officials in the respective communication departments took the pains to identify the relevant personnel, who in turn narrowed down the search based on internal organizational knowledge, several exchanges with the author regarding research objectives, and their professional experience, and helped zero in on the right person to interview. The other interviews then are to be taken with the caveat that such was not the case there.

\subsection{Recruitment, Profile and Position Relative to Policy-Making}

As already implied above, it was not an easy matter to determine the positions equivalent to the common American designation of a 'Policy Analyst'. That was a definite part of the trouble with soliciting and confirming interviews. Even after an initial favourable contact was established with an agency, officials concerned seemed hard put to find a person that matched the required description. The positions of the eventual interviewees were analogous, but naturally not entirely congruent. Due to the differences in the job descriptions, the different meanings of designations and roles, not all interviews covered the exact same checklist of issues in entirety. In all cases, one of the main themes explored in the interview was the role of the analyst - the educational background, recruitment processes, career tracks and analytical capabilities and typical workflows related to analysis.

Public policy schools and Masters in Public Policy (MPP) programs are not exactly ubiquitous around Europe. While comprehensive reviews on the matter might 
appear to suggest otherwise at a first glance (Geva-May, Nasi, Turrini, \& Scott, 2008), reading into the details reveals that the titles, content of programs varies considerably, and relatively few programs include core courses in Policy Analysis. The older programs tend to have been refurbished version of programs at departments of political science, public administration or various such. We also know from curriculum reviews that while approaches vary in programs entitled MPP, programs with other titles placed at various departments are rarely even comparable in their content or the careers they target (Hur \& Hackbart, 2009). Schools of Government or of Public Policy with an express vision and programs designed as MPP from their launch have only recently begun to appear. Indeed, one of the earliest universities on the continent has only just opened its School of Government ("Oxford's government school opens," 2012). It follows that there is not much scope yet for a systematized recruitment procedure for whatever the equivalent position may be called in various European governments. As a corollary, the professional track is also ruled out as a well-defined career aspiration on the supply side.

There would appear to be no centralised clearing house for jobs in public sector across Europe. A relevant section of an EU website, under the head, "Access to jobs in the public sector", briefly outlines the right of EU citizens to work in the public sector across the union, but makes no reference to a jobs website where they may search for such positions in one place (EU, 2014). The EU Careers website is restricted to jobs at European institutions (EU, n.d.). The European Job Mobility Portal collates jobs across all EU member states, but whereas the data it collects largely comes from public employment services, the jobs on offer are largely in the private sector and in all industries across the board.

By contrast, in the US, PublicServiceCareers.org has been available since 2006 (APPAM, NASPAA, \& ASPA, 2008). The website was launched jointly by the Association for Public Policy Analysis and Management (APPAM), the American Society for Public Administration (ASPA) and the Network of Schools of Public Policy, Affairs, and Administration (NASPAA), all of which were established long before. What is more, consistent with the integration of the profession of Policy Analysis in the government and academia, the website lists job openings in both arenas. That indicates a recognition that a person working as a Policy Analyst or related field within the government is equally qualified to apply for the position of a professor teaching and conducting research in their subject area. This research project worked on the premise that alongside analytical innovations of the sort proposed in chapters 4 and 5, Europe would do well to progress on such understanding of the profession as well. Improving analysis alone would not be sufficient to sustain a lead in environmental policy. 
Mr van Humbeeck opines that one of the reasons for the lack of rigorous economic analysis is that there are very few economists working at the environmental policy offices. They are mostly professionals with an engineering or science background or lawyers (personal communication, June 6, 2012).

A curious observation regarding their positions is that whereas the analysts in the member states were senior in age and commensurate in designation, those at the European Parliament were all much younger and in near-entry-level positions, despite the designation. Yet, while the senior analysts in the member states noted multiple links in the chain of command between them and policy makers (elected representatives), the younger analysts at the European parliament attested to a much more direct access and seemingly everyday contact with members of parliament. In one sense, that is a telling commentary on the marked differences in the administrative and hierarchical structures at the European level as contrasted with those at the national levels. One perhaps expects the European level of institutions as the overarching bodies at a supranational level to be even more complex and stratified, and at least with respect to the distance between the policy maker and the policy analysts, that appears not to be the case. With direct regards to the content of this thesis, the somewhat counter-intuitive implication might be that it is at the European level that analytical innovation is likely to come earlier.

When Mr van Humbeeck was asked "If the government were to create positions entitled policy analysts, is the 'cabinet office' the ideal place for them?" he replied that in his opinion, it was not the ideal situation. In the recent reforms mentioned above, it was decided to limit the number of people there to "five or ten" and restricted to a coordination role. With that picture in mind, the ideal place should be the administration. The work of the cabinet, he feels, is not to provide answers, but to ensure that the answers are available at the right time.

It is of interest to examine where the demand for analysis originates and where that prerogative lies, if explicit. In Flanders, it appears that the analysis conducted at the agency was seldom on an ad-hoc demand from the administration or the cabinet office. It is mostly the council at the agency that decides on issues to take up, independently of the ministers. Each year the council makes a list of issues and the government cannot strike down those issues or reports. That is different from the role of the German agency. There the research work and reports are commissioned explicitly by the environment ministry and only those that are demanded are taken up. Whereas at the Swedish Naturvardsverket, both those modes seem equally likely - the environment ministry routinely commissions analysis of proposals and the agency itself also initiates analytical projects from time to time. Ms Ahlroth did mention a certain preference for an explicit commission from the environment ministry. Even when a proposal or an idea 
originates at the Naturvardsverket, they attempt to "sell it" to the ministry to win such a commission, to ensure that the efforts they are about to invest are not for nothing (S. Ahlroth, personal communication, September 26 2011).

Mr van Humbeeck highlights another issue that may be at play. It is beginning to change now, but ten years ago or so, he says, civil servants were not expected to "think" about policy, which was seen as the prerogative of the elected politician. One of the objectives of introducing RIA in Flanders, it appears, was to change the way government works. Earlier, the civil servants felt it was not for them to discuss policy options. Three years ago, a new government brought in the reforms - the size of cabinets was reduced, and administration was given a greater role and say in policy making. That is a striking revelation. The division of the arms of the government is clear in most democracies. But here, policy analysis is being implicitly equated with policy advocacy and political prerogative. That may or may not be a politician's way of avoiding objective analysis from neutral bureaucrats, labelling analysis as 'meddling with policy'. The reforms then, are good news, but mind-sets take long to change. Recruitment linkages with graduate schools of Public Policy might speed up the change.

\subsection{Use of CBA or CEA}

In general, the experts conceded that matters of costs and benefits have entered into policy-making debates in the past in certain sectors and continue to do so on occasion, but stressed that they do not drive the discussion. Attempts are made to assess the range of costs and benefits, but they are not always (some said "almost never") explicitly monetized.

As a case in point, the German interview began with highlighting what literature already says: "In Germany, the discussion is usually around moral imperatives rather than driven by arguments based on costs and benefits. The rationale being that if something is determined to be the right thing to do, then the government aim at it, at any reasonable cost." (B. Schweppe-Kraft, personal communication, June 21, 2012). That almost evokes Kantian deontology. Mr van Humbeeck (personal communication, June 6, 2011) echoes it when he says, "In countries such as Belgium, influenced by Latin law, more discussion is around major criteria and ideological differences. Major design influence on policy comes from that level of political choices, before it comes to the equivalent of a Policy Analyst." The congruence in the exact quotes across countries and sectors shows the level at which those ideas and values are entrenched. Dr Renda too observes as much in his own doctoral dissertation (Renda, 2011), and confirmed it in the interview, albeit with qualifiers. The other interviews lead sufficient credence to the 
qualifiers. Mr van Humbeeck does not recall a case of the US guidelines for CBA having been used in Flanders for the purposes of environmental policy, perhaps because it is rightly perceived as too complicated, with tall data requirements. He also points to what he perceives as a contrast: "In the US, policy is a lot more bottom-up; they start from the facts. In Europe, it tends to more top-down. We start from the goals and political considerations on the path to them. That leaves less scope for facts and figures, because then we seek for figures that fit the narrative." He cautions that the picture is not precisely as black and white, but that those paradigms definitely play an entrenched role. Both he and Dr Renda remark on the somewhat persistent lack of objective, quantitative data in public RIA assessments.

In Sweden as in Germany, there appears to be considerable difference between the prevalence of CEA or methods resembling it across sectors. In some sectors, such as transport in the case of Sweden, there is a long-standing tradition of exhaustive analysis, recurring research contracts with universities, active development of computerized models, constant stream of updated quantitative data and so forth. In other areas, costs and monetization get a much lower billing. The picture painted above of a different European approach to analysis thus would appear not to represent all areas of environmental policy across the board. The reality is more chequered.

Some of the problem in adoption of the CBA standard appears to be the usual culprit of coordination. When the EU launched the RIA system, officials at the DG Environment were less than enthusiastic, as they had their own robust tools. They felt that integrated assessments or RIA would dilute their analysis. Now they were required to look at not only environmental impacts but social and economic ones as well. That led to a lack of demand for more sophisticated products that focused on environmental impacts. The European experts interviewed almost all suggested some version of that view. The predominant practice is to use analytical tools that are more appropriate for project evaluation. Those tools are imperfect as they are when applied to projects. At policy levels they are even less robust (A. Renda, personal communication, May 4, 2011).

\subsection{Data Sources and Processing}

To be clear, we are only concerned here with data of an economic or financial nature - compliance cost curves, accounting data ${ }^{19}$, monetized benefits and so forth, not scientific or technical data. In the latter category, advanced economies

\footnotetext{
${ }^{19}$ Recall section 4.4 on page 59.
} 
would appear to be placed at similar levels if the level of regulation is taken as an indication of what data might be required to be monitored.

Given what we observe above regarding the prevalence of formalized CBA and CEA, it should come as no surprise that the interviewees admitted to deficiencies in accounting and financial data concerning policy instruments. That is both actual data collected and the capabilities to predict them based on a number of variable parameters with the help of computer models.

The most consistent finding is that both the member states and European institutions appear to rely on external agencies for analysis. Policy analytical exercises are routinely "outsourced" to research institutes, civil society, universities, think-tanks and various such. That agrees with the findings on the previous section - given the lack of personnel with a formal background on policy analysis, and the lack of a system-wide support for in-house public policy analysis, public agencies turn to external agents for an ad-hoc hiring of analytical talent. The situation contrasts with the USA where large agencies exist within the ambit of the federal and state governments with clear mandates to perform analytical work as a core and routine matter.

Another consistent and somewhat disheartening finding is that the data sources and data-processing is most advanced in one single area - climate change and associated areas such as the energy sector. A cynical way to interpret that is simply that as a global hot-button, front-burner issue and the most politicized one at national and supranational levels, climate change has hogged all attention, interest, effort and funding away from other environmental concerns at their expense.

The actual evidence is somewhat mixed. While a global survey suggest that is not the case at least at the level of the consumer-citizen (The Nielsen Company, 2011), at the policy level, politicians have spoken of such a trend (Vidal, 2012).

A comment by Ms Ahlroth (personal communication) suggests a less cynical and slightly more practical explanation. She implied that the reason there is disproportionately more data in the transport and energy sector than in other environmental areas such as land use is that the former directly involves impacts to human health. The dose-response kind of phenomenon for gaseous emissions to the atmosphere have been extensively studied for decades and a lot of information is readily available. Countries in US and Europe benefit mutually from all the shared information from that research. The same is not case, say, for the effect of agricultural effluents into freshwater on ecosystem and biodiversity. The link to human health there is not direct and simple and hence there has been less research on specific quantifiable effects. 
Between costs, administrative burden for businesses seem to receive much more interest than other parts of compliance costs or other categories of costs to other stakeholders including those to the regulator. (A. Renda, personal communication, May 4, 2011)

The three policy advisors in the European Parliament appeared to be the most content with the data-gathering resources at their disposal. That is to say, they seemed more confident of being able to source the data that they need for their analytical purposes readily than analysts in the member states.

\subsection{To Conclude}

If policy is to remain at the cutting-edge, then Europe cannot remain behind in Policy Analysis either. In the years immediately prior to this research project, a look at job boards suggested that the position of a 'Policy Analyst' was harder to come by in Europe. The job exists of course, but is scattered between various job profiles.

A large section of the interviews was geared towards assessing the nature and fit of recruitment processes. It became apparent in a majority of the interviews that the analysts were not conversantly familiar with a number of developments in environmental policy that form the core of relevant MSc programs. And the statement is not about the state-of-the-art and fresh-off-the-press either. For one instance, tools such as LCA have been in wide use even across Europe for over two decades. They are relatively more recent in the public sphere, but there are entire sections of EU websites devoted to it. In the Erasmus Mundus masters that the author attended, LCA was an early core part of the curriculum, upon which much of the subsequent more advanced semesters were based.

It was also not as if all the interviewees were senior officials who had graduated from universities very long ago, and as such, relied on the more up-to-date knowledge of the fresher talent that they supervised. The experience of analysts interviewed ranged from less than three years to over twenty. Even if that were the case, the gap in knowledge would point to a need for continual training at the senior levels.

However, that is not the main conclusion of interest here. For the interviews indicated that the distance from domain knowledge was not primarily a result of inadequate education, whether old or recent, but that of mismatched education. As 
mentioned earlier, nearly all of the analysts had a background in economics or something other than policy analysis. Environmental agencies in Europe need to begin recruiting from programs in both, Public Policy and Environmental Policy, and arranging routine training for current analysts in collaboration with those programs.

Figure 6-1 below attempts to illustrate in summation the systemic overview as gleaned from the interviews and systemic remedies.

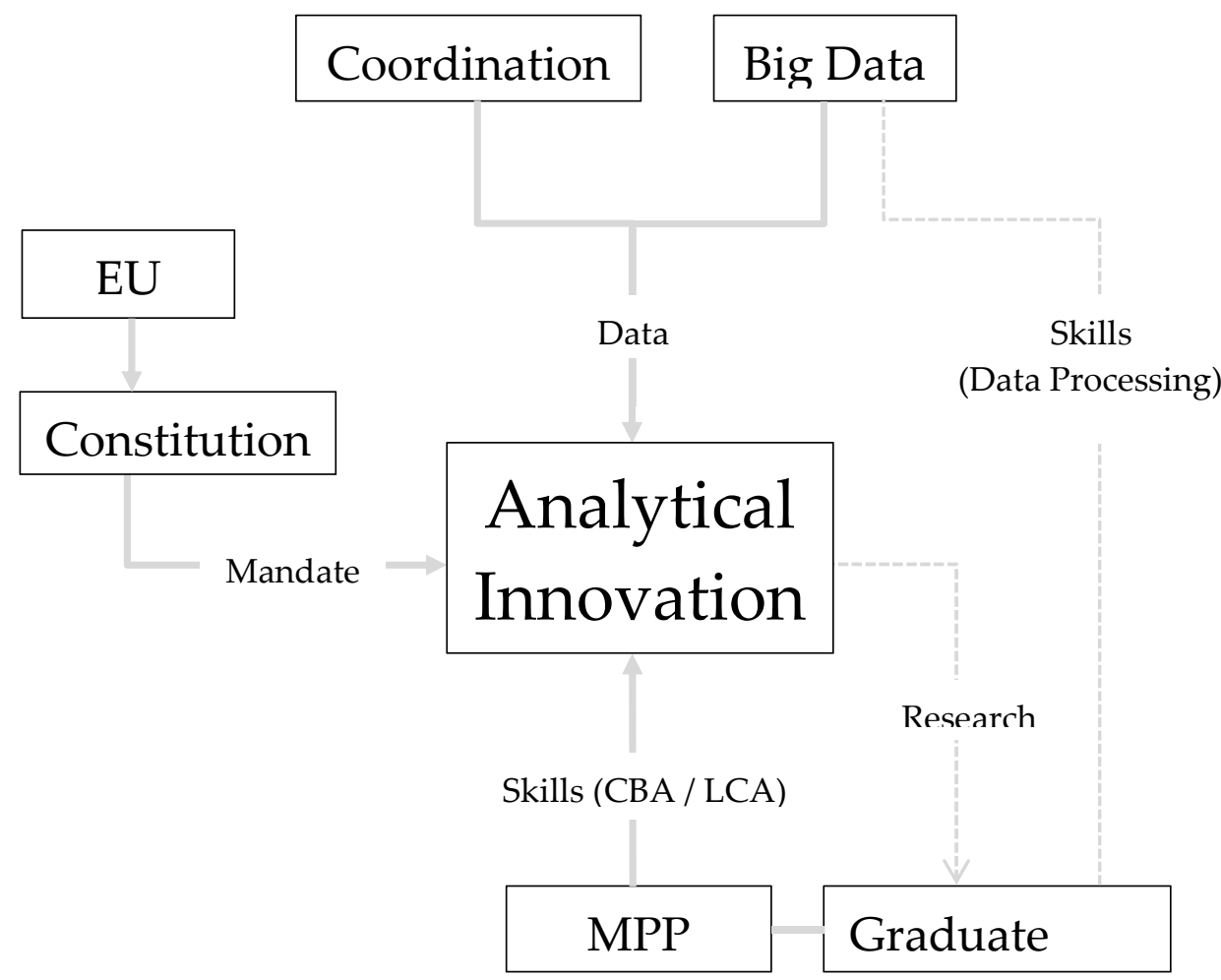

Figure 6-1 Schematic: Human Capital Sourcing and Building for Policy Analysis

The analytical innovation proposed calls for several structural elements in support. It calls for additional data or for harnessing data from disparate sectors. Better coordination among government agencies is an obvious source of more usable data. But a less obvious source is Big Data, a term for the impending data revolution. The practice of analysis would also benefit from institutionalized recruitment from the growing number of graduate schools of government or public policy across Europe. The schools can serve as a ground for training in the targeted 
skills required, whether they be in CEA or in handling Big Data. The European mandate for RIA, already in place, could provide the legislative basis for initiating these support structures.

Of all the limitations that the jurisdictions studied face, it would appear that sourcing data is the biggest hurdle. MPPs programs are beginning to sprout, models are being developed, CBA and RIA are getting adopted, but much of that will take years to all grow and fit together seamlessly. If there was a way to source some new data relevant to environmental policy, it would have a more immediate effect that would bear upon the uptake of analytical innovation of the sort proposed here earlier. The next chapter investigates just such sources of data that while easily available, would not put a strain on the burdened treasuries of Europe in these wary economic times. 
Which of the following depiction describes the location of the Policy Analyst in the policy making process? How did that come to be?

- $\quad$ On tenure within a government agency explicitly mandated with RIA

- On tenure within a government agency explicitly mandated with Policy Analysis

- Attached to a politician's private staff

- Contracted from a consultancy

What is the place for CBA/CEA? Frequency, scope, scale.

How different is that place across sectors?

Are accounting models of the USEPA kind (Chapter 5) prevalent? Who creates them? What is the access regime like?

Is the analyst familiar with LCA? If yes, is that through direct use?

What are the typical constraints in an analytical cycle? With regards to data sources, data costs, analytical capabilities?

What is the analyst's opinion on the proposed method adaptation? With specific reference to the following:

- Value - reference to goals mentioned in thesis

- Feasibility - whether capacity exists

- Additional Costs

Does the analytical context support the use of the adapted method - where modified units and referenced cost would help contextualize policy better? 


\section{Chapter 7 A Word on Data and Analysis}

This disquisition builds partly from the very premise that environmental policy is the toughest of all to sell. Among the greatest and well-known challenges peculiar to this sector are:

- Tragedy of the commons (Hardin, 1968): By and large, costs are recurring and often private, benefits are public ${ }^{20}$. Costs are relatively small but measureable. Benefits consist of maintaining something invisible, the loss of which would bring unimaginable catastrophe. The key word is unimaginable. People usually do not sit around imagining it.

- Time horizons: Most commonly, the kinds of benefits that environmental policy attempts to secure at a large scale (e.g. planetary services) do not accrue directly and short term to real constituents. By and large, voters do not agitate for them, at least not as vociferously and commonly as for tangible, fungible goods and political and civil rights. The general public rarely monitors the state of ecosystem services and environmental indicators at nature's relaxed time scale the way they monitor food prices and changes in pension rules as an everyday matter. Politicians are often not bothered beyond the stipulated term of office.

- Information asymmetry: Businesses commonly know more than the regulator about what is technologically possible and what the market can absorb, in terms of pollution mitigation and other kinds of environmental measures. The problem is compounded by legal hurdles in the sharing of intellectual property at the cutting-edge of technology.

More than in other sectors then, the need is to seek every tiniest potential efficiency (especially in practical and political terms) and extend it to related parties, especially businesses, as a way of selling policies to them - it is after all business that bears the bulk of the onus of compliance.

The analytical approach proposed in chapter 4 calls for disparate and elaborate classes of data. Naturally, so does its testing. The chapter on professional assessments also investigates the extent to which such data and the abilities to collect and process it are available in EU member states. As we take stock of what these data requirements are, at some point we must also examine what the immediate future holds for data collection and what opportunities lie in the emerging trends in data science.

\footnotetext{
${ }^{20}$ Bearing again in mind the proviso in section 2.5.3 on page 21 regarding the understanding of 'costs'. Qualifiers such as 'many important categories of' costs etc. are omitted for succint emphasis.
} 
The following categories of data are relevant to environmental policy:

- Emission inventories for industrial sectors

- Cost profiles for pollution abatement technologies

- Life cycle data on resource and energy use for products and services, including in intermediary sectors

- Emission profiles for lifestyles

- Geographical indicators - This includes local and regional characteristics such as soil, climate, topography etc.

- Dose-response research regarding pollutants and their effects on life and nature

- Biodiversity information - data on species, their identity, density, threats, corridors essential for their survival, indicators of ecosystem health and resilience

- Land use patterns and biocapacities of areas under various forms of land use

- Satellite imagery with some of the above categories of geographical information

- Weather patterns, climate and microclimate data

It is readily evident from the non-exhaustive list above that apart from being difficult in terms of policy, environmental policy is a particularly data-burdened sector, and that policy analysts are required to handle data from sources as diverse as chemical labs, cost accountants, ecologists and remote sensing satellites. Whereas the earlier sections of this work seek to make environmental choices better-informed, the approach seems to exacerbate the data requirement aspect. That is where the recent advances in data science might help. We take a look at one of the most talked-about phenomenon since about 2011, Big Data.

The discovery of efficiencies relies on data. The more connected, cross-referenced data there is on the sources of emissions and economic activity, the better it is for policy design. This chapter explores the trends in data generation and utilization, with examples that speak to environmental policy. We will also study how the data explosion and advances in data sciences might help the kind of policy analysis methods that the thesis proposes. 


\subsection{What is Big Data?}

In 2009, MIT's Technology Review (Knight, 2009) published a surprising finding that large internet firms could potentially save millions of dollars in energy bills, simply by including real-time data on energy pricing in the algorithms that route internet traffic to servers in different locations. Dependent on a number of factors, the cheapest locations at a given moment shift widely during an average day without a predictable pattern. However, with price data that is easily available rerouting is simple enough. The researchers showed how information on the daily fluctuations in electricity prices across the US could be used to route internet traffic to server located at the lowest energy prices at any given time. The analysis revealed that the companies could reduce their energy bills ${ }^{21}$ by as much as $40 \%$ ! Why did the firms not already know this? In the answer lies the nature of Big Data.

The research idea came to a PhD student at MIT. The data he needed to test his hunch that there might be some energy savings to be made? Approximately 275 billion internet browser requests made every day. Needless to say, that somewhat exceeds the limits of most analytical software. As of this writing, the term seems to everywhere and everyone seems to have a slightly different take on it, so it is one of those terms easier to describe than to define:

Edd Dumbil (2012) on the O'reily Radar, a blog of information technology experts, says:

Big data is data that exceeds the processing capacity of conventional database systems. The data is too big, moves too fast, or doesn't fit the strictures of your database architectures... The hot IT buzzword of 2012, big data has become viable as cost-effective approaches have emerged to tame the volume, velocity and variability of massive data. Within this data lie valuable patterns and information, previously hidden because of the amount of work required to extract them.

Where does all the Big Data originate? Several $21^{\text {st }}$ century trends are driving the rapid generation of unprecedented volumes of data.

Internet of Things. The term encompasses the phenomenon we are witnessing where most objects of everyday use have begun to or soon will incorporate all kinds of digital sensors that are capable of broadcasting the data wirelessly or over the internet. Some examples of sensors are Radio Frequency Identifiers (RFID) tags

\footnotetext{
21 The article uses the word 'energy consumption' but later goes on to clarify that the research in question focuses on energy costs. However, the same approach could very well be extended to enhance energy efficiency as well.
} 
and Geographical Position System (GPS). Thus objects, instruments and all sorts of appliances join the internet which was hitherto a network open only to computers. The archetype of this phenomenon are things like the wrist watch that measures the heart-rate and saves the data online, or a refrigerator that likewise monitors and records calorie intake.

Semantic Web. Most information openly available on a websites or internet servers is either intelligible to computers or humans but not to both. For instance, at the Internet Movie Database, a human user has to run searches to retrieve data, and thus ask a computer. On the other hand, where a user can clearly spot the address and phone number on a website, to the computer it is often just some more text on the webpage. The Semantic Web denotes the movement among web developers to identify every bit of information held online in systematic standardised taxonomies. That way, wherever an address is mentioned, for instance, a computer would recognise it with a geographic identifier and could run relevant operations on it, say ordering by latitude and longitudes or by country and so forth.

Augmented Reality. The same sensors that enable the Internet of Things, also help portable computing devices recognise and interact with the immediate environment. For instance, a tourist walking around Paris can hold up their phone's camera up to a landmark, the phone identifies it and displays information relevant to a tourist in that season, or even on that particular date. A person looking up a film can be directed to the nearest theatre and advised as to the next show timings and the most convenient public transport route and timings. A customer in a shop can read barcodes off a bottle of wine or a book and consult reviews online.

Apart from the above, there has also been a definite trend since the turn of the century to move from conventional desktop applications on computers to browsers, and finally towards 'apps' - dedicated little applications for each individual task. Tasks that would have been isolated on individual machines are now conducted online via distributed or 'cloud' computing, and the 'app' paradigm is a more social, connected one. For instance, in the previous century, anyone who cared to digitally enhance their photographs might have used dedicated software on their computer such as Adobe Photoshop ${ }^{\circledR}$, and then possibly shared it via email. Today, that task is more commonly accomplished on the same device that captured the image, including the sharing, all by apps. This model generates steady streams of data that span networks enabled by many firms. Additionally, the data is enriched with details such as the time, location and context of the activity besides user engagement metrics such as clicks and shares. In other words, the data comes supplemented with rich 'metadata'. 
Such and other trends then have led to virtual explosions of data. Contrary to popular belief, not all the data deluge is down to technology alone. The Open Data movement has led to demands for governments to release all the troves of data that public agencies collect and hold, but which is ironically not often in the public domain. The Open Data gurus are betting that the merger of open streams of data from private and public sources will transform economies and institutions alike (Thaler \& Tucker, 2013).

The data explosion presents many opportunities for environmental policy. For a start,

a) Supply chains would tally up all the pollutants to be tracked, the taxes paid and equipment purchased could be relatively analysed.

b) Every public transaction would have the entire context embedded and could relay the information freely.

c) Public information could directly aggregate information from private sources if tagged correctly.

d) The environment is a geographically oriented subject. GPS, RFID and else can gather all the data spread around for automated geospatial documentation and analysis.

\subsection{Data for Policy}

The more we know of the context, the better the policy is. Social welfare and protection, particularly in Europe, already works with advanced degrees of information aggregation and integration. We know the public sector has the capacity to handle it. We also know that in sectors where the government falls behind the private sector in coping with complex and big data, as with finance, regulation very quickly becomes toothless in achieving its objectives.

Technology used to be the only major change in terms of which we saw the future. It held the greatest of promises, and hopes of solving all our problems. Then one technology alone brought about a revolution that now offers at least as great a paradigm to paint a hopeful future by - big data. Everyone is talking about it. The Economist newspaper believes Big data holds challenges and opportunities for corporations and consumers, governments and citizens alike ("Building with big data," 2011). 
When faced with population and resource pressures, they have said since the last century that technology will save us. Today, with new and additional challenges, the promise is that data can save us. And there are several ways in which this will play out.

As a material input is monitored down the supply chain and along the product life cycle, the same channel that tells us about the carbon can inform us of the sulphur or mercury content, if we say we care. Business terms such as 'supply chain' might make the application of high tech sensor data seem very limited. An illustrative example of the versatility of application of distributed sensors are cows in the Netherlands that send signals to internet servers so farmers can monitor their health and movement (Jefferies, 2011).

As more and more data is released, applications move beyond what each individual dataset enables. Soon, people begin to connect and merge data and Big Data becomes 'Bigger Data', as it were. By merging bioinformatics databases from two different sources, scientists have been able to discover new drugs (Aldhous, 2011) and the methodology is expected to continue to lead to such discoveries. Another outstanding example of a scientist using large new datasets to examine age-old questions in economics from a different angle and generate new answers is Cesar Hidalgo's recent work (Hausmann \& Hidalgo, 2011). He disaggregates industrial output into sectors and more than 5000 product categories to unpack Growth Theory and take it into a bold new direction.

Just as the transition away from paper money reduces the proliferation of black markets, increasingly the penetration of data gathering sensors around all infrastructure networks-manufacture, transport, utilities - would help eliminate wasteful inefficiencies. Geo-coded Information from regularly-spaced sensors along all sorts of distribution networks would help pinpoint the location of leaks and assess the extent, for instance. A fitting example is work on an Urban Operating System ("Smart cities to get their own OS," 2011) that a firm called Living PlanIT is developing. The idea is for machines and sensors embedded in buildings and civic infrastructure to share all the data they generate in real time, giving rise a sort of urban consciousness that anticipates problems and deficiencies and automates solutions and directs resources where needed.

Fortunately, as mentioned earlier, Big Data developments have been accompanied by the Open Data movement. Many institutions, corporations, organisations and governments that hold data have opened the floodgates on their stores ("Data.gov," n.d.; UK Government, n.d.; World Bank, n.d.) and are pressuring others to (United States Mission to OECD, 2011). 
All of the above and more heralds an era of smarter decision-making in general across organisation, and there is no reason public agencies should sit it out.

\subsection{The Caveat}

As with everything else, however, there are downsides to Big Data. A paper presented at a Symposium on the Dynamics of the Internet and Society (Boyd \& Crawford, 2011) gives a word of caution to academics against hype. Among the issues they flag are privacy and data abuses by the state, inequality ${ }^{22}$, and a shift in the nature of 'research' itself.

Wired magazine carried two interesting articles on this back to back. One points out greater scope for cherry-picking and spurious correlations (Ogas, 2013). It has an interesting chart that shows how the number of spurious correlations rises rapidly with the number of variables thrown in. The other article essentially maintains that the hype around 'Big' data is yet another example of our very modern obsession with size (Arbesman, 2013). The author feels we should show rather more interest in what he calls 'long data', by which he means data with a "massive historical sweep", which can really bring out broad patterns.

These are criticisms with a valid place. None, however, quite apply to the specific use of new sources of data the following sections will illustrate.

\subsection{New Sources of Environmental Data}

Big Data is expected to help bring several critical advances in dealing with environmental and social challenges, from demographics, food shortage, crime and education to transport and building energy management ("ESS: Big Data for Social Good," n.d.; Fehrenbacher, 2011).

Let us explore some of the ready sources of public data to examine what policy making stands to gain. Among the most prominent holders and sharers of galactic proportions of data about consumers and citizens is Google. The most lucrative chunks of the data that Google has stored is not in the public domain. The company uses it directly to run its advertising business, its main source of revenue.

\footnotetext{
22 Particularly in the sense of the phrase "digital divide", which variously denotes the gaps in access to the internet, or bandwidth or in computing skills.
} 
However, the portion of data that Google has released in the public domain, it has done so in a very professional and systematised manner. Some examples include

Google Insights for Search ${ }^{\circledR}$ - This is data on the popularity of all search terms typed on its search engine all over the world since the year 2004.

Google Correlate ${ }^{\circledR}$ - The same data on search activity as above, but here, Google allows one to explore correlations between search terms.

Google nGrams ${ }^{\circledR}$ - Density distributions of all words that occur in over 5 million books published in the last two centuries.

Is any of this particular trove of public data of relevance to public policy? We need only look at the case of Google Flu Trends ${ }^{\circledR}$ (GFT) widely reported including in Nature and The New York Times (Ginsberg et al., 2008; Helft, 2008). As Figure 7-1 shows, activity on the search engine demonstrates quite a good fit with data from official agencies. What is more, given the nature and source of its data Google is able to update it at a much greater frequency than public agencies such as the Centre for Disease Control in the U.S. As a result, the company is able to accurately predict flu outbreaks ahead of time. 


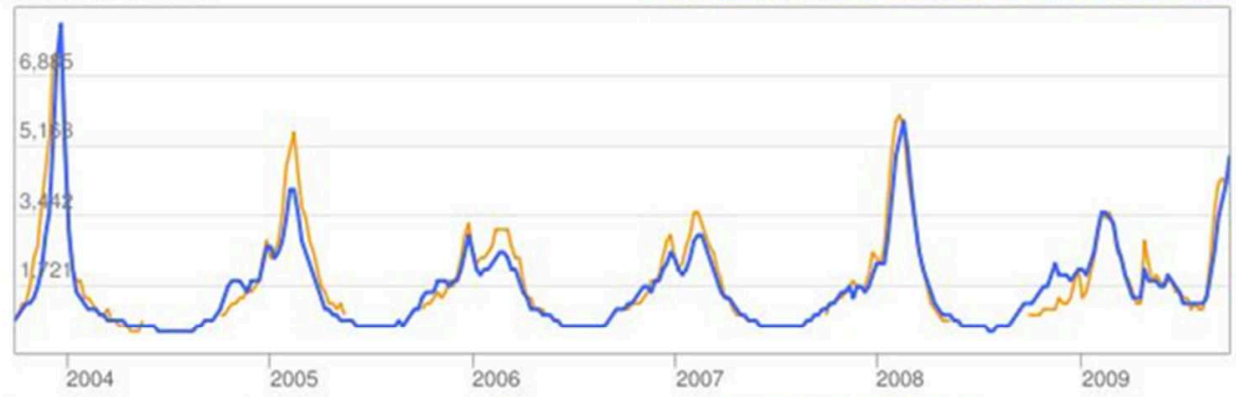

United States: Influenza-like illness (ILI) data provided publicly by the U.S. Centers for Disease Control.

Netherlands Flu Activity

Influenza estimate

Google Flu Trends estimate Netherlands data

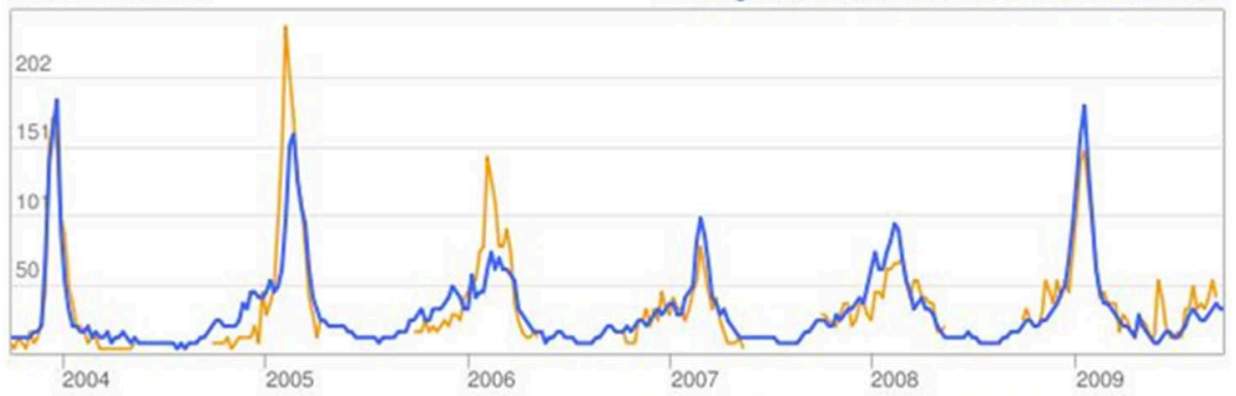

Netherlands: Influenza-Iike illness (ILI) data provided publicly by the European Influenza Surveillance Network of the European Centre for Disease Prevention and Control.

Ukraine Flu Activity

Influenza estimate Google Flu Trends estimate Ukraine data

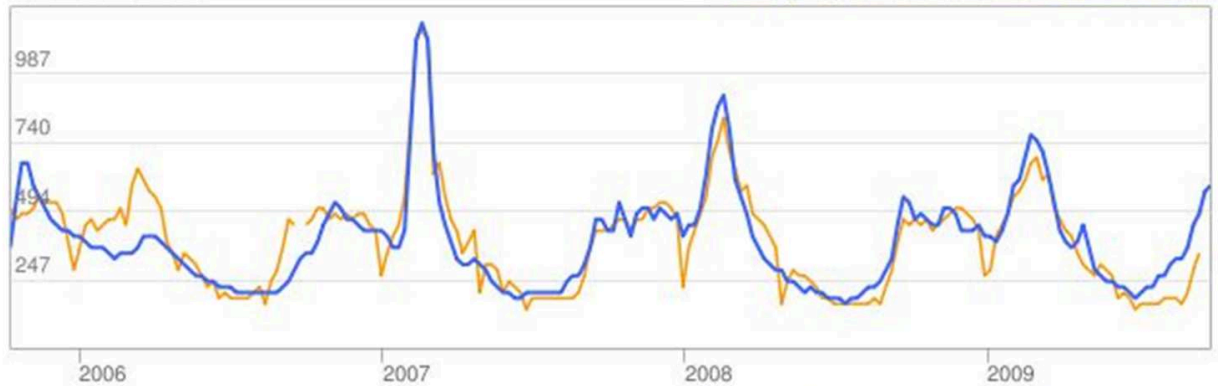

Ukraine: Acute respiratory infection (ARI) data provided publicly by the European Influenza Surveillance Network of the European Centre for Disease Prevention and Control.

Figure 7-1 Correlation Between Relevant Online Search Activity and Official Flu Data $^{23}$

${ }^{23}$ Figure generated at the Google Flu Trends website ("Google Flu Trends: How does this work?," n.d.). 
Since this thesis is going to press in 2014, it would be remiss to overlook prominent critique of the work that appeared earlier this year in an article in Science (Lazer, Kennedy, King, \& Vespignani, 2014). The article points out that the algorithm had missed predictions in more recent years since the Nature paper appeared. But at the same time, the new paper also conceded that "greater value can be obtained by combining... GFT and lagged CDC data". The fact thus remains that what Google provides is data that enhances our analytical grasp of a complex system at no additional cost to the public. In some cases, the data will have predictive power of its own, perhaps limited in purpose, in others in will offer a good complement to conventional sources of data. Either way, in policy matters so critical to society, it is certainly worth exploring.

\subsubsection{Citizen Recycling}

To test similar value for the field of environmental policy, the author created a European dataset for the search term "recycling" and compare it to official data from EUROSTAT for the recycling of Waste Electrical and Electronic Equipment (WEEE). The choice of the term and waste category is not without a basis. Having lived in four EU countries, the author can personally relate to the situation. While the mechanism for household municipal waste disposal may vary, they are known to the public. It is a routine matter and either the colour or the bags or the collection cycles or the collection cycles are common knowledge. When it comes to small appliances, however, it is not a weekly matter and one often has to ask around. Ask around, as one increasingly does these days, or ask Google. When looks up data on Google Insights for Search for a one word term, Google also gives a list of the most popular phrases that included that term and that constitute the data. And indeed, among the top phrases is usually "recycling centre" or some variation thereof.

The first part of this task was interesting but tedious. It involved translating the word 'recycling' into some two dozen languages, and for each of the terms, looking up data narrowed down for the relevant country. (For each search typed into its search engine, Google records the IP address, and hence the geographical location.) The Table 7-1 consolidates data on search term popularity on Google and EUROSTAT data on recycling for 2008 ("Waste electrical and electronic equipment (WEEE)," n.d.). The number that appears in the third column is a measure of the relative popularity of the search term in June 2008. In a nutshell, the numbers indicate the popularity of the search relative to the most popular it has been recorded to be, popularity being defined by the proportion of all the searches terms entered into the search engine that the search term in question constitutes. More 
detailed explanation of what the data denotes is available at Google Support (Google, n.d.). The data is normalised relative to the total searches in a location, so is comparable.

Table 7-1 Recycling: Search Term Popularity on Google and EUROSTAT Data

\begin{tabular}{|c|c|c|c|c|}
\hline Country ${ }^{24}$ & Search Term & $\begin{array}{l}\text { Search } \\
\text { Popularity }{ }^{25} \\
(\%)\end{array}$ & $\begin{array}{l}\text { Total } \\
\text { Waste } \\
\text { Recycled } \\
\text { and Reused } \\
(\%)\end{array}$ & $\begin{array}{l}\text { Waste } \\
\text { Collected } \\
\text { from } \\
\text { Households } \\
\text { (Kg per } \\
\text { capita) }\end{array}$ \\
\hline $\begin{array}{l}\text { Czech } \\
\text { Republic }\end{array}$ & recyklace & 30 & 82 & 0.114 \\
\hline Denmark & genbrug & 60 & 84 & 0.934 \\
\hline Germany & recycling & 75 & 73 & 0.99 \\
\hline Ireland & recycling & 43 & 72 & 0.518 \\
\hline Greece & $\alpha v \alpha \kappa u ́ \kappa \lambda \omega \sigma \eta$ & 47 & 81 & 0.079 \\
\hline Spain & reciclaje & 54 & 67 & 0.079 \\
\hline France & recyclage & 42 & 71 & 0.218 \\
\hline Italy & riciclaggio & 45 & $\mathrm{~N} / \mathrm{A}$ & 0.06 \\
\hline Latvia & pārstrāde & 20 & 81 & 0.198 \\
\hline Lithuania & perdirbimo & 26 & 63 & 0.26 \\
\hline Netherlands & recyclage & 71 & 72 & 0.568 \\
\hline Austria & recycling & 49 & 73 & 0.712 \\
\hline Poland & recyklingu & 46 & 47 & 0.036 \\
\hline Portugal & reciclagem & 32 & 88 & 0.186 \\
\hline Slovakia & recyklácia & 16 & 74 & 0.245 \\
\hline Finland & kierrätys & 44 & 77 & 0.322 \\
\hline Sweden & återvinning & 67 & 70 & 0.813 \\
\hline $\begin{array}{l}\text { United } \\
\text { Kingdom }\end{array}$ & recycling & 73 & 79 & 0.285 \\
\hline Norway & gjenvinning & 34 & 75 & 0.607 \\
\hline
\end{tabular}

${ }^{24}$ Some countries from the EU-25 were omitted for the following considerations. Multilingual states such as Belgium and Luxembourg were left out given the difficulty of identifying a single search term for comparison. Estonia and Hungary are absent as Google reports insufficient search volume for the terms 'ümbertöötlemine' and 'újrafeldolgozás' respectively. The relevant EUROSTAT data is missing for Slovenia.

${ }^{25}$ Data generated with Google Insights for Search (http://www.google.com/insights/search/) 
As Table 7-2 below shows, the search popularity of the respective term for recycling in a country is correlated to the amount of WEEE waste collected per capita from households.

Table 7-2 Correlation between search popularity and waste collected per capita

\section{Correlations}

\begin{tabular}{||l||l|l|l||}
\hline \hline \multicolumn{2}{||l||}{} & search & kg_per_home \\
\hline search & Pearson Correlation & 1.00 & .56 \\
& Sig. (2-tailed) & .01 \\
\hline kg_per_home & $N$ & 19 & 19 \\
\hline & Pearson Correlation & .56 & 1.00 \\
& Sig. (2-tailed) & .01 & 19 \\
\hline
\end{tabular}

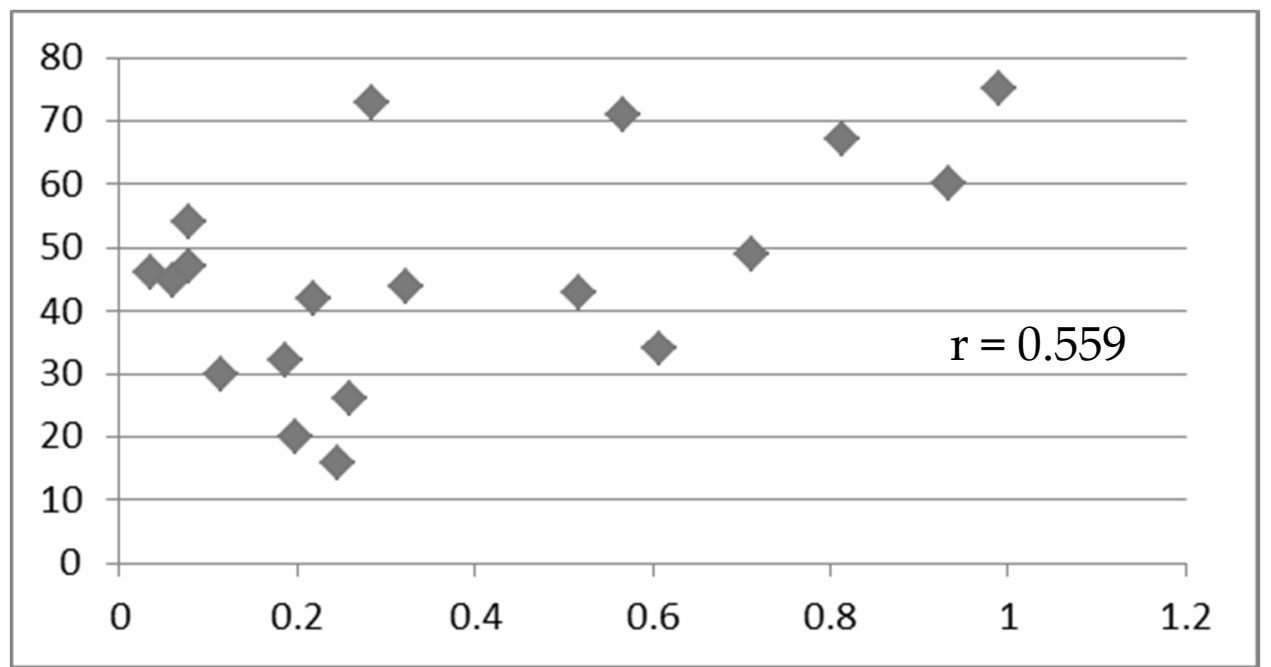

Figure 7-2 Search Popularity in \% (Y axis) vs. WEEE Collected from Households Kg per Capita 
Just to emphasize the point, Figure 7-3 demonstrates that the search popularity is not correlated with just any relative metric on recycling. There appears to be no correlation with the proportion of WEEE recycled and reused in total.

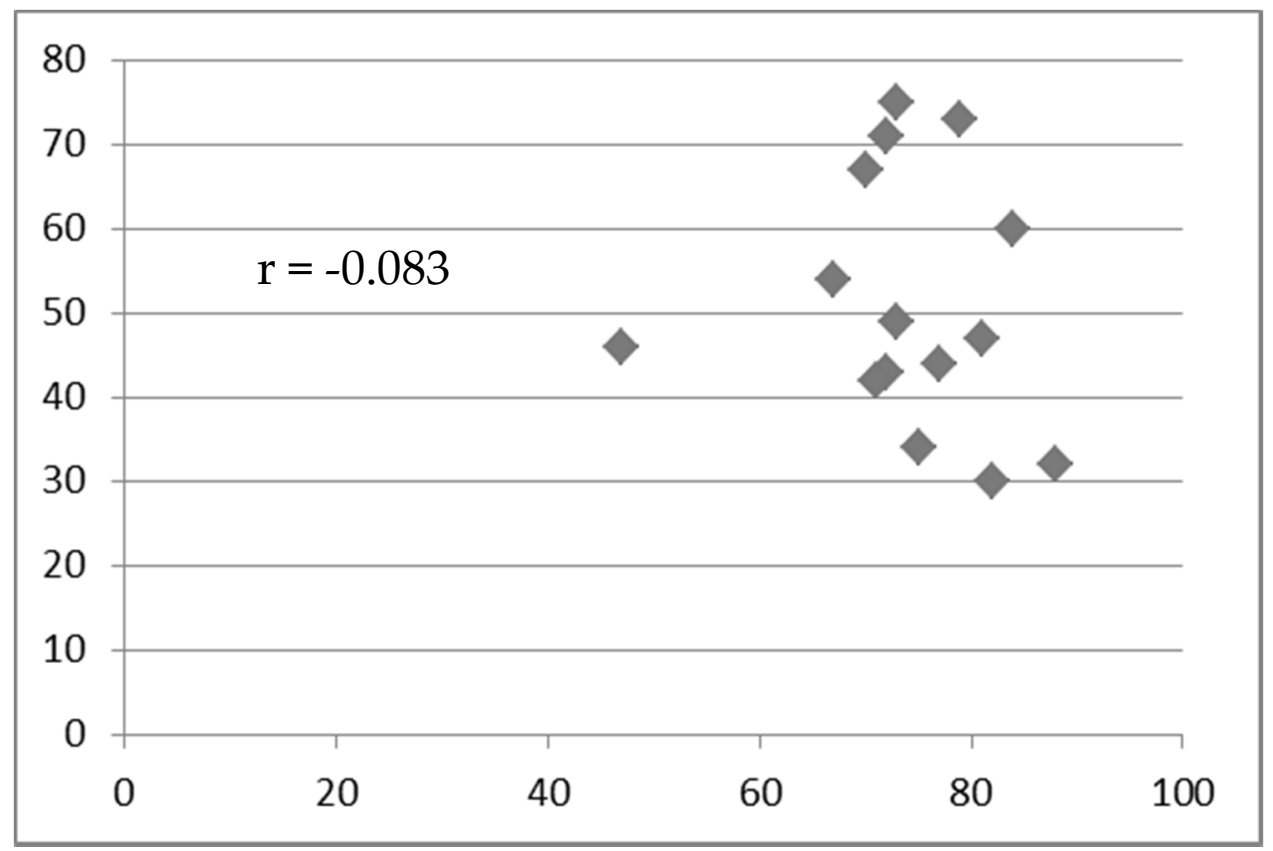

Figure 7-3 Search Popularity in \% (Y axis) vs. Total WEEE Recycled and Reused (\%)

The correlation holds only with the relative measure of waste collected from households, and that is as one would expect. After all, the total recycling of WEEE may work through several other policy channels, especially through institutional arrangements and in bulk volumes. These may range from regulation and incentives that apply to firms to public procurement practices. Whereas, much of the searches are likely to be generated by individuals looking for options for recycling, and later contributing to the stream of WEEE that comes from households.

Now that we know that the search volumes are an indication of the potential for waste collection from households, here is a look (Figure 7-4) at how much the popularity varies geographically within a country and over time. 


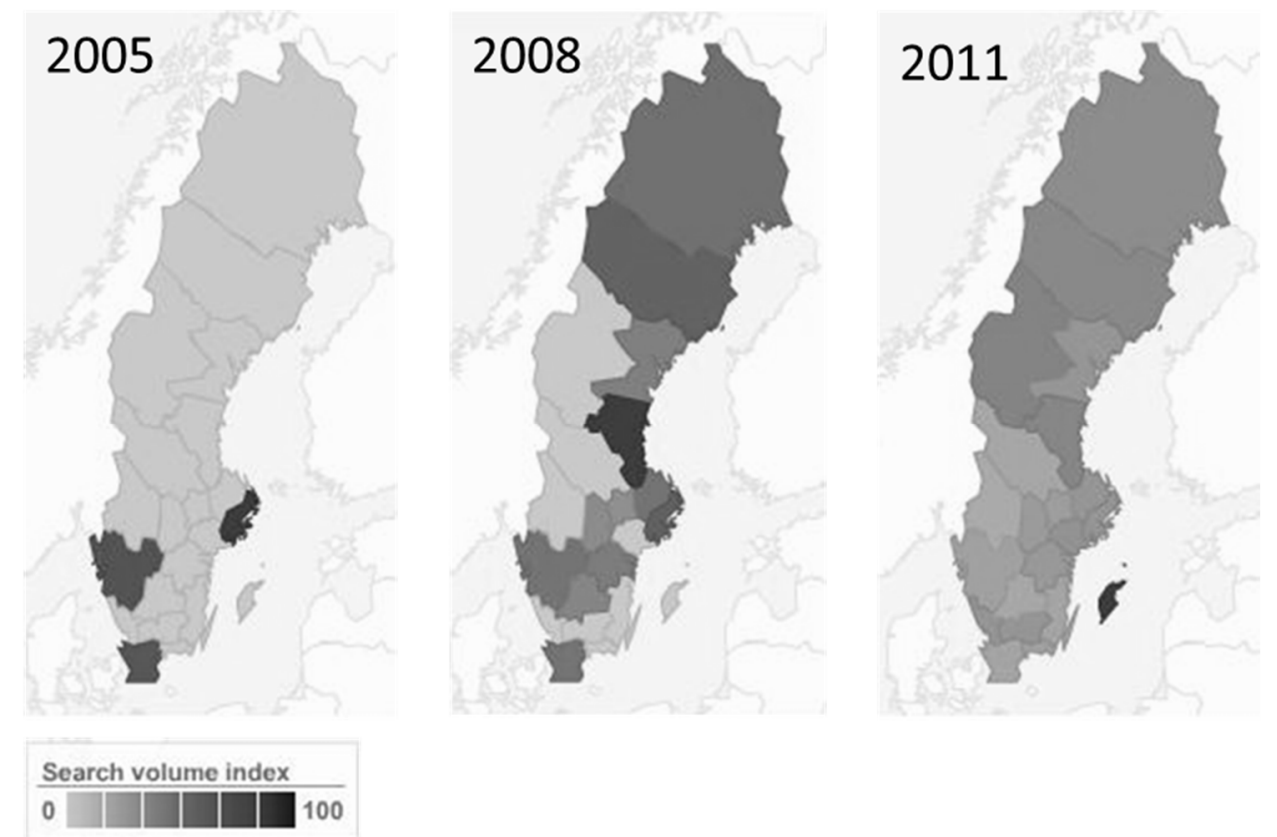

Figure 7-4 Geographic Variation in Search Activity for the Swedish equivalent of "recycling"26

Firstly, it is important to clarify what the map represents. One might be tempted to infer, for instance, that the darker shades merely correspond to population centres and hence either unremarkable or simply the indication of some demographic or mobility trend or a gradual convergence in either access to or activity on the internet. However, the data is richer than that. The map represents the relative search interest, i.e. the percentage of the chosen search term relative to all the other searches. Hence, the indicator is valid regardless of the degree of internet access or activity or any other geographically distributed variable.

\subsubsection{Consumer Shopping}

Is it possible to replicate the striking graphs for flu activity for economic activity e.g. aggregate consumer activity? A second test was done with US census data. The data for the retail sector records sales for a wide variety of consumer goods. Retail

${ }^{26}$ Data and map generated at Google Trends ( http://www.google.com/trends/) 
data was retrieved from the website of the U.S. Census Bureau ${ }^{27}$. The matching online search data from Google came from Google Correlate ${ }^{28}$ mentioned above.

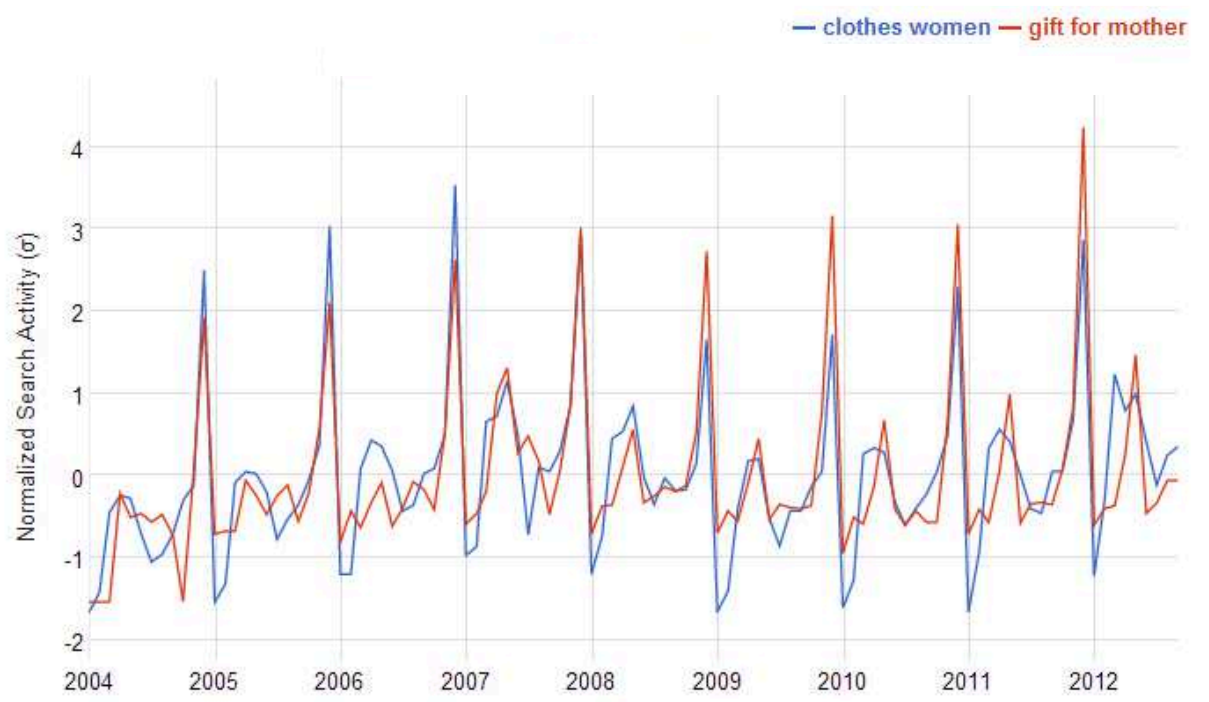

Figure 7-5Census Data for Retail Sales of Women's Clotbing vs. Online Search Activity for "Gift for mother"

The Figure 7-5 shows the real census data for women's clothing plotted next to the search terms "gift for mother". Over an eight year period, the plots show a pretty good fit. Below, in Figure 7-6, is a similar plot generated in MS Excel with related search terms added.

When comparing these plots with Google's own charts for flu activity from the Nature article, what we must bear in mind is that these are clean, standalone search terms, and that too in a narrow category of "gifts". The flu graphs show 'estimated flu activity', which is a variable constructed from data on a whole array of search terms selected by an algorithm to improve the fit of the curve. A graph of the individual search terms demonstrates the correlation in a transparent fashion and also how simple it is to identify it. In the Figure 7-6 below, for instance, it is apparent that over the entire period, "gift for mother" (in red) is a better fit than "gift for girlfriend" (in yellow). The algorithm would account and adjust for that by weights and by selecting or dropping the terms.

\footnotetext{
${ }^{27}$ U.S. Census Bureau website is at www.census.gov

${ }^{28}$ Google Correlate website is at www.google.com/trends/correlate/
} 


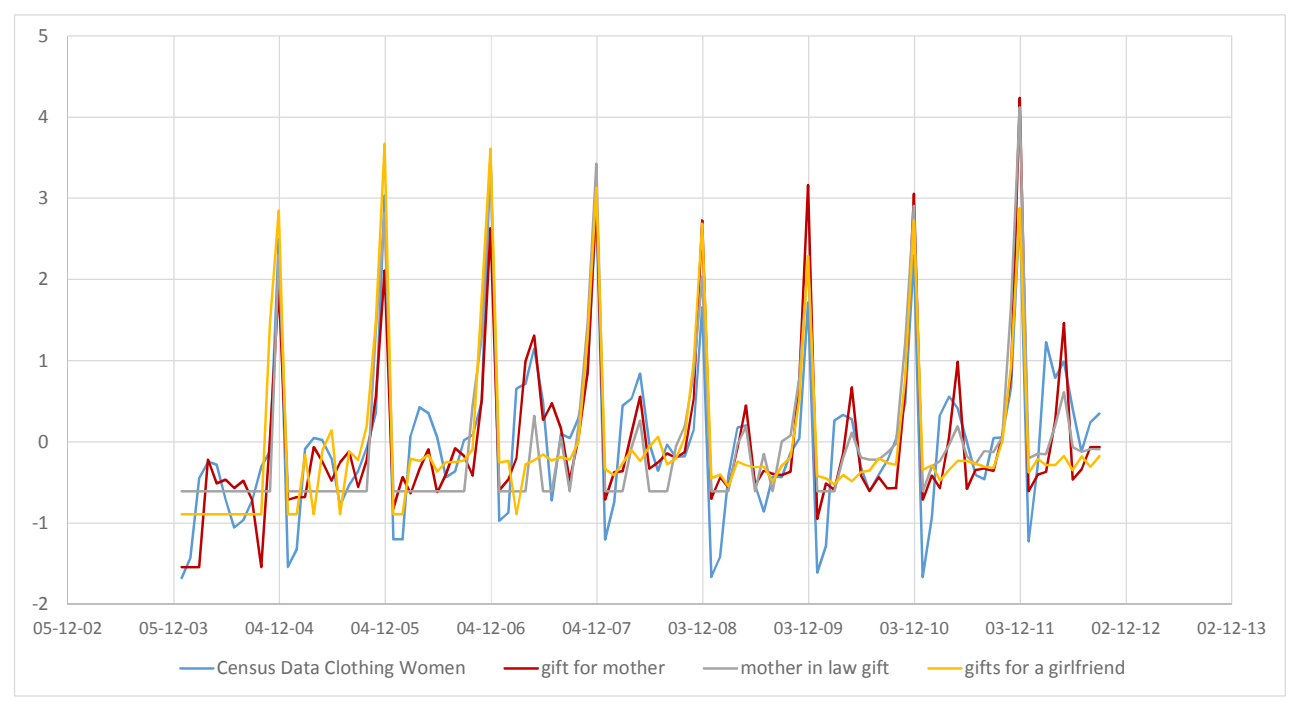

Figure 7-6 Retail Sales of Women's Clothing vs. Normalized Search Activity for Related Terms

For instance, in the graph 7-7 below, one of the best fits is a term ("travel gift") that might not be the first that jumps to mind when one thinks of men's clothing, but the algorithm helpfully singles it out for the user.

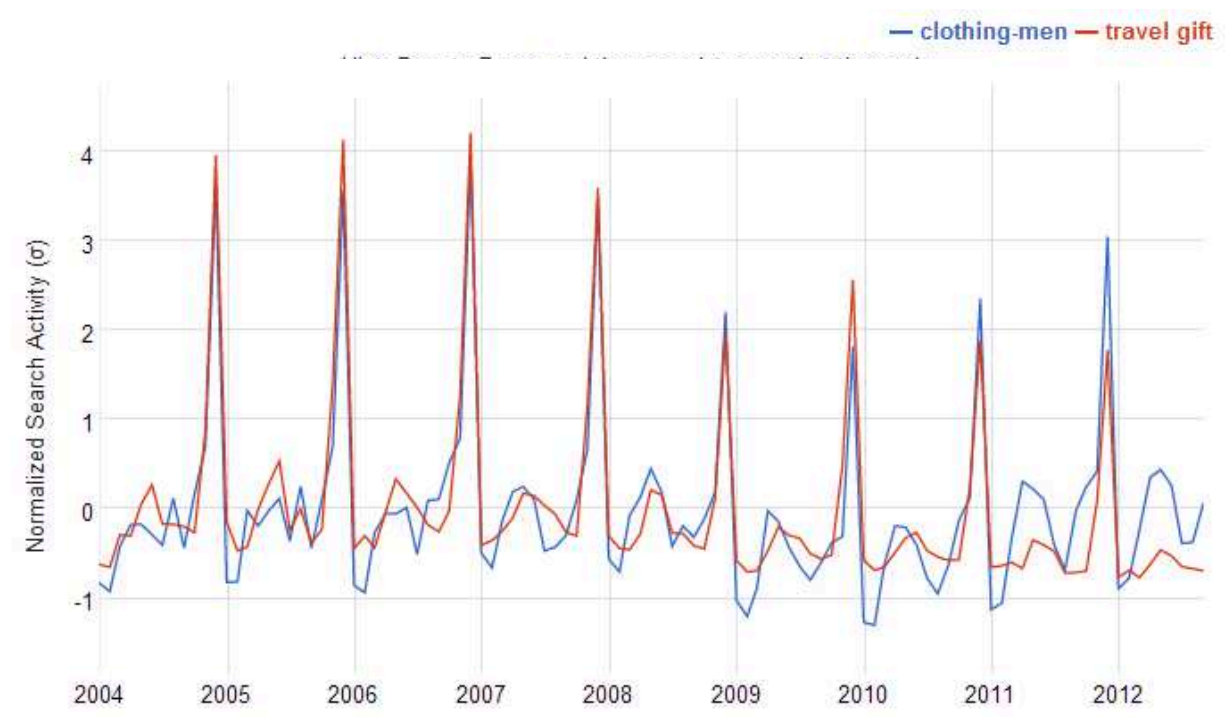

Figure 7-7Retail Sales of Men's Clotbing vs. Normalized Search Activity for "travel gift" 
Note also that the search terms compared here are from a free dataset set that Google offers at Google Correlate ${ }^{\circledR}$ website. Here, one does not choose and enter search terms, as with Google Trends®. Instead, one uploads external data of interest (census data in this case), and Google throws up a list of well-correlated terms. The data is available for download, but is not exhaustive. To construct an index based on the search terms that gives prediction good enough for policy purposes, ideally one would use programmatic access to the source data, which is unlikely to be outside the capabilities of a European government.

Such algorithms can then be used to estimate all manner of environmental factors. Sales in the retail sector can help derive seasonal estimates for everything from commercial packaging waste to the probability of congestion around retail districts.

\subsection{Relevance to Policy Analysis}

How is the data relevant then to the foregoing discussion on policy analysis or indeed, the narrower lens of cost-effectiveness? Surely Sweden, with one of the highest relative recycling rates as evident from the EUROSTAT data in Table 7-1, would be interested in exploring and explaining the gradual convergence in interest in recycling obvious in the data.

When evaluating allocation of public efforts (expenditure) in promoting recycling, for instance, the Google numbers would be in the denominator of the 'functional unit'. The government would want to spend more where interest in recycling in relatively lagging.

What is remarkable, of course, is that while EUROSTAT, like any public statistical department anywhere, represents a huge bureaucratic machinery collecting, processing and presenting data with considerable delays and significant gaps, the data from Google is next to immediate, available to anyone with an internet connection, and available free of charge. It is generated automatically by computers, an objective record of citizen activity. It is hence transparent, open, legitimate in that sense, relatively less susceptible to measurement errors

Given the fact that large open datasets speak to matters of policy, governments should want to take notice and advantage. The analytical method proposed and critically examined in the earlier sections would offer just one of the ways in which to do so. 
Likewise, the latter graphs 7-5 through 7-7 on retail sales might not seem as immediately relevant to environmental policy as perhaps to trade or commerce policy, but they take the demonstration beyond the fact that vast troves of free data show clear predictive potential and policy relevance. The graphs show that depending on the context, sometimes correlation is good enough. The search terms with a good predictive power do not always seem intuitive, but there will be times when the stakes are not high and a quick calculation at zero cost will serve the purpose. Of course, this is not go all aboard with the advice of Mayer-Schönberger and Cukier (2013), who suggest it is time to "move" from causation to correlation. Only to flag that this is an analytical option that will have its virtue in its time and place. That said, the garment manufacturing is one of the most polluting industries, besides the environmental damage from packaging, advertising, and transport. It might not hurt to have means of predicting seasonal fluctuations in the demand for clothing or one of a host of other retail items.

\subsection{Policy Analysis in the Age of Big Data}

And yet, governments seem to be new to data analytics. A report by Accenture that surveyed governments in six countries (Australia, Canada, France, Spain, the UK and the US) found that more than half of the officials were not familiar with analytics (Accenture, 2012). And that is just data already held in administrative records, not the vast troves that come to be known as Big Data. This section highlights the specific ways in which governments could harness data and analytics to improve environmental policy analysis with less effort and expense.

\subsubsection{Resource Efficiency}

At the most basic and immediate level, more data often equals better data. If information is shared in real time, as it is being generated, data can reveal massive inherent efficiencies and help remedy them. Sharing information on surplus and shortages and connecting them can direct resources where they are needed as when they are. When wastage and leaks are identified and quantified, they enable similar efficiencies.

The earlier example of the MIT student's insight into harnessing the energy price differential fits here somewhat. But an even better example from the same industry is the use of network bandwidth. Internet bandwidth is consumed in two ways: urgent, for things like as viewing a website, and "delayable", which might include 
activities such as data archiving. Careful analysis of data showed that bandwidth could be priced in tiers varying by peak and off-peak hours and bandwidth could be used much more efficiently ("Micro stars, macro effects," 2012).

\section{The Sharing Economy}

A civic and economic trend that is gaining popularity is characterised as the 'Sharing Economy' which cashes on that very fact ("The rise of the sharing economy," 2013). The prime examples are carpooling networks (such as Uber), but the trend is rapidly expanding to shared libraries, spaces, equipment etc. Many of these networks are organised via apps on phones. There is no reason why that same form of real time information cannot be used to optimise the allocation of every kind of resource, including water, nutrition, insurance and even expertise.

Analysing mass behaviour helps better understand the temporality and geography of needs.

As mentioned before, new sensor technologies and methods are delivering new streams of data. Methods that make use of current and ubiquitous technologies are also adding to the bulk. Joining in all the interest in gestural interfaces and motiontrack, researchers have revealed that Wi-Fi signals inside homes and offices can be used to track human movements. But beyond a being machine interface, the same method can also be used to measure indoor mobility and add to our knowledge of indoor space usage. It could be used to automate heating and lighting without the expenditure on new hardware. That is to say, the space usage patterns can be used for smarter heating and lighting fixtures, without the added investment into motion sensors.

\section{Betters Models}

Just as new measurements can help improve models, they can challenge older models. Scientists have recently been able to measure a wide array of Volatile Organic Compounds (VOCs) that were previously unaccounted for in climate models because they could not be measured (Park et al., 2013). As these compounds play a key role in atmospherically chemistry and determine the effects of pollutants, better data in this case means more accurate models.

Mobility data has been used to estimate the transport carbon footprint of a large number of individuals in real time (Manzoni, Maniloff, Kloeckl, \& Ratti, 2010). Also mobile data such as could be used to club various dimensions - such as traffic behaviour under certain weather conditions and pollutant response under the same weather. 


\subsubsection{New Denominators for the Chapter 4 Approach}

The data revolution may also have a very direct connect to the essence of Chapter 4 , the adapted analytical approach. New sources and forms of data can broaden the scope for more bespoke denominators i.e. reference policy units.

For instance, studies of mobility patterns (González, Hidalgo, \& Barabási, 2008) might give a unit for transport and emissions policy and allow for fine-tuning in near-real time. For decades, transport policy has been geared around the unit of 'person-kilometre'. For the first time, we now exhaustive data on the movement of people. Triangulating from mobile phone and Wi-Fi network use, we know precisely how many times an average worker start her car, how many stops she makes in a routine day, what times she leaves and returns to places, what routes she prefers. We can infer precisely what proportion of the public use public transport, how often and between what stops, during which periods. A new functional unit of 'person-hour' or 'person-kilometre-hour' would allow for addition the time dimension and factor in the cost of time. The same policy option can optimize for coverage and congestion.

\subsubsection{Bottlenecks, Hotspots and Crises}

In Policy Analysis, the term 'monitoring' is generally used in the context of evaluations, where the progress of a project or the implementation of a policy is tracked. But the latest technologies also enable crises a round-the-clock environmental monitoring, which can be used to track status in real time, but also to anticipate bottlenecks, hotspots or crises before they manifest themselves and cause damage.

We have seen that demand for products and services can be predicted before the fact. Conversely, products or advice can also be prescribed in response to other data streams. The Weather Co. (formerly the Weather Channel) now sells data on searches to help other companies predict what consumers might buy (Rosman, 2013). If a woman checks the weather and finds it to be humid, she is shown an advertisement for a formulation of a popular shampoo brand designed to reduce frizzy hair. If the weather is dry, she is likely to see an ad for a volume-enhancing version from the same company.

There is good news for the natural environment too. Technology has enabled scientists and government to crowdsource real-time population data on birds (Robbins, 2013) and insects ("App to aid hunt for rare insect," 2013). Amateur 
biologist and concerned citizen alike now use apps of their phone to capture the wild sounds they hear around them and send them to a central database where they are identified, logged and catalogued. That helps us have good data of species distribution and vitality.

It follows from all this monitoring that problems get flagged as they emerge. Just as monitoring the weather can drive appropriate consumption, the monitoring of consumption in turn means that peak resource demand or pollution associated with the products and services can likewise be predicted. Remedial response can be timed better if the key predictors are monitored.

\subsubsection{World Input-Output}

Section 5.2.5 presented a quantitative case from German EIO-LCA data. Likewise, Environmentally-Extended Input-Output tables hold a great potential for macrolevel public environmental strategy (Tukker, Akerlof, van Oers, \& Heijungs, 2006). But the Multi-region IO movement and the Environmentally Extended IO movements seem to be stalled for the lack of data. At their intersection, much can be accomplished from the data explosion.

As described above, data on a wide variety of consumption goods can be inferred from large datasets. The economic behaviour of citizens at large can be predicted. Combined with insights of the kind discussed in previous sections, Input-Output analysis will empower governments and regional bodies such as the EU to set and achieve long-term economy-wide environmental goals. States would also use the analysis to determine the best pathways for a greener growth and set their commerce and innovation agenda in accordance.

\subsubsection{Nanny Statecraft}

Cass Sunstein, referenced earlier for his support of Cost Benefit Analysis, and Richard Thaler wrote a book 'Nudge', citing numerous cases where behavioural insight could help governments change behaviour better and sooner, not by substantively changing incentives, but mostly by presenting them in a different way (Thaler \& Sunstein, 2009). That different way, in most cases is a slightly suggestive way of framing choices to correct for well-studied lapses in human decision-making such as the 'status-quo bias' (Samuelson \& Zeckhauser, 1988).

Thaler calls it 'Libertarian Paternalism'. For a different political constituency, a slightly more palatable alterative might be what has been called 'Asymmetric Paternalism' (Camerer, Issacharoff, Loewenstein, O’Donoghue, \& Rabin, 2003). 
Regardless of how fast which variant spreads across the Continent, any form of paternalism would doubtless benefit from what governments learn about behaviour from the masses of anonymised data.

Governments have already begun instituting measures. A recent initiative in the US was reportedly inspired by the Behavioural Insights Team in the UK (Reiner, 2013; Subramanian, 2013). To quote from a Presidential memo (Executive Office of the President of USA, 2013) sent to the heads of executive departments and agencies:

"Applying behavioural insights to improve results and lower costs in direct operations: ...Major advances have been made in research regarding the influences that drive people's decisions and choices, and these new insights can significantly improve policy outcomes at a lower cost."

Mobility datasets have helped reveal the differences between urban and rural societies not just in terms of mobility but also their different network structures and the economic behavioural differences between socioeconomic strata (Eagle, de Montjoye, \& Bettencourt, 2009). Whether organ donation should be an opt-in or opt-out choice, in what order questions must be placed on a tax form, what time of day is the best to call or email you to solicit your vote, and which aspects of environmentally friendly products appeal to what demographics - all these and more are the sorts of answers that government could start seeking in the giant haystack of data.

\subsubsection{Uncertainty, Precaution and Discounting}

Lastly, to come a full circle and connect all the way back to the Chapter 2 on the review of Economic Analysis (Section 2.5 Old Issue and 2.6 Current Issues).

Big Data may help answer some of the most vexing issues that bedevil the policy analyst's profession. 'Revealed Preferences' techniques used to involve unreliable surveys or quasi experiments. But in the digital age, consumer preferences are very explicitly revealed for large numbers and over long periods.

Large scale data on personal expenditure or individual transactions can help economists 'discover' or estimate or approximate the social discount rate choice for a given population. The results may not be universal but within reasonable bounds, they could hold for a policy maker's immediate constituents. Latest research with such personal transactions data suggests that personal attributes and 
actions can reliably be predicted with great accuracy (Krumme, Llorente, Cebrian, Pentland, \& Moro, 2013).

The elasticity of marginal utility of consumption has been used to derive social discount rates (Evans, 2005) and attempts to study the marginal utility of consumption with the help of such large digital datasets have now begun to appear (Blumenstock, Eagle, \& Fafchamps, 2012; Nevskaya \& Albuquerque, 2012).

Along those lines, one can imagine that purchases made on online retailers can be used to estimate the degree of precaution that individuals express in their buying decisions, by allocating their expenses between various categories of products with different risk profiles.

\subsection{To Conclude}

When this part of the research was presented to colleagues in internal seminars, and in subsequent discussions, a concern kept surfacing whenever the name Google was uttered - privacy. It is perhaps an inevitable fallout of a post-Snowden milieu $^{29}$. The extent of government surveillance, the proper terms of use for free internet services and transparency regarding data sold to or shared with advertisers is a matter of ongoing public discourse and legal battles. For the purpose illustrated in this chapter though, the blanket aversion to large firms and their data services is misguided. The simple reason is that the search activity data used above is anonymised. It does not include any metadata about the user other than geography at that a fairly low resolution, as the examples too imply.

Moreover, this data is recorded regardless of whether the user inputs a search from a highly secure computer, over an encrypted network and with browser settings that do not allow local information to be set or gleaned. The internet would be virtually unnavigable without a powerful search engine and the data it generates at the minimum that is referenced here is quite innocuous but immensely useful for a range of purposes. Privacy is a serious and valid concern when the data in question includes personal information or reasonable identifiers and Google does widely collect such data, but such is not the data this chapter is championing for public agencies to harness.

It behoves the chapter also to reiterate here the observations above (from section 7.4) in response to the critique of GFT, as it offers a fitting note to conclude an

\footnotetext{
${ }^{29}$ In mid-2013 and regularly since for a period, Edward Snowden, a computer professional who had provided services for American intelligenc agencies, shared with major newspapers startling revelations about the extent of digital surveillance by some governments, and the complicity, willynilly, of large technology firms. The stories commanded headlines around the world for months.
} 
exploration of the potential of a much-hyped contemporary trend. While the critique is certainly valid and timely, the original objectives of the project need to be borne in mind when reassessing its potential. The combination of Google's algorithm and CDC data leads to better prediction results than either taken alone. That is the key take-home message. The central data collection by public agencies is not redundant or obsolete. The new data streams simply improve the capability and value of analysis. In other words, they provide a "complementary signal" to available information. And as such, it is currently the only such source of a corrective complementary signal, let alone the fact that it is virtually free to the public and to public agencies alike.

That then is also the gist of this chapter. The forms and sources of data touted here as 'new' are not to be seen as a silver bullet. From the perspective of public agencies responsible for policy-relevant research, they offer more of a silver lining to the looming dark clouds of an overwhelming explosion in data. 


\section{Chapter 8 To Valorise and Conclude}

\subsection{Answers Sought}

The research aims set out for the thesis were fairly simple and straightforward. Easily established, but non-trivial. Here is a summary of the investigation:

Is there a gap between policy ideas and analytical practice in Europe? An unqualified 'yes'. Is there much Europe could do to further its lead in environmental policy? Yes. Are the analytical innovations proposed simple enough to empirically demonstrate with real government data? Yes. Do the analysts find the same proposals easy to implement? A qualified 'no'. Is data one of the major issues that qualify the answer? Yes. What aspects of data are the problem? Sources and costs. Is there some hope on the horizon that bridges the chasm? Yes, in the form of big and open data.

\subsubsection{The gap}

Right early in this, the initial chapters attempted to portray the gap described above as the established view in literature. The exploration on the way to finding the literature to make that case was eye-opening. For it fuelled the curiosity as to the questions to raise, especially in the interviews, for the analysts themselves better than any academic outsiders can explain it. The quantitative empirical parts of the research also proved the point in a way. When it came to finding public data to test the proposed analysis it was a difficult search, including at the European level. While some computerised models that can generate or analyse data for a robust economic analysis are now beginning to appear in the public domain, they definitely lag well behind the dates of efforts visible on the USEPA website. It is one thing to find academic literature in support of a view, but quite another to hit upon a truth in such a practical manner.

The fact that UK is the only country in Europe where at least projects to assess systematic cost-effectiveness and their results were readily found - if not the underlying computer models - in the public domain, might point to language as a possible cause of oversight. While the author allows that as a cautious qualifier to the findings, there are a few rebuttals. With a working knowledge of French and Spanish, the author did look up government websites in France, Belgium and Spain close to exhaustively without success. Also, with the help of freely available 
technology such as Google Translate ${ }^{\circledR}$, in countries where information about the projects slightly similar to those sought was available, as in Germany, it was not difficult to find. It was only that the environmental assessment projects, while fairly technical in design, did not appear to be primarily meant as costeffectiveness studies. What is more important, neither the results (in the form of cost curves) nor the models, if any dedicated ones were developed and used, were available publicly at the same website. Thirdly, the interviewees backed up the finding, in a general sense. Speaking either for the place where they were employed or for their own countries of which they had some professional knowledge, they confirmed the lack of US EPA-style models (such as those employed in sections 5.2.1 to 5.2.3) in Belgium, Sweden, Italy, Germany and at the European level.

To be fair, the gap is far from uniform. That is not just to accommodate the regional discrepancies this work will miss because of the rather limited regional scope of the interviews despite their depth. It is also to note that even within countries, some environmental issues see a lot more attention than others. That is again, often and at least partly, a consequence of the absence in most cases of a designated agency mandated by some form of budgetary oversight as in the US (such as OMB and OIRA mentioned in chapter 2). A second reason is apparent when we name the sector that appears to receive all the disproportionate interest: it is climate change. Sweden, the European Commission, and several groups at the European Parliament all have commissioned exhaustive research into the economics of climate change - of various facets, at various levels, with both broad and narrow economic foci. Within the domain of energy and climate research, there is also some evidence of accounting models of the USEPA kind used in the quantitative part of this thesis. Whether it is the political interest in energy security or genuine political will to maintain environmental stewardship in the global climate accords, when compared to the analytical capabilities in every other environmental issue, the efforts seem lop-sided, at least through the lens of this research work.

\subsubsection{Analytical Innovation}

The computerised models from USEPA and DEFRA alike did help demonstrate the potential for analytical innovation of the kind that is the central proposal of this work. The hope is that the examples from models including OMEGA, IAPCS, COST, FORSCOPE etc. sufficiently demonstrate the potential value of unorthodox units for cost-effectiveness comparisons. Somewhat contrived as the hypothetical policy choices discussed may be, they build on either real-world data or the simulated results based on real-world parameters that are the best estimates used 
by the policy-making public authority in question. It must be born in mind also that many of the examples use US data to make the case that the unorthodox units may yield important information in the European case. Labour laws and tax regimes, to mention just two sources, have a direct and non-trivial bearing on a large number of cost parameters inherent in cost-benefit calculations. Needless to establish, therefore, that some of the variables in question are likely to vary substantially more across member states than would be the case within the US.

\subsubsection{Adoption in Analysis}

Regrettably, the road to adoption of new forms of analysis around the EU appears far from an easy one. Despite or more likely due to the relatively recent mandates, CBA or CEA do not appear to enjoy a broad-based hands-on awareness within the public sphere. The interviews would seem to indicate that what little awareness does exist is sketchy and sceptical. That is not surprising, again given the first finding. Even the official CBA reports released by the European Commission fall well short of the CBA standard as stipulated in the US. Secondly, it was not easy to explain the modification in CEA as inspired by LCA. Even those that had a good conceptual and practical grasp of LCA, tended to take the phrase "inspired by" to mean "expanded to incorporate". Only during the ensuing discussion of the cost increases entailed that the misunderstanding became apparent. Analysts generally did not pinpoint major hurdles in the simple arithmetic experimentation that multiple reference units for CEA would involve. Costs of any additional data aside that was the expectation going into the interviews. However, given the overall picture of where the use of CBA or CEA currently stands, it remains unclear whether the uptake of the analytical innovation proposed would be smooth, if instroduced.

The general attitude to data, to collection, maintenance, analysis appears to be a barrier. In general, for environmental policy purposes in Europe, much more data is generated in response to regulation than in anticipation of it. As a consequence, any innovation in analysis that suggests data burdens implies a corresponding escalation in costs. The proposed analytical innovation would indeed partly rely on data synergies with various other sectors of policy, so data costs could be shared, but the synergies in turn would entail costs of coordination and transaction.

One sure indication is for a greater need to inculcate a sense of Policy Analysis as a regular profession, with its recruitment and continuous training tied to graduate education, which itself needs encouragement. 


\subsubsection{Promise of Big Data}

Which brings us neatly to the last bit of enquiries and findings - the on-going onslaught of the Big Data buzz in almost every sphere of economic activity, and likewise potentially, in every sector of policy. Much of the large quantities of data being generated in current time is either free or easily freed. That is to say, either it is already in the public domain, or public agencies can bring it under the public domain. The particular class of Big Data explored at the end of this thesis - record of activity on the internet - is absolutely free. Even the costs of storage and analysis (computational capability) are largely borne by the corporation that generates that data. All the policy analysts needs to do is to brainstorm, then pick and choose variables of policy relevance. It would be a matter of time before they settle on a certain selection of variable for systematised analysis such as CEA and institutionalised analytical frameworks enough to inform decisions of policy design. The exploratory analysis with Google search activity data shows significant correlation with EURSTAT data. On top of that, given that first fact, the data also provides insights to more than spark the curiosity of policy analyst and policy makers alike. Policy hinges on the public agenda more than on anything else. A free and open barometer of shifting public priorities and sentiments should sound too lucrative to ignore to a policy maker, just as it would to a marketing manager.

The chapter of course suggest harnessing the immense power of sources of Big Data other than the internet, for just one instance, that from RFID tags, GPS signals and various other mobile sensors and instruments.

To conclude on the same note that we began on, the embattled sector of environmental policy needs to exploit every conceivable efficiency, especially in the analysis stage, to make it more palatable and amenable. Free new forms of data would hardly seem a trivial prospect to consider.

\subsection{Valorisation}

It is difficult to assess the magnitude of public value for a piece of any work that researches public affairs. On top of that, as indicated at several places in the dissertation, this is not merely a piece of policy-relevant research as majority of research in economics, public policy or in governance is. This is research on how policy analysis itself is carried out and explores improvements. As such, the scope of its influence is far broader than one policy problem, or even an entire policy sector such as environmental policy. When one studies policy analysis itself, what improvements do result from it have potential benefits for the entire spectrum of a 
government's sphere of activity. In that sense, the societal value of this research is even harder to assess than other research that analyses policy solutions for a chosen problem in a select sector. What can be claimed is that even the tiniest added value in a broader work means significant gains for society as they aggregate across the board.

At its very core, this research seeks to improve the practice of policy analysis in small way and that should make governments more efficient in a commensurate way. That benefit would multiply with the number of policy sectors and member states that find worth in trying the proposed adaptation. At its widest scope within the domain of environmental policy, as the introductory words lay it out, a lead in environmental policy could help the economic bloc leverage a competitive advantage in trade with the rest of the world. The introductory chapter gives references that corroborate such a link, but the actual quantification of the value would of course depend on the uptake of the analytical innovation and its success over time. As it happens, the difficulty of quantifying societal benefits from future actions with several uncertain parameters is exhaustively covered within the pages of this thesis.

That being said, this research does puts forth and explores specific original ideas that promise specific potential values.

\subsubsection{What is new?}

This disquisition embarks on the largely unchartered territory of environmental policy analysis in Europe. It asks not what policies are best for what nation, not what barriers and drivers motivate stakeholders in any given sector or any level, nor which policy goals deserve to be higher in the prodder of priorities. It asks not what the most efficient options to solve a particular problem are, but how governments arrive at their answers as to efficiency, whatever the problem at hand. It takes a step back from the environmental content that receives more attention in Europe than perhaps anywhere else, to focus instead on the analytical process that has received less attention.

At the heart of the dissertation is the innovative methodological design proposed for CEA analysis. The suggestion to experiment with unorthodox reference units for CEA comparisons, taking direct inspiration from LCA, is most certainly new in literature. Much of the dissertation is devoted to a discussion of why the omission 
may not indicate a failure on Eugene Bardach's twenty-dollar bill test ${ }^{30}$ (Bardach, 2005, p. 53). Moreover, Bardach's observation concerns policy options, where it applies far more than to analytical methods, which seem to have a slow evolution culture of their own pace. The thesis not only describes this admittedly minor but entirely new design feature, but also tests it with real-world policy relevant data to demonstrate circumstances where it might be worth trying.

This thesis might be one of few works to treat policy instruments with the metaphor of commercial products, inasmuch as, the idea of modifying CEA by toying with reference units, drawing inspiration from LCA, stems directly from that metaphor. (The title Metachoice, Metadata and Metaphor was considered.) It is, after all, not a great stretch ${ }^{31}$. Policy can very well be said to be a product of parliamentary deliberation and democratic policy processes. This research takes the analogy all the way to fruition, in that it derives inspiration from analysis on one side to directly improve that on the other. It also puts the analogy to the test.

Several of the models used towards that purpose were only released very recently (late in year 2010 or sometime in 2011). While few researchers are likely to use it and take the exact same tack on CEA workflow, the timing of the release means that even other research with such data has only recently been enabled.

The very same also true for search data opened up Google. This researcher is aware of hardly any work that uses data from either of the three sources cited here for revelations in policy analysis. Following Google's lead, the focus there too has been on the specific policy questions and solutions, content, in other words, rather than analytical methods or processes.

The insights gained from the interviews, particularly regarding the profession of the policy analyst, would also contribute to the teaching of policy analysis in Europe. Some information indeed does figure in a forthcoming paper by this researcher concerning policy analysis pedagogy, which was first presented at a teaching workshop preceding Association for Policy Analysis and Management (APPAM) annual fall conference in 2011.

\footnotetext{
30 The test tells of an anecdote with two economist friends walking along a street when one notices a $\$ 20$ bill lying on the sidewalk. The other remarks that if no one has yet picked it up, it is unlikely to be a 20-dollar bill lying on the sidewalk. If a seemingly simple good idea seems to have never before occurred to someone, there are either likely good reasons or it is not such a good idea after all

${ }^{31}$ Compare, for instance, the idea of demand and supply for regulation from George Stigler's Theory of Regulation (Stigler, 1971) and the terms it inspired such as a 'Market for Regulation' (Ulen, 1980).
} 


\subsubsection{Potential Values}

Also as part of valorisation, it is worth reiterating (from section 4.3) some of the values that the analytical innovation and subsequent disquisition intended to offer.

While the thesis is of immediate use to analysts in member states of the European Union and those working for "federal" institutions such as the European Commission, the applied aspects can potentially aid any jurisdiction in the world that is reassessing its environmental policies. Indeed, most common aims of environmental thought are likely to fail at the global level unless all nations of the world think and act on common principles.

The analytical innovation will help to construct equivalence between types of instruments for better comparison, by underscoring cost categories that stand out, cost types that are common and their equivalent amounts for a proper comparison. More significantly, the method enables incorporating contextual variables at the point of comparison. In the case of some policy instruments and in some political contexts economic and geographical differences between regions may assume significance. Accounting for and incorporating such contextual factors can often smoothen policy making.

Once the method takes hold, the experienced analyst is expected to arrive at quicker decisions, cheaper decisions and more flexible decisions. In select scenarios, the method might eliminate tedious studies on measuring and monetizing benefits of a policy, especially with regards to finer design matters of an instrument, relying instead on secondary data and theory regarding the generation of the benefits and their relations to contextual parameters.

In federal systems such as the European Union, a federal policy often translates into an overarching legislative framework within the bounds of which governments are then directed to design laws or instruments for their jurisdictions, making design adjustments for contextual variables. The resulting variety of transposed instruments is bound to range in a broad spectrum with regards to several key parameters, costs being the most prominent among them.

Even for a single instrument, variations in costs under certain categories such as enforcement, compliance, monitoring and so forth, can significantly alter its attractiveness as a policy measure. A sensitivity analysis should be a routine consideration in the transposition of EU directives in member states. The very design of the method would help an analyst narrow down on and control critical design factors in the design of policy instruments, specifically for each generic type of instrument. 
A slightly different issue related to transposition in the EU, but nonetheless one that strongly supports the emphasis on hard tangible costs of introducing new policy, arises in areas that progressively fall under the ever-expanding union. The right choices when transposing the directives would benefit immensely from a careful comparison of costs. Expansion involves a government obliged to introduce new instruments, the skeletal frameworks for which were designed long ago. When faced with the more intricate choices in the design of instruments, when it comes down to stipulations for reporting requirements or penalties on noncompliance etc., they need a method that helps them minimize the abrupt, accumulative burden on their economy. Hence, apart from the efficiency gains for individual member states, the methods will speed up policy diffusion in the EU.

The combined improvements to the CEA design provide scope for integrating governance analysis into routine policy analysis: regulation costs such as handling forms, monitoring, wages etc. will reflect on governance structures and help gauge their effect on the potency of policy instruments. Given the enhanced comparative equivalence, analysts can use the method to benchmark administrative costs against other countries. A method geared for the purpose can prove vital in estimating the "distortionary effect" of enforcement costs (Pearce, 2000), for instance.

The constructed equivalence (as explained in section 4.1.2) could serve as a first step to resolving the discussion around "disproportionate costs" (Turner 2007). The concept of proportional costs is tied to the issues and arguments around the 'Precautionary Principle' addressed in section 2.6.3. When one wishes to be cautious, [Cost $<=$ Benefit] may no longer be the chosen 'rational-choice' decision rule. By what factor costs are allowed to exceed measureable benefits is an expression of the degree of precaution. That factor assumed in the decision rule has to counter the claims of disproportionality. A proper frame of reference will go a long way in helping tackle these questions and arm the analyst with justification to cite for the choices.

Similarly, the method will also aid analysis of the effect of interaction between divergent policy sectors. That kind of information is normally lost to analyst simply aggregating costs and comparing them to aggregated benefits. Unless the taxonomy of the costs included is significantly broadened and properly referenced to the context, an analyst cannot design instruments that are fairer and easier to comply with and for those reasons, easier to sell to local industry. 


\subsubsection{Recommendations}

It would be a telling irony if near its conclusion, a dissertation centred on costeffectiveness would harp on recommendations without a systematic study of the cost implications. One cannot lament the neglect of the CBA standard in chapter three and then go on to list a number of things that public agencies ought to do to remedy that fact, when this dissertation has not explicitly measured or commented on the costs that each of those things entail.

Nevertheless, this is a dissertation in Public Policy and as such, its conclusions are bound to have a normative tone regarding public affairs. Also, this endeavour began with the worthy goal of matching European lead in environmental policy in terms of the design of the instruments with the state of the art of policy analysis and perhaps even take it beyond. The aim is to improve the systems and methods used for environmental policy analysis across the board, such that they bring forth the most efficient and hence the most saleable policy solutions. That normative aim is difficult to quantify for the totality of the EU, but if it is deemed worthy, than certain institutional or procedural changes would naturally follow.

- Investing in accounting models alongside technical models, and, in the spirit of the first quantitative case (section 5.2.1) and particularly figure 5-5, program computers to automatically and periodically monitor current policy parameters against up-to-date data for similar thresholds and decision-inflection points.

- Instituting the formal study of policy analysis, not restricted by a sector or academic discipline, in schools of public policy, and graduate programs specializing in policy sectors alike.

- Tying recruitment of personnel to the schools, much in the tradition of business schools. They may be permanent or contractual, but they must be dedicated staff for policy analysis.

- Existing staff may benefit from training, especially with a focus on the impending revolution in data science.

- Coordination towards data-sourcing synergies across policy sectors within a member state and across member states in the EU. 
- Extensive use of free and open data. Governments could spear-head the open data revolution as has already begun happening in some parts of the world (United States Mission to OECD, 2011).

\subsection{Limitations}

Preceding discussion right from the chapters 2 through 7 has made attempts to come candid and clean on the limitations of the research work wherever they were felt. However, three specific limitations deserve reiteration here among the conclusions.

The ideal situation would have been to demonstrate cases built on EU Directives such that the use cases would of instrument choices between member states to illustrate the added value of accommodating context. However, the lack of computerised accounting models for calculating costs of policy instruments precluded such consistent comparison. At the interview stage, some analysts did point to a few such models in their countries and while most of the models were not in the public domain, for some where there was faint promise, it was rather late in the research process to navigate the access regime.

Secondly, the profile of the interviewees could have been coordinated to be more uniform. That would have been easier through a professional organisation such as a European counterpart of the Association for Policy Analysis and Management (APPAM) in USA or an alumni association from an academic school of Public Policy, of which the few across the EU happen to be all quite young.

The proposed adaptation assumes linearity among the various parameters used to modify the reference unit. That is a generally tenable assumption for the quantitative cases chosen, but also arguably in other cases, at least as a first approximation. For instance, when constructing the unit 'dollar per ton NOx per unit labour cost', the assumption that the pollution mitigation costs vary linearly with respect to labour inputs is implied. Firstly, because we use an accounting model, it should be possible to check the relationship assumed, which is likely to be linear. In cases where not, ceteris paribus, between two use contexts for an instrument, the assumption of linearity is good for a comparison by first approximation. In certain cases, however, given the political or economic context, it is conceivable that the assumption may have a significant bearing on an element of the design of a policy instrument that hurts an interested party. 


\subsection{Further Research}

One certain prospect for further research would naturally be to attempt to overcome the limitations cited above. Government agencies could aid the research effort by releasing to the public domain any accounting models they do use. This might also allow for collaborating with universities to develop them to a high standard.

Likewise, the dialogue with policy analysts could also be expanded to a wider area and in a coordinated manner, perhaps with project assistance from a European public institution, especially given the benefits to the European Union emphasized earlier.

The direction that the author intends to pursue in the near future though is to pick up where this dissertation leaves off with the previous chapter in particular. To serve the purposes of and within the scope of this dissertation, chapter 7 only scratches the surface of the potential of Big Data. The prospect of someday improving analysis and developing policy analysis in anticipation of the impending data revolution remains an inviting one. 


\section{References}

Accenture. (2012). Government Analytics: What Governments Stand to Gain (or Lose). London. Retrieved from http://www.accenture.com/us-en/Pages/insightgovernment-analytics-what-governments-stand-gain-lose.aspx

ACCF. (2007, May). International Comparison of Depreciation Rules International Comparison of Depreciation Rules. Retrieved January 8, 2008, from http://www.accf.org/publications/reports/sr-intdepreciationrules.html

Ackerman, F., \& Heinzerling, L. (2002). Pricing the Priceless: Cost-Benefit Analysis of Environmental Protection. University of Pennsylvania Law Review, 150(5), 1553-1584.

Adey, R. (1992). Letters. Economist, 323(7764), 6-8. doi:Letter

Adler, M. D., \& Posner, E. A. (Eds.). (2001). Cost-benefit analysis: legal, economic, and philosophical perspectives. Chicago: University of Chicago Press.

Adler, M., \& Posner, E. A. (2006). New foundations of cost-benefit analysis. Harvard Univ Press.

Adler, M., \& Posner, E. A. (2009). New foundations of cost-benefit analysis. Regulation \& Governance, 3(1), 72-83. doi:10.1111/j.1748-5991.2009.01045.x

Agichtein, E., Brill, E., \& Dumais, S. (2006). Improving web search ranking by incorporating user behavior information. In Proceedings of the 29th annual international ACM SIGIR conference on Research and development in information retrieval (pp. 19-26). New York, NY, USA: ACM. doi:10.1145/1148170.1148177

Albrecht, J. (2006). The use of consumption taxes to re-launch green tax reforms. International Review of Law and Economics, 26(1), 88.

Aldhous, P. (2011, August 18). Internet databases reveal new uses for old drugs. New Scientist, (2826). Retrieved from http://www.newscientist.com/article/mg21128264.800-internet-databasesreveal-new-uses-for-old-drugs.html

APPAM, NASPAA, \& ASPA. (2008). Public Service Careers. Retrieved April 22, 2014, from http://publicservicecareers.org/ 
App to aid hunt for rare insect. (2013, May 31). BBC. Retrieved from

http://www.bbc.co.uk/news/uk-england-hampshire-22729217

Arbesman, S. (2013, January 29). Stop Hyping Big Data and Start Paying Attention to "Long Data." Wired. Retrieved from http://www.wired.com/opinion/2013/01/forget-big-data-think-long-data/

Arrow, K. J., Cropper, M. L., Eads, G. C., Hahn, R. W., Lave, L. B., Noll, R. G., ... Stavins, R. N. (1996). Is There a Role for Benefit-Cost Analysis in Environmental, Health, and Safety Regulation? Science, 272(5259), 221-222. doi:10.1126/science.272.5259.221

Ashford, N. A. (1981). Alternatives to Cost-Benefit Analysis in Regulatory Decisions. Annals of the New York Academy of Sciences, 363(1), 129-137.

Bailey, M. J., \& Jensen, M. C. (1972). Risk and the Discount Rate for Public Investment. In M. C. Jensen (Ed.), Studies In The Theory Of Capital Markets (pp. 269-93). New York: Praeger Publishers. Retrieved from http://papers.ssrn.com/sol3/papers.cfm?abstract_id=390110

Bailey, P. D., Haq, G., \& Gouldson, A. (2002). Mind the gap! Comparing ex ante and ex post assessments of the costs of complying with environmental regulation. European Environment, 12(5), 245-256.

Bardach, E. (2005). A practical guide for policy analysis : the eightfold path to more effective problem solving. Washington, D.C.: CQ Press. Retrieved from http://www.loc.gov/catdir/toc/ecip0422/2004020091.html

Bernstein, A. (1999). Precaution and Respect. In C. Raffensperger \& J. A. Tickner (Eds.), Protecting public health \& the environment: implementing the precautionary principle. Washington D.C.: Island Press.

Black, R. (2010, May 10). Nature loss "to damage economies." BBC. Retrieved from http://news.bbc.co.uk/2/hi/science_and_environment/10103179.stm

Bluffstone, R., Semeniene, D., \& Jantzen, J. (2003). How Much Will It Cost to Join the Club? The Extra Costs of Approximating Lithuanian Environmental Laws with Those of the European Union. Environmental and Resource Economics, 26(2), 279-303.

Blumenstock, J., Eagle, N., \& Fafchamps, M. (2012). Charity and Reciprocity in Mobile Phone-Based Giving in the Aftermath of Earthquakes and Natural Disasters. Retrieved from http://users.ox.ac.uk/ econ0087/earthquakes.pdf 
Boardman, A. E., \& Greenberg, D. H. (1998). Discounting Factor and the Social Discount Rate. In F. Thomson \& M. T. Green (Eds.), Hanbook of Public Finance. New York: Marcel Dekker.

Boardman, A. E., Greenberg, D. H., Vining, A. R., \& Weimer, D. L. (1997). “Plugin" shadow price estimates for policy analysis. The Annals of Regional Science, 31(3), 299-324.

Boardman, A. E., Vining, A., \& Waters, W. G. (1993). Costs and benefits through bureaucratic lenses: Example of a highway project. Journal of Policy Analysis and Management, 12(3), 532-555. doi:10.2307/3325305

Bomberg, E. (1994). Policy Networks on the Periphery: EU Environmental Policy and Scotland. In S. Baker, K. Milton, \& S. Yearley (Eds.), Protecting the Periphery: Environmental Policy in Peripheral Regions of the European Union. Psychology Press.

Boyd, D., \& Crawford, K. (2011). Six Provocations for Big Data. Presented at the A Decade in Internet Time: Symposium on the Dynamics of the Internet and Society, Oxford. Retrieved from http://papers.ssrn.com/sol3/papers.cfm?abstract_id=1926431

Bressers, H., \& Klok, P.-J. (1988). Fundamentals for a Theory of Policy Instruments. International Journal of Social Economics, 15(3/4), 22 - 41. doi:10.1108/eb014101

Bromley, D. W. (1990). The ideology of efficiency: Searching for a theory of policy analysis. Journal of Environmental Economics and Management, 19(1), 86-107.

Bryne, J. (1987). Policy Analysis and the Administrative State: The Political Economy of Cost-Benefit Analysis. In F. Fischer \& J. Forester (Eds.), Confronting Values in Policy Analysis: The Politics of Criteria. Newbury Park: Sage Publications.

Building with big data. (2011, May 26). The Economist. Retrieved from http://www.economist.com/node/18741392

Burwell, S. (2014, February 7). 2014 Discount Rates for OMB Circular No. A-94. Memorandum. Retrieved from http://www.whitehouse.gov/sites/default/files/omb/memoranda/2014/m14-05.pdf

Camerer, C., Issacharoff, S., Loewenstein, G., O’Donoghue, T., \& Rabin, M. (2003). Regulation for Conservatives: Behavioral Economics and the Case for 
“Asymmetric Paternalism." University of Pennsylvania Law Review, 151(3), 1211-1254.

Carnegie Mellon University Green Design Institute. (2013). Economic Input-Output Life Cycle Assessment (EIO-LCA) Germany (58 sectors) Producer model. Retrieved from http://www.eiolca.net/

Cellini, S. R., \& Kee, J. E. (2010). Cost-Effectiveness and Cost-Benefit Analysis. In Handbook of Practical Program Evaluation (Third.). Wiley: Jossey-Bass.

Center for Progressive Reform: OMB and Cost-Benefit Analysis. (n.d.). Retrieved July 2, 2009, from http://www.progressiveregulation.org/costBenefit.cfm

China leads world in green energy investment. (2011, September 15). BBC.

Retrieved from http://www.bbc.co.uk/news/business-14201939

Christie, M. (2001). A comparison of alternative contingent valuation elicitation treatments for the evaluation of complex environmental policy. Journal of Environmental Management, 62(3), 255-269.

Christoforou, T. (2004). The Precautionary Principle, Risk Assessment, and the Comparative Role of Science in the EC and the US Legal Systems. In M. G. Faure \& N. J. Vig (Eds.), Green giants? Environmental policies of the United States and the European Union. MIT Press.

Clements, P. (1992). Letters. Economist, 323(7764), 6-8. doi:Letter

Coase, R. H. (1960). The problem of social cost. The Journal of Law and Economics, $3(1), 1$.

Cole, D. H., \& Grossman, P. Z. (2002). Toward a Total-Cost Approach to Environmental Instrument Choice, 223-241.

Cost-benefit analysis. (2009, September 15). Retrieved February 20, 2010, from http://www.economist.com/businessfinance/management/displaystory.cf m?story_id=E1_TQNJRRPR

Crandall, R. W. (1981). The Use of Cost-Benefit Analysis in Regulatory DecisionMaking. Annals of the New York Academy of Sciences, 363(1), 99-107.

Cuttle, S., McLeod, C., Chadwick, D., Scholefield, D., Haygarth, P., Newell-Price, P., ... Humphrey, R. (2006). An inventory of methods to control diffuse water pollution from agriculture - User manual DEFRA project ES0203. DEFRA / ADAS UK Ltd. Retrieved from 
http://randd.defra.gov.uk/Document.aspx?Document=es0203_4145_FRA.p df

Data.gov. (n.d.). Retrieved January 16, 2012, from http://www.data.gov/

Davis, F. D., Bagozzi, R. P., \& Warshaw, P. R. (1989). User Acceptance of Computer Technology: A Comparison of Two Theoretical Models. Management Science, 35(8), 982-1003.

DEFRA. (2010). Cost Curves for Diffuse (Water) Pollutants - FARMSCOPER, DEFRA Project WQ0106. Retrieved February 21, 2011, from http://randd.defra.gov.uk/Default.aspx?Menu=Menu\&Module=More\&Loc ation=None\&Completed $=0 \&$ ProjectID $=14421$

Dekker, T. (2008). Desert and Distributive Efficiency. Éthique et Économique, 5(2). Retrieved from https://papyrus.bib.umontreal.ca/jspui/handle/1866/3405

Denis, C., \& Koopman, G. (1998, November). EUCARS: A Partial Equilibrium EUropean CAR emissions Simulation model, Version 3.0. European Commission. DG II, Economic Papers No. 130. Retrieved from http://ec.europa.eu/economy_finance/publications/publication11201_en.pd $\mathrm{f}$

Denzin, N. K., \& Lincoln, Y. S. (1994). Handbook of qualitative research. Newbury Park, CA: Sage Publications.

DOE. (1991). Policy appraisal and the environment. HMSO, London.

Driesen, D. M. (n.d.). Is Cost-Benefit Analysis Neutral? SSRN eLibrary. Retrieved from http://papers.ssrn.com/sol3/papers.cfm?abstract_id=708402

Dryzek, J. (1982). Policy analysis as a hermeneutic activity. Policy Sciences, 14(4), 309-329. doi:10.1007/BF00137394

Dumbill, E. (2012, January 11). What is big data? Retrieved from http://radar.oreilly.com/2012/01/what-is-big-data.html

Dunn, W. N. (2007). Public Policy Analysis: An Introduction (4th ed.). Prentice Hall.

Eagle, N., de Montjoye, Y.-A., \& Bettencourt, L. M. (2009). Community computing: Comparisons between rural and urban societies using mobile phone data. Computational Science and Engineering, 4, 144-150.

Elster, J., \& Roemer, J. E. (Eds.). (1993). Interpersonal comparisons of well-being. Cambridge University Press. 
Eroglu K., \& Goodrich D. (1998). Regulatory compliance, a manufacturer's perspective. Electromagnetic Compatibility, 1998. 1998 IEEE International Symposium on, 1, 250-252 vol.1.

ESS: Big Data for Social Good. (n.d.). Retrieved January 16, 2012, from http://www.hsph.harvard.edu/ess/bigdata.html

EU. (2014, February 26). Your Europe: Access to public service positions in other EU countries. Retrieved April 22, 2014, from http://europa.eu/youreurope/citizens/work/finding-job-abroad/access-tojobs-in-the-public-sector/index_en.htm

EU. (n.d.). EU Careers. Retrieved April 22, 2014, from http://europa.eu/epso/index_en.htm

European Commission. (2007, December 21). Press release IP/07/1985: Commission takes steps to cut industrial emissions further. Retrieved from http://europa.eu/rapid/press-release_IP-07-1985_en.htm

European Commission. (2011). EU environment policy supporting jobs and growth. Luxembourg. Retrieved from http://ec.europa.eu/environment/enveco/industry_employment/pdf/facts_a nd_figures.pdf

European Commission. (n.d.). LCA Web Site. Retrieved January 27, 2010, from http://lct.jrc.ec.europa.eu/about-lca-lct

Europe Industrial Center. (n.d.). Retrieved October 14, 2009, from http://www.mapsofworld.com/europe/industrial-center.html

Evans, D. J. (2005). The Elasticity of Marginal Utility of Consumption: Estimates for 20 OECD Countries*. Fiscal Studies, 26(2), 197-224. doi:10.1111/j.14755890.2005.00010.x

Executive Office of the President of USA. (2013, July 26). Memo: Next Steps in the Evidence and Innovation Agenda. Office of Management and Budget. Retrieved from http://www.whitehouse.gov/sites/default/files/omb/memoranda/2013/m13-17.pdf

Executive Order 12291. (1981, February 17). Retrieved July 3, 2009, from http://en.wikisource.org/wiki/Executive_Order_12291 
Executive Order 12866. (1993, September 30). Retrieved July 3, 2009, from http://en.wikisource.org/wiki/Executive_Order_12866

Executive Order 13258. (2002, February 26). Retrieved July 3, 2009, from http://en.wikisource.org/wiki/Executive_Order_13258

Executive Order 13422. (2007, January 18). Retrieved July 3, 2009, from http://en.wikisource.org/wiki/Executive_Order_13422

Executive Order 13497. (2009, January 30). Retrieved July 3, 2009, from http://en.wikisource.org/wiki/Executive_Order_13497

Faure, M. G. (2008). Designing Incentives Regulation for the Environment. Working Paper, SSRN eLibrary. Retrieved from http://papers.ssrn.com/sol3/papers.cfm?abstract_id=1290523

Faure, M. G., \& Niessen, N. (2006). Environmental law in development: Lessons from the Indonesian Experience by Michael Faure. Edward Elgar Publishing.

Fehrenbacher, K. (2011, October 24). How big data will help manage a world of 7 billion people. Retrieved October 28, 2011, from http://gigaom.com/cleantech/how-big-data-will-help-manage-a-world-of7-billion-people/

Forbes, V. E., \& Calow, P. (2006). Ecology in a cost-benefit society: the issues. Integrated Environmental Assessment and Management, 2(2), 154-5.

Friedman, B. D. (1995). Regulation in the Reagan-Bush Era: The Eruption of Presidential Influence. University of Pittsburgh Press.

Friedman, T. L. (2009, December 9). Going Cheney on Climate. The New York Times. Retrieved from http://www.nytimes.com/2009/12/09/opinion/09friedman.html

Fullerton, D., \& West, S. E. (2002). Can Taxes on Cars and on Gasoline Mimic an Unavailable Tax on Emissions? Journal of Environmental Economics and Management, 43(1), 135-157. doi:10.1006/jeem.2000.1169

Garber, A. M., \& Phelps, C. E. (1997). Economic foundations of cost-effectiveness analysis. Journal of Health Economics, 16(1), 1-31. doi:10.1016/S01676296(96)00506-1

Geva-May, I., Nasi, G., Turrini, A., \& Scott, C. (2008). MPP programs emerging around the world. Journal of Policy Analysis and Management, 27(1), 187-204. doi:10.1002/pam.20314 
Ginsberg, J., Mohebbi, M. H., Patel, R. S., Brammer, L., Smolinski, M. S., \& Brilliant, L. (2008). Detecting influenza epidemics using search engine query data. Nature, 457(7232), 1012-1014. doi:10.1038/nature07634

González, M. C., Hidalgo, C. A., \& Barabási, A.-L. (2008). Understanding individual human mobility patterns. Nature, 453(7196), 779-782. doi:10.1038/nature06958

Gooday, R., \& Anthony, S. (2010). Mitigation Method-Centric Framework for Evaluating Cost-Effectiveness Defra Project WQ0106 (Module 3). DEFRA / ADAS UK Ltd. Retrieved from http://sciencesearch.defra.gov.uk/Default.aspx?Menu=Menu\&Module=Mo re\&Location=None\&Completed $=0 \&$ ProjectID $=14421$

Google. (n.d.). What do the numbers on the graph mean? Insights for Search Help. Retrieved January 15, 2012, from http://support.google.com/insights/bin/answer.py?hl=enGB\&answer $=87285$

Google Flu Trends: How does this work? (n.d.). Retrieved January 15, 2012, from http://www.google.org/flutrends/about/how.html

Goulder, L. H., Parry, I. W. H., Williams, R. C. W., \& Burtraw, D. (1999). The costeffectiveness of alternative instruments for environmental protection in a second-best setting. Journal of Public Economics, 72(3), 329-360. doi:10.1016/S0047-2727(98)00109-1

Gubrium, J. F., \& Holstein, J. A. (2002). Handbook of Interview Research : Context E Method. SAGE.

Hahn, R. W., \& Litan, R. E. (2005). Counting Regulatory Benefits and Costs: Lessons for the US and Europe. J Int Economic Law, 8(2), 473-508. doi:10.1093/jielaw/jgi030

Hajkowicz, S. (2008). Rethinking the economist's evaluation toolkit in light of sustainability policy. Sustainability: Science Practice and Policy, 4(1).

Halpern, C. (2010). Governing Despite its Instruments? Instrumentation in EU Environmental Policy. West European Politics, 33(1), 39-57. doi:10.1080/01402380903354064

Hanke, S. H., \& Anwyll, J. B. (1980). On the discount rate controversy. Public Policy, 28(2), 171-183. 
Haq, G., Bailey, P. D., Chadwick, M. J., Forrester, J., Kuylenstierna, J., Leach, G., ... Oberthur, S. (2001). Determining the costs to industry of environmental regulation. European Environment, 11(3), 125-139.

Hardin, G. (1968). The Tragedy of the Commons. Science, 162(3859), 1243-1248. doi:10.1126/science.162.3859.1243

Hargreaves, S. (2013, April 17). China trounces U.S. in green energy investments. CNNMoney. Retrieved from http://money.cnn.com/2013/04/17/news/economy/china-greenenergy/index.html

Hausmann, R., \& Hidalgo, C. (2011). The Network Structure of Economic Output. Journal of Economic Growth, 16, 309-342.

Helft, M. (2008, November 12). Google Uses Searches to Track Flu's Spread. The New York Times. Retrieved from

http://www.nytimes.com/2008/11/12/technology/internet/12flu.html

Helm, D. (1998). The assessment: environmental policy objectives, instruments, and institutions. Oxf Rev Econ Policy, 14(4), 1-19. doi:10.1093/oxrep/14.4.1

Hertin, J., Jacob, K., Pesch, U., \& Pacchi, C. (2009). The production and use of knowledge in regulatory impact assessment - An empirical analysis. Forest Policy and Economics, 11(5-6), 413-421. doi:10.1016/j.forpol.2009.01.004

Heyde, J. M. (1995). Is contingent valuation worth the trouble? The University of Chicago Law Review, 62(1), 331-363.

Hicks, J. R. (1939). The foundations of welfare economics. The Economic Journal, 49(196), 696-712.

Hindle, T. (2008). Guide to management ideas and gurus. London: Profile.

HMT. (2003). Green book: appraisal and evaluation in central government. HMSO, London.

Ho, L. S. (2000). The nature of optimal public policy. International Journal of Social Economics, 27(7/8/9/10), 1013-1019. doi:10.1108/03068290010337422

Hopkins, W. (2008). Research Designs: Choosing and Fine-tuning a Design for Your Study. Sportscience, 12, 12-21. 
Humbeeck, P. V. (2006). Data Collection for Cost Estimation in Regulatory Impact Analysis. European Network for Better Regulation. Retrieved from http://www.enbr.org/public/Van\%20Humbeeck.pdf

Hur, Y., \& Hackbart, M. (2009). MPA vs. MPP: A Distinction Without a Difference? Journal of Public Affairs Education, 397-424.

ICS. (2004, April). Cry wolf - predicted costs by industry in the face of new regulations. International Chemical Secretariat. Retrieved from http://www.chemsec.org/downloads/?filename=Cry_wolf_report.pdf

Jefferies, D. (2011, August 18). How the "internet of things" could radically change local government. Guardian. Retrieved from http://www.guardian.co.uk/local-governmentnetwork/2011/aug/18/internet-of-things-local-government

Johannesson, M. (1995). The relationship between cost-effectiveness analysis and cost-benefit analysis. Social Science $\mathcal{E}$ Medicine, 41(4), 483-489. doi:10.1016/0277-9536(94)00353-U

Jordan, A., \& Adelle, C. (2012). Environmental Policy in the EU: Actors, Institutions and Processes. Routledge.

Judson, O. (2009, December 8). A Wild Celebration - Opinionator Blog NYTimes.com. Retrieved from http://opinionator.blogs.nytimes.com/2009/12/08/a-wild-celebration/

Kahneman, D. (2003). Maps of Bounded Rationality: Psychology for Behavioral Economics. The American Economic Review, 93(5), 1449-1475.

Kaldor, N. (1939). Welfare propositions of economics and interpersonal comparisons of utility. The Economic Journal, 49(195), 549-552.

Kaplan, N., Soderberg, E., Pickett, D., \& Meyers, J. (1994). IAPCS: A Computer Model that Evaluates Pollution Control Systems for Utility Boilers. Air $\mathcal{E}$ Waste, 44(6), 773-780. doi:10.1080/1073161X.1994.10467279

Kaplow, L., \& Shavell, S. (2002). Fairness versus welfare. Harvard University Press.

Kau, J. B., Keenan, D., \& Rubin, P. H. (1982). A General Equilibrium Model of Congressional Voting. The Quarterly Journal of Economics, 97(2), 271-293. doi:10.2307/1880758

Kemp, M. C., \& Pezanis-Christou, P. (1999). Pareto's compensation principle. Social Choice and Welfare, 16(3), 441-444. doi:10.1007/s003550050154 
Keohane, N. O., Revesz, R. L., \& Stavins, R. N. (1996). The Positive Political Economy of Instrument Choice in Environmental Policy. SSRN eLibrary. Retrieved from http://papers.ssrn.com/sol3/papers.cfm?abstract_id=5096

Kitchenham, B. A., \& Pickard, L. M. (1998). Evaluating software engineering methods and tools: part 9: quantitative case study methodology. SIGSOFT Softw. Eng. Notes, 23(1), 24-26. doi:10.1145/272263.272268

Knetsch, J. L. (1995). Assumptions, behavioral findings, and policy analysis. Journal of Policy Analysis and Management, 14(1), 68-78. doi:10.2307/3325433

Knight, W. (2009, August 17). Energy-Aware Internet Routing. Technology Review. Retrieved from http://www.technologyreview.com/business/23248/

Kolb, J. A., \& Scheraga, J. D. (1990). Discounting the benefits and costs of environmental regulations. Journal of Policy Analysis and Management, 9(3), 381-390. doi:10.2307/3325282

Kopp, R. J. (1992). Why existence value should be used in cost-benefit analysis. Journal of Policy Analysis and Management, 11(1), 123-130. doi:10.2307/3325136

Kopp, R. J. (1993). Environmental economics: not dead but thriving. Resources, (Spring), 7-12.

Krumme, C., Llorente, A., Cebrian, M., Pentland, A., \& Moro, E. (2013). The predictability of consumer visitation patterns. Scientific Reports, 3. doi:10.1038/srep01645

Lasswell, H. D. (1956). The decision process : seven categories of functional analysis. College Park: Bureau of Governmental Research, College of business and Public Administration, University of Maryland.

Lazer, D., Kennedy, R., King, G., \& Vespignani, A. (2014). The Parable of Google Flu: Traps in Big Data Analysis. Science, 343(6176), 1203-1205. doi:10.1126/science.1248506

Leontief, W. (1970). Environmental Repercussions and the Economic Structure: An Input-Output Approach. The Review of Economics and Statistics, 52(3), 26271.

Leroy, P., \& Crabbé, A. (2008). The Handbook of Environmental Policy Evaluation. Earthscan. 
Lévêque, F. (2000). Why environmental policy instruments in textbooks are not used whereas used instruments are not studied. In Conference at the Donald Bren School Environmental Sciences and Management. University of California, Santa-Barbara. Retrieved from http://www.cerna.ensmp.fr/Documents/FL-ConfSantaBarbara.pdf

Levi-Faur, D. (Ed.). (2012). The Oxford Handbook of Governance. Oxford University Press.

Lewis, B. (2013, November 14). Europe cannot afford to give up climate leadershipreport. Reuters. Brussels. Retrieved from http://www.reuters.com/article/2013/11/14/us-climate-talks-euidUSBRE9AD00Z20131114

Linder, S. H., \& Peters, B. G. (1984). From Social Theory to Policy Design. Journal of Public Policy, 4(3), 237-259.

Lind, R. C. (1982). A primer on the major issues relating to the discount rate for evaluating national energy options. In R. C. Lind, K. Arrow, \& G. R. Corey (Eds.), Discounting for Time and Risk in Energy Policy (pp. 21-94). Washington, D.C.: Resources for the Future.

Lind, R. C., Arrow, K. J., Corey, G. R., Dasgupta, P., Sen, A. K., Stauffer, T., ... Stockfisch, J. A. (2013). Discounting for Time and Risk in Energy Policy. Routledge.

Lipton, E. (2010, May 12). With Obama, Regulations Are Back in Fashion. The New York Times. Retrieved from http://www.nytimes.com/2010/05/13/us/politics/13rules.html?scp=1\&sq=re gulatory+philosophy\&st=nyt

List, J. (2007, October 15). What Can Policymakers Learn from Experimental Economics? Resources for the Future. Retrieved from http://www.rff.org/rff/News/Weekly_Policy_Commentary/10_12_07_List_ Commentary.cfm

Litman, T. (2001). What's it worth? Economic Evaluation For Transportation Decision-Making. Presented at the Internet Symposium on Benefit-Cost Analysis, Canada: Victoria Transport Policy Institute. Retrieved from http://www.vtpi.org/worth.pdf

Lord, J., Laking, G., \& Fischer, A. (2006). Non-linearity in the cost-effectiveness frontier. Health Economics, 15(6), 565-577. doi:10.1002/hec.1083 
MacLeod, Harrington, W., \& Morgenstern, R. D. (2006, March 14). Comparing the Ex ante and Ex post Costs of Complying with Regulatory Changes.

DEFRA. Retrieved from

http://www2.defra.gov.uk/science/project_data/DocumentLibrary/SD14011 \%5CSD14011_3366_FRP.pdf

Magalini, F., \& Huisman, J. (2006). Compliance key factors of the EU WEEE directive - how far is one from a full implementation? Electronics and the Environment, 2006. Proceedings of the 2006 IEEE International Symposium on, 1 pp.

Manzoni, V., Maniloff, D., Kloeckl, K., \& Ratti, C. (2010). Transportation mode identification and real-time CO2 emission estimation using smartphones. Cambridge Mass.: Massachusetts Institute of Technology. Retrieved from senseable.mit.edu/co2go/images/co2go-technical-report.pdf

Mayer-Schönberger, V., \& Cukier, K. (2013). Big data: a revolution that will transform how we live, work, and think. Boston: Houghton Mifflin Harcourt.

Micro stars, macro effects. (2012, November 24). The Economist. Retrieved from http://economist.com/news/21567079-meet-economists-who-are-makingmarkets-work-better-micro-stars-macro-effects

Moore, M. A., Boardman, A. E., \& Vining, A. R. (2013). The choice of the social discount rate and the opportunity cost of public funds. Journal of BenefitCost Analysis, 4(3). doi:10.1515/jbca-2013-0023

Moore, M. A., Boardman, A. E., Vining, A. R., Weimer, D. L., \& Greenberg, D. H. (2004). "Just give me a number!" Practical values for the social discount rate. Journal of Policy Analysis and Management, 23(4), 789-812. doi:10.1002/pam.20047

Moyer, E., Woolley, M., Glotter, M., \& Weisbach, D. A. (2013). Climate Impacts on Economic Growth as Drivers of Uncertainty in the Social Cost of Carbon. Coase-Sandor Institute for Law and Economics Working Paper, 652.

Nature loss "to damage economies." (2010, May 10). BBC. Retrieved from http://news.bbc.co.uk/2/hi/science_and_environment/10103179.stm

Nevskaya, Y., \& Albuquerque, P. (2012). A Continuous Time Model of Product Usage: Measuring the Effect of Product Design and Rewards in Online Games (SSRN Scholarly Paper No. ID 2098915). Rochester, NY: Social Science Research Network. Retrieved from http://papers.ssrn.com/abstract=2098915 
Newell-Price, J. P., Harris, D., Taylor, M., Williams, J. R., Anthony, S. G., Duethmann, D., ... Misselbrook, T. H. (2011). An Inventory of Mitigation Methods and Guide to their Effects on Diffuse Water Pollution, Greenhouse Gas Emissions and Ammonia Emissions from Agriculture - Defra project WQ0106. DEFRA / ADAS UK Ltd. Retrieved from http://randd.defra.gov.uk/Document.aspx?Document=MitigationMethodsUserGuideDecember2011FINAL.pdf

Obama, B. (2009, April 23). The White House - Press Office - Presidential Memorandum Regarding Regulatory Review. Retrieved July 2, 2009, from http://www.whitehouse.gov/the_press_office/Presidential-MemorandumRegarding-Regulatory-Review/

OECD. (2008). OECD environmental outlook to 2030. Retrieved from http://www.oecd.org/document/22/0,3343,en_2649_34487_40221270_1_1_1 _1,00.html

Ogas, O. (2013, February 8). Beware the Big Errors of "Big Data." Wired. Retrieved from http://www.wired.com/opinion/2013/02/big-data-means-big-errorspeople/

Ogus, A. I. (2006). Costs and cautionary tales. Hart Publishing.

OMB. (1996, January 11). Economic Analysis of Federal Regulations Under Executive Order 12866. Retrieved January 5, 2008, from http://www.whitehouse.gov/omb/inforeg/riaguide.html\#iii

O’Neill, C., \& Sinden, A. (2009, May 12). The cost-benefit dodge. Retrieved July 3, 2009, from http://www.philly.com/inquirer/opinion/20090512_The_costbenefit_dodge.html

Oxford's government school opens. (2012, September 20). BBC. Retrieved from http://www.bbc.co.uk/news/uk-england-oxfordshire-19652277

Pareto, V. (1894). Il massimo di utilità dato dalla libera concorrenza. Giornale Degli Economisti, 2(9), 48-66.

Park, J.-H., Goldstein, A. H., Timkovsky, J., Fares, S., Weber, R., Karlik, J., \& Holzinger, R. (2013). Active Atmosphere-Ecosystem Exchange of the Vast Majority of Detected Volatile Organic Compounds. Science, 341(6146), 643647. doi:10.1126/science.1235053

Payne, J., \& Bettman, J. R. (1993). The Adaptive Decision Maker. 
Pearce, D. W. (1994). The precautionary principle and economic analysis. In T. O'Riordan \& J. Cameron (Eds.), Interpreting the precautionary principle (pp. 132-151). London: Earthscan.

Pearce, D. W. (1998). Cost benefit analysis and environmental policy. Oxf Rev Econ Policy, 14(4), 84-100. doi:10.1093/oxrep/14.4.84

Pearce, D. W. (2000). Cost-benfit analysis and environmental policy. In D. Helm (Ed.), Environmental policy: objectives, instruments, and implementation. Oxford University Press.

Pearce, D. W., Atkinson, G., \& Mourato, S. (2006). Cost-benefit analysis and the environment: recent developments. OECD Publishing.

Pfleeger, S. L. (1994). Design and analysis in software engineering: the language of case studies and formal experiments. SIGSOFT Softw. Eng. Notes, 19(4), 1620. doi:10.1145/190679.190680

Pizer, W. (1997). Prices vs. Quantities Revisited: The Case of Climate Change. Resources For the Future. Retrieved from http://ideas.repec.org/p/rff/dpaper/dp-9802.html

Porter, M., \& van der Linde, C. (1995). Toward a New Conception of the Environment-Competitiveness Relationship. The Journal of Economic Perspectives, 9(4), 118, 97.

Posner, R. (1972). Economic Analysis of Law. Boston,: Little, Brown.

Posner, R. (2000). Cost-Benefit Analysis: Definition, Justification, and Comment on Conference Papers. The Journal of Legal Studies, 29(s2), 1153-1177.

Radaelli, C. (2009). Desperately Seeking Regulatory Impact Assessments: Diary of a Reflective Researcher. Evaluation, 15(1), 31-48. doi:10.1177/1356389008097870

Radaelli, C. M. (2004a). Getting to Grips with Quality in the Diffusion of Regulatory Impact Assessment in Europe. Public Money \& Management, 24(5), 271-276. doi:Article

Radaelli, C. M. (2004b). The diffusion of regulatory impact analysis-Best practice or lesson-drawing? European Journal of Political Research, 43(5), 723-747.

Radaelli, C. M. (2005). Diffusion without convergence: how political context shapes the adoption of regulatory impact assessment. Journal of European Public Policy, 12(5), 924. doi:10.1080/13501760500161621 
Raffensperger, C., \& Tickner, J. (Eds.). (1999). Protecting Public Health and the Environment: Implementing The Precautionary Principle. Island Press.

Red light, green light. (2014, March 8). The Economist. Retrieved from http://www.economist.com/news/business/21598670-chinas-anti-pollutiondrive-will-make-it-good-place-clean-energy-firms-red-light-green

Reiner, P. (2013, August 13). Are You Willing to Be Nudged Into Making the Right Decision? Retrieved from http://www.slate.com/blogs/future_tense/2013/08/13/research_shows_whe n_nudging_works_and_when_it_doesn_t.html

Renda, A. (2011). Law and Economics in the RIA World.

Revesz, R. L., \& Stavins, R. N. (2007). Environmental Law and Policy. In M. A. Polinsky \& S. Shavell (Eds.), The Handbook of Law and Economics. Amsterdam/Boston: North Holland / Elsevier. Retrieved from http://www.hks.harvard.edu/fs/rstavins/Papers/Environmental_Law_and_ Policy_Handbook_Chapter_by_Revesz_\&_Stavins.pdf

Richardson, H. (2000). The Stupidity of the Cost-Benefit Standard. The Journal of Legal Studies, 29(s2), 971-1003.

Robbins, J. (2013, August 19). Crowdsourcing, for the Birds. The New York Times. Retrieved from http://www.nytimes.com/2013/08/20/science/earth/crowdsourcing-for-thebirds.html

Rosenthal, D. H., \& Nelson, R. H. (1992). Why existence value should not be used in cost-benefit analysis. Journal of Policy Analysis and Management, 11(1), 116-122. doi:10.1002/pam.4050110109

Rosman, K. (2013, August 14). Weather Channel Now Also Forecasts What You'll Buy. Wall Street Journal. Retrieved from http://online.wsj.com/article/SB10001424127887323639704579012674092402 660.html

Rousseau, S., \& Proost, S. (2005). Comparing Environmental Policy Instruments in the Presence of Imperfect Compliance - A Case Study. Environmental and Resource Economics, 32(3), 337-365.

Sagoff, M. (2008). The economy of the earth. Cambridge University Press. 
Samuelson, W., \& Zeckhauser, R. (1988). Status quo bias in decision making. Journal of Risk and Uncertainty, 1(1), 7-59. doi:10.1007/BF00055564

Saretzki, T. (2007). The Policy Turn in German Political Science. In F. Fischer, G. Miller, \& M. S. Sidney (Eds.), Handbook of Public Policy Analysis (p. 587).

Schmid, A. A. (1989). Benefit-Cost Analysis: A Political Economy Approach (illustrated edition.). Westview Press.

Sen, A. (2000). The Discipline of Cost-Benefit Analysis. The Journal of Legal Studies, 29(s2), 931-952.

SEPA. (2006). Swedish charge on nitrogen oxides - Cost-effective emission reduction. Swedish Environmental Protection Agency, Stockholm. Retrieved from http://www.naturvardsverket.se/Documents/publikationer/620-8245-0.pdf

Shapiro, S., \& Schroeder, C. (2008). Beyond Cost-Benefit Analysis: A Pragmatic Reorientation. Harvard Environmental Law Review, 32(2), 433.

Simon, H. A. (1991). Bounded Rationality and Organizational Learning. Organization Science, 2(1), 125-134.

Slovic, P. (1987). Perception of risk. Science, 236(4799), 280-285. doi:10.1126/science.3563507

Slovic, P. (Ed.). (2000). The perception of risk(Vol. xxxvii). London, England: Earthscan Publications.

Smart cities to get their own OS. (2011, September 30). BBC. Retrieved from http://www.bbc.co.uk/news/technology-15109403

Stavins, R. N. (1996). Correlated Uncertainty and Policy Instrument Choice. Journal of Environmental Economics and Management, 30(2), 218-232. doi:10.1006/jeem.1996.0015

Stevels, A. (2003). Is the WEEE Directive EcoEfficient? Electronics and the Environment, 2003. IEEE International Symposium on, 7-12.

Stigler, G. J. (1971). The Theory of Economic Regulation. The Bell Journal of Economics and Management Science, 2(1), 3-21.

Subramanian, C. (2013, August 9). "Nudge" Back in Fashion at White House. Time. Retrieved from http://swampland.time.com/2013/08/09/nudge-back-infashion-at-white-house/ 
Summers, L. H. (1992). Summers on Sustainable Growth. The Economist, 323(7761), 65.

Sunstein, C. (2004). Your Money or Your Life. The New Republic: A Journal of Politics and the Arts. Retrieved from http://www.tnr.com/article/books-andarts/your-money-or-your-life

Sunstein, C. (2005). Laws of fear: beyond the precautionary principle. Cambridge UK: Cambridge University Press.

Susskind, L., Jain, R. K., \& Martyniuk, A. O. (2001). Better Environmental Policy Studies: How To Design And Conduct More Effective Analyses (1st ed.). Island Press.

Swanson, T., \& Kontoleon, A. (2004). What future for environmental liability? The use of liability systems for environmental regulation in the courtrooms of the United States and the European Union. In M. G. Faure \& N. J. Vig (Eds.), Green giants? Environmental policies of the United States and the European Union. MIT Press.

Technology-Based Emission and Effluent Standards and the Achievement of Ambient Environmental Objectives. (1982). The Yale Law Journal, 91(4), 792813.

Thaler, R. H., \& Sunstein, C. R. (2009). Nudge: Improving Decisions About Health, Wealth, and Happiness (Revised \& Expanded.). Penguin Books.

Thaler, R. H., \& Tucker, W. (2013). Smarter information, Smarter Consumers. Harvard Business Review, 91(1), 44-54.

The Nielsen Company. (2011). Sustainable Efforts \& Environmental Concerns. Retrieved from http://blog.nielsen.com/nielsenwire/consumer/globalconcern-for-climate-change-dips-amid-other-environmental-andeconomic-concerns/

The rise of the sharing economy. (2013, March 9). The Economist. Retrieved from http://www.economist.com/news/leaders/21573104-internet-everythinghire-rise-sharing-economy

Trumbull, W. N. (1990). Who has standing in cost-benefit analysis? Journal of Policy Analysis and Management, 9(2), 201-218. doi:10.2307/3325412 
Tukker, A., Akerlof, G., van Oers, L., \& Heijungs, R. (2006). Environmentally extended input-output tables and models for Europe. Spain: European Commission.

Turner, R. (2007). Limits to CBA in UK and European environmental policy: retrospects and future prospects. Environmental $\mathcal{E}$ Resource Economics, 37(1), 253-269.

Tversky, A., \& Kahneman, D. (1981). The Framing of Decisions and the Psychology of Choice. Science, 211(4481), 453-458.

UK Better Regulation Commission. (2005). Regulation - Less is More. Reducing Burdens, Improving Outcomes. Retrieved July 3, 2009, from http://archive.cabinetoffice.gov.uk/brc/publications/lessismoreentry-2.html

UK Government. (n.d.). Opening up government. Retrieved January 16, 2012, from http://data.gov.uk/

UK Government Social Research Unit. (2007, December 12). Policy Hub - Magenta Book, Chapter 1, What is Policy Evaluation? Retrieved December 27, 2007, from

http://www.policyhub.gov.uk/evaluating_policy/magenta_book/chapter1. asp

UK National Audit Office. (2007, July 25). Reducing the cost of complying with regulations: The delivery of the Administrative Burdens Reduction Programme, 2007. Retrieved November 27, 2008, from http://www.nao.org.uk/pn/06-07/0607615.htm

Ulen, T. S. (1980). The market for regulation: The ICC from 1887 to 1920 . The American Economic Review, 70(2), 306-310.

UN. (1992). A/CONF.151/26 (Vol. I) Report of the United Nations Conference on Environment and Development. Retrieved March 20, 2010, from http://www.un.org/documents/ga/conf151/aconf15126-1annex1.htm

United States Mission to OECD. (2011, October 11). Press Release - U.S. and UK Urge OECD to Make Data Freely Available Online. Retrieved October 11, 2011, from https://usoecd.cms.getusinfo.com/data.html

U.S. Chamber of Commerce - Cost-Benefit Analysis and Regulatory Accounting. (n.d.). Retrieved January 5, 2008, from http://www.uschamber.com/issues/index/regulatory/costbenefitanalysis.ht $\mathrm{m}$ 
USEPA. (2009, October). EPA Optimization Model for Reducing Emissions of Greenhouse Gases from Automobiles (OMEGA). Assessment and Standards Division, Office of Transportation and Air Quality. Retrieved from http://www.epa.gov/oms/climate/models/420b09035.pdf

US EPA. (2010, November 9). EPA Air Compliance Advisor. Retrieved January 22, 2011, from http://www.epa.gov/ttnecas1/cost.htm

USEPA. (n.d.). Life Cycle Assessment. Retrieved January 27, 2010, from http://www.epa.gov/nrmrl/lcaccess/

US EPA. (n.d.). Optimization Model for reducing Emissions of Greenhouse gases from Automobiles (OMEGA) [Data \& Tools]. Retrieved September 24, 2010, from http://www.epa.gov/oms/climate/models.htm

U.S. Office of Management and Budget. (2003, September 17). Circular A-4, Regulatory Analysis. Retrieved from

http://www.whitehouse.gov/sites/default/files/omb/assets/regulatory_matt ers_pdf/a-4.pdf

Vidal, J. (2012, June 6). Zac Goldsmith: climate change pushes other issues off the agenda. The Guardian. Retrieved from

http://www.guardian.co.uk/environment/2012/jun/06/climate-changeother-issues-goldsmith

Vig, N. J., \& Faure, M. G. (2004). Green giants? Environmental policies of the United States and the European Union. MIT Press.

Vining, A., \& Boardman, A. E. (2006). Metachoice in policy analysis. Journal of Comparative Policy Analysis, 8(1), 77.

Vining, A. R., \& Weimer, D. L. (1998). Passive Use Benefits: Existence, Option, and Quasi-Option Value. In F. Thompson \& M. T. Green (Eds.), Hanbook of Public Finance (pp. 319-346). New York: Marcel Dekker.

Viteritti, J. P. (1982). Policy Analysis in the Bureaucracy: An Ad Hoc Approach. Public Administration Review, 42(5), 466. doi:10.2307/975649

Vogler, J., \& Stephan, H. (2007). The European Union in global environmental governance: Leadership in the making? International Environmental Agreements: Politics, Law and Economics, 7(4), 389-413. doi:10.1007/s10784007-9051-5 
Vo $\beta$, A., \& Schmid, G. (1991). Cost-effectiveness analysis of air-pollution control measures. Energy, 16(10), 1215-1224. doi:10.1016/0360-5442(91)90150-K

Walker, W. E., Rahman, S. A., \& Cave, J. (2001). Adaptive policies, policy analysis, and policy-making. European Journal of Operational Research, 128(2), 282289. doi:10.1016/S0377-2217(00)00071-0

Waste electrical and electronic equipment (WEEE). (n.d.). Retrieved January 16, 2012, from http://epp.eurostat.ec.europa.eu/portal/page/portal/waste/data/wastestrea $\mathrm{ms} /$ weee

Weimer, D. L., \& Vining, A. R. (1999). Policy Analysis: Concepts and Practice. Prentice Hall.

Weimer, D. L., \& Vining, A. R. (2005). Policy analysis : concepts and practice (4th ed.). Upper Saddle River NJ: Pearson Prentice Hall.

Weinter, D. L. (1992). The Craft of Policy Design: Can It Be More Than Art? Review of Policy Research, 11(3-4), 370-388.

Willis, J. W. (2007). Foundations of Qualitative Research: Interpretive and Critical Approaches. SAGE Publications.

Winter, S. G. (2003). Understanding dynamic capabilities. Strategic Management Journal, 24(10), 991-995. doi:10.1002/smj.318

World Bank. (n.d.). Data - The World Bank. Retrieved January 16, 2012, from http://data.worldbank.org/

Yin, R. K. (2003). Applications of case study research. London: SAGE.

Zelkowitz, M. V., \& Wallace, D. R. (1998). Experimental models for validating technology. Computer, 31(5), 23 -31. doi:10.1109/2.675630

Zerbe Jr., R. O. (1998). Is cost-benefit analysis legal? Three rules. Journal of Policy Analysis and Management, 17(3), 419-456. doi:10.1002/(SICI)15206688(199822)17:3<419::AID-PAM3>3.0.CO;2-J 


\section{Appendix I}

The following is an excerpt from the public documentation of the OMEGA model, specifically the Interim Joint Technical Assessment Report available online (US EPA, n.d.). It is reproduced here as a ready reckoner of the inner workings of a typical accounting model used in environmental policy. For the other models and quantitative cases, all references to documentation include hyperlinks.

\section{EPA Documentation of OMEGA model Analysis}

\section{F1.1 Overview of OMEGA}

This Appendix provides the methodology underlying the technical assessment of the future vehicle scenarios presented in Chapter 6. As in the analysis of the MY 2012-2016 rulemaking, evaluating the feasibility of these scenarios included identifying potentially available technologies and assessing their effectiveness, cost, and impact on relevant aspects of vehicle performance and utility. The wide number of technologies which are available and likely to be used in combination required a method to account for their combined cost and effectiveness. As described in Chapter 6, this included developing three distinct technology pathways which emphasized one or the other of the more advanced technologies, such as hybrids, advanced gasoline engine, plug-ins and battery EVs.

Applying these technologies efficiently to the wide range of vehicles produced by various manufacturers is a challenging task. In order to assist in this task, EPA has developed a computerized model called the Optimization Model for reducing Emissions of Greenhouse gases from Automobiles (OMEGA). Broadly, the model starts with a description of the future vehicle fleet, including manufacturer, sales, base $\mathrm{CO}_{2}$ emissions, footprint and the extent to which emission control technologies are already employed. For the purpose of this Technical Assessment Report analysis, 63 generic vehicle platforms - were used to capture important differences in engine design, vehicle design and vehicle utility. The model is then provided with a list of technologies which are applicable to various types of vehicles, along with their cost 
and effectiveness and the maximum percentage of vehicle sales which can receive each technology. This list varies slightly depending on whether model year 2020 or 2025 standards are being evaluated and on the specific technology pathway being evaluated. The model combines this information with economic parameters, such as fuel prices and a discount rate, to project how manufacturers could apply available technology in order to meet specified levels of emission control. For this Technical Assessment Report, as all vehicle sales have been combined into a single manufacturer, the model indicates how the industry when complying as a single manufacturer might use technology to reduce GHG emissions. The resulting output is a description of which technologies are added to each vehicle platform, along with the accompanying cost.

OMEGA includes several components, including a number of pre-processors that assist users in preparing a baseline vehicle forecast, ${ }^{1}$ creating and ranking technology packages, ${ }^{2}$ and calculating the degree to which technology is present on baseline vehicles. The OMEGA core model assembles this information and produces estimates of increases in vehicle cost and $\mathrm{CO}_{2}$ reduction. Based on the OMEGA core model output, the technology penetration of the new vehicle mix and the scenario impacts (fuel savings, emission impacts, and other monetized benefits) are calculated by post-processors. The pre- and post- processors are Microsoft Excel spreadsheets and visual basic programs, while the OMEGA core model is an executable program written in the $\mathrm{C \#}$ language. The files used in this analysis, as well as the current version of OMEGA, are available in the TAR docket. 


\section{Figure F1.1-1: Information Flow in the OMEGA Model}
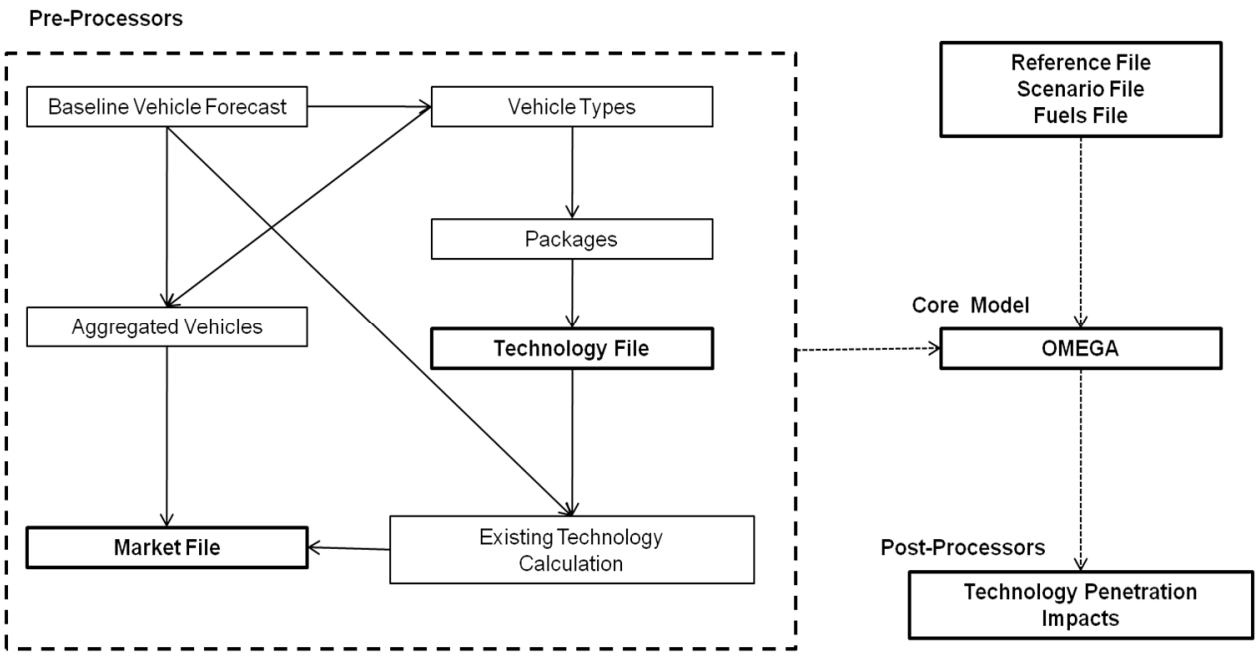

A detailed description of the OMEGA model, as well as the general modeling methodology is provided in the MY 2012-2016 rule preamble Section III.D. Consequently, the interested reader may find additional depth there, ${ }^{3}$ or in the OMEGA user guide on the EPA website. ${ }^{4}$ The remainder of this appendix assumes a basic knowledge of OMEGA's operation, and focuses on the particular data sources and methodologies used in the scenario analysis described in Chapter 6.

\section{F1.2 Summary of Inputs}

The inputs underlying the OMEGA analysis have significant impacts on the results, and are described in detail elsewhere in this Assessment Report, as follows. The fleet projection used for this analysis is described in Appendix A. The vehicle technology packages are described in Chapter 3 and Appendix B. The inputs relating to air conditioning controls are outlined in Appendix D. The other economic and environmental outputs are described in Appendix E. The detailed description of analytic scenarios, including the standards modeled and the reasoning behind a single fleet analysis, is available in Chapter 6. Generally, the table of contents to this technical assessment is a useful guide to additional detail.

\section{F1.3 Configuration of the Scenario File}

The scenario file in OMEGA contains a directory of data input files, a group of economic parameters, and a set of $\mathrm{CO}_{2} \mathrm{~g} / \mathrm{mile}$ targets. For the Technical 
Assessment Report analysis, OMEGA was configured so that each technical pathway/model year combination was a single scenario file containing six runs. Four runs corresponding to each of the four emission control scenarios (i.e., 3\% per year, $4 \%$ per year, etc.) were included. Also included were a diagnostic run requiring maximum application of technology, as well the reference case scenario of MY 2016 GHG standards from the recent MY 2012-2016 final rule. As a result, six scenario files were created ( $2 \mathrm{MYs} \times 3$ technical pathways), and each scenario file contained parameters for six OMEGA runs.

The emission control scenarios were each configured with a flat standard corresponding to the appropriate stringency. No limits were placed on credit transfers between the car and truck fleets. As in the MY 2012-2016 final rule analysis, EPA accounted for the emission reductions and technology costs due to air conditioning controls outside of the OMEGA model. In the MY 2025 timeframe, air conditioning remains a highly costeffective technology to control GHG emissions, and consequently, EPA projects that the entire market will convert to low leakage, high efficiency systems. In the time frame of MY 2020 and later, these emission reductions were assigned a statutory value of 20.6 grams in the reference scenario ${ }^{5}$ and 15.3 grams in the control scenarios. ${ }^{6}$ An example of the adjustments is shown in Table F1.3-1. The MY 2016 footprint curves and the flat standards were each adjusted by the maximum potential AC credits to produce the credit adjusted targets. The agencies note, as discussed in Chapter 6 above, that the upcoming federal rulemaking analysis will consider fuel economy and emission control scenarios defined in terms of attribute-based standards, but we believe the scenarios considered here are meaningful for purposes of this assessment.

Table F1.3-1: Adjustment of Standards for Air Conditioning Credits

\begin{tabular}{|c|c|c|c|}
\hline Scenario & $\begin{array}{c}\text { Sales- } \\
\text { Weighted MY } \\
2025 \text { Target }\end{array}$ & $\begin{array}{c}\text { Projected } \\
\text { AC Credits }\end{array}$ & $\begin{array}{c}\text { Sales-Weighted MY } \\
\text { 2025 Credit } \\
\text { Adjusted Target }\end{array}$ \\
\hline Reference & 248.1 & 20.6 & 268.7 \\
\hline $3 \%$ & 190.1 & 15.3 & 205.4 \\
\hline $4 \%$ & 173.1 & 15.3 & 188.4 \\
\hline $5 \%$ & 157.6 & 15.3 & 173.9 \\
\hline $6 \%$ & 143.2 & 15.3 & 158.5 \\
\hline
\end{tabular}


A further adjustment was made with respect to the credit adjusted targets listed above. The scenarios described in this document are defined by a sales weighted average of car and truck $\mathrm{CO}_{2}$ emissions. When credit transfer is allowed between cars and trucks, OMEGA weights the $\mathrm{CO}_{2}$ average by both sales and vehicle miles traveled (VMT). ${ }^{32}$ Light trucks generally are driven more than cars, so the sales and VMT weighted $\mathrm{CO} 2$ emission average tends to be slightly lower than the salesweighted average. To account for this difference, the diagnostic run was used to produce VMT and sales weighted targets that corresponded to the sales weighted targets listed above. These calibrated targets can be seen in the scenario files available in the TAR docket.

We also updated the VMT ratios used in car/truck credit transfer to the appropriate MY lifetime values discussed in Appendix E.

\section{F1.4 Configuration of the Technology File}

The technology input file defines the technology packages which the model can add to the vehicle fleet. A separate technology file was developed for each of the six technology pathway/model year combinations considered in this Technical Assessment Report. While the individual technology costs were the same between technology pathways, they differed between MY 2020 and MY 2025 due to the learning effects discussed in the Appendix 3 and the MY 2012-2016 Final Rule Section II.E. Due to the different limits on maximum penetrations of several key technologies (discussed in Chapter 6), each of the technology pathways also required a separate technology file and model run. The change in those maximum penetration rates also slightly affected the set of most cost effective technology packages selected for inclusion in the OMEGA model runs. The processes to build and rank technology packages for the technology file are described in the Chapter 3 and Appendix B of this report. This section describes the configuration of the OMEGA Technology input file which occurs after the ranked packages are developed.

\section{F1.4.1 Multiple Fuel Tracking}

OMEGA 1.0.2, which was used during the MY 2012-2016 rule analysis, tracked $\mathrm{CO}_{2}$ emissions at the vehicle platform level. For the present analysis, an upgrade was made to the OMEGA model to track $\mathrm{CO}_{2}$ emissions by fuel within each

\footnotetext{
32 This practice is consistent with EPA's MY 2012-2016 regulations allowing VMT weighted credit transfer between car and truck fleets.
} 
vehicle platform. As a result, a vehicle platform can be composed of sub-vehicles, each with its own fuel, $\mathrm{CO}_{2}$ emission rate and electricity consumption rate. To facilitate this tracking, every technology is encoded with its operating fuel, as well as the fuel of the vehicles to which it applies. In combination with technology specific caps, ${ }^{33}$ this allows a vehicle platform to be split so that subsequent technologies can be applied to the specific subsets of the vehicle (Table F1.4-1). Thus, for example, a certain fraction of a vehicle's sales can be equipped with a diesel engine.

Subsequent diesel-based technologies can then be applied more simply and directly to this subset of sales. The model keeps track of the sales and $\mathrm{CO}_{2}$ emission rates of both the gasoline and diesel versions of the vehicle.

In the example below, Technology Package 3 is applied to the gasoline fuel vehicle created by the application of Technology Package 1. Technology Package 4 is applied to the diesel fuel vehicle created by the application of Technology Package 2.

Table F1.4-1: Example of Multiple Fuel Technology File

\begin{tabular}{|c|l|c|c|c|}
\hline $\begin{array}{c}\text { Tech } \\
\text { Package }\end{array}$ & \multicolumn{1}{|c|}{ Name } & Cap $^{1}$ & $\begin{array}{c}\text { Fuel of the } \\
\text { Technology }\end{array}$ & $\begin{array}{c}\text { Fuel to which the } \\
\text { Technology } \\
\text { Applies }\end{array}$ \\
\hline 1 & $\begin{array}{l}\text { GDI Gasoline } \\
\text { Engine }\end{array}$ & $100 \%$ & Gasoline & Gasoline \\
\hline 2 & Diesel Engine & $15 \%$ & Diesel & Gasoline \\
\hline 3 & Gasoline Hybrid & $100 \%$ & Gasoline & Gasoline \\
\hline 4 & Improved Diesel & $100 \%$ & Diesel & Diesel \\
\hline
\end{tabular}

1Please note that OMEGA technology caps are relative to the population on that fuel, so a $100 \%$ cap on technology package four indicates that it applies to $100 \%$ of the $15 \%$ of vehicles which were converted to diesel in step

In the current TAR analysis, this model feature simplified the ability to apply several types of electric vehicle and plug-in electric vehicle technology packages to the same baseline vehicle. In addition, we found it useful when applying certain advanced gasoline technology packages which had caps of less than $100 \%$. For example, most of the technology paths limit the use of advanced (e.g., EGRboosted) gasoline engine technologies to less than $100 \%$. In most cases, further

33 - Cap\| is a shorthand term for the maximum penetration rates for certain technologies which define the various technology paths. 
technology packages can be applied to both the vehicles which received this advanced gasoline technology and those that did not. By effectively treating -advanced gasoline engines $\|$ as including a change in fuels, we were able to simplify the addition of subsequent technologies to both the subset of vehicle sales with this technology and that without it. This could have been accomplished without taking advantage of the OMEGA model's new fuel tracking capability, but the estimation of the cost and effectiveness of the subsequent technology packages would have had to consider the fact that they were being applied to a subset of the vehicle's sales which did not have the average attributes of that vehicle at that stage of technology addition.

For example, if EGR boost technology is added to $50 \%$ of the sales of those vehicles operating on gasoline, it may be possible to hybridize both the vehicles with and without the EGR boost technology, with differing costs and effectiveness. It is possible to determine the overall impact of hybridizing the non-EGR vehicles first and then the EGR-boosted vehicles and developing the appropriate OMEGA model inputs which accomplish both of these steps of technology addition. However, since we were not using all of the fuel types currently tracked in the OMEGA model (e.g. E10), it was easier to separate the EGR-boosted vehicles from those without this technology by changing the former vehicles' fuel to -E10 Il. We simply made the fuel properties of E10 exactly the same as those for gasoline. Then for example, the incremental effect of hybridizing the non-EGR boosted vehicles could be used directly in the model without the need to sales weight this impact by including the fact that the emissions of the non-EGR vehicles were not changing.

To further illustrate this issue, consider the case of Vehicle A, a gasoline vehicle with $\mathrm{CO}_{2}$ emissions of $300 \mathrm{~g} / \mathrm{mile}$. In this example scenario, diesel packages are limited to $50 \%$ of the fleet because of concerns relative to production capacity. ${ }^{34}$ In this case, two sequential diesel packages should be applied to the same $50 \%$ subset of the vehicle (Table F1.4-2). As can be seen in this table, OMEGA 1.3 now more accurately attributes the reductions to the appropriate subset within the vehicle platform.

\footnotetext{
${ }^{34}$ Please note, this is just an example, and has no implications relative to actual maximum penetration rates for diesel vehicles.
} 
Table F1.4-2: Tracking $\mathrm{CO}_{2}$

\begin{tabular}{|l|l|c|c|c|c|c|c|}
\hline Step & $\begin{array}{l}\text { Package } \\
\text { Fuel }\end{array}$ & $\begin{array}{c}\text { Maximum } \\
\text { Penetration } \\
\text { Limit }\end{array}$ & Reduction & $\begin{array}{c}\text { OMEGA } \\
1.0 .2 \\
\text { Applied } \\
\text { to average } \\
\text { vehicle. }\end{array}$ & \multicolumn{2}{|c|}{$\begin{array}{c}\text { OMEGA 1.3 } \\
\text { Applied to a specific } \\
\text { fuel within a } \\
\text { platform. }\end{array}$} \\
\hline & & & $\mathrm{CO}_{2}$ Avg & $\begin{array}{c}\text { CO2 } \\
\text { Avg }\end{array}$ & $\begin{array}{c}\text { CO2 } \\
\text { Gas }\end{array}$ & $\begin{array}{l}\text { CO2 } \\
\text { Dies } \\
\text { el }\end{array}$ \\
\hline 1 & Diesel & $50 \%$ & $10 \%$ & 285 & 285 & 300 & 270 \\
\hline 2 & Diesel & $50 \% / 100 \%$ & $10 \%$ & 270.75 & 271.5 & 300 & 243 \\
\hline
\end{tabular}

${ }^{1}$ The maximum penetration limit in the second step applies to $50 \%$ of the total vehicles (OMEGA 1.0.2) or 100\% of the diesel vehicles (OMEGA 1.3)

In the analysis presented in this report, we encode limited technologies to different fuels so that the appropriate reductions are taken. As an example, plugin hybrids are coded to diesel fuel. The fuels input file was modified so that the appropriate gasoline fuel properties are attributed to — diesel II fuel.

\section{F1.4.2 Tracking of Electricity}

OMEGA 1.3 also tracks electrical consumption in kWh per mile. Each technology package is now associated with an -electricity conversion percentage $\|$ which refers to the increase in the energy consumed by the electric drivetrain relative to reduction in the consumption of energy from liquid fuel. Electricity is a highly refined form of energy which can be used quite efficiently to create kinetic energy. 
Thus, electric motors are much more efficient than liquid fuel engines.

Consequently, the electric consumption percentage input in in the Technology File for plug-in vehicles is generally well below than $100 \%$. It may be possible that this percentage could exceed $100 \%$ under certain circumstances, for example when one type of plug-in vehicle is being converted into another plug-in vehicle and electricity consumption per mile is increasing due to larger and heavier batteries, etc. However, that was not the case for any of the technologies evaluated in this analysis.

\section{F1.5 Configuration of the Market File}

\begin{tabular}{|c|c|c|c|}
\hline $\begin{array}{l}\text { Vehicle Type } \\
\#\end{array}$ & Name & Cam & Engine \\
\hline 1 & Subcompact Car & DOHC & I4 \\
\hline 2 & Compact Car I4 & DOHC & I4 \\
\hline 3 & Midsize Car/Small MPV (unibody) & DOHC & I4 \\
\hline 4 & $\begin{array}{l}\text { Compact Car/Small MPV } \\
\text { (unibody) }\end{array}$ & DOHC & V6 \\
\hline 5 & Midsize/Large Car & DOHC & V6 \\
\hline 6 & Midsize Car/Large Car & DOHC & V8 \\
\hline 7 & $\begin{array}{l}\text { Mid-sized MPV (unibody)/Small } \\
\text { Truck }\end{array}$ & DOHC & $\mathrm{I} 4$ \\
\hline 8 & $\begin{array}{l}\text { Midsize MPV (unibody)/Small } \\
\text { Truck }\end{array}$ & $\mathrm{SOHC}$ & V6 \\
\hline 9 & Large MPV (unibody) & SOHC & $\mathrm{V} 8$ \\
\hline 10 & Large MPV (unibody) & SOHC & V8 \\
\hline 11 & Large Truck (+ Van) & SOHC & V6 \\
\hline 12 & Large Truck + Large MPV & $\mathrm{OHV}$ & V6 \\
\hline 13 & Large Truck (+ Van) & $\mathrm{OHV}$ & V8 \\
\hline 14 & Large Truck (+Van) & SOHC3V & V8 \\
\hline 15 & Large Car & $\mathrm{OHV}$ & V8 \\
\hline
\end{tabular}




\begin{tabular}{|l|l|l|l|}
\hline 16 & Large MPV (unibody) & DOHC & V6 \\
\hline 17 & Large MPV (unibody) & DOHC & V8 \\
\hline 18 & Large Truck (+ Van) & DOHC & V6 \\
\hline 19 & Large Truck (+ Van) & DOHC & V8 \\
\hline
\end{tabular}

F1.5.1 Creating the Generic Vehicles

As discussed in Section F1.4 above, vehicle manufacturers typically develop many different models by basing them on a smaller number of vehicle platforms. The platform typically consists of a common set of vehicle architecture and structural components. This allows for efficient use of design and manufacturing resources. In the MY 2012-2016 Final Rule, EPA created over 200 vehicle platforms which were used to capture the important differences in vehicle and engine design and utility of future vehicle sales of roughly 16 million units in the 2016 timeframe. For the current analysis, we are not differentiating between manufacturers, and consequently require fewer vehicle platforms for the analysis. The approximately sixty vehicle platforms are a result of mapping the 1130 vehicle fleet into the 19 engine based vehicle types (Table F1.5-1) and the 10 body size and structure based utility classes (Table F1.5-2). As not all vehicle types match to all utility types, the number of generic vehicles is less than the multiplicative maximum of the two tables.

Table F1.5-1 : Vehicle Types in the TAR Analysis

Table F1.5-2 : Vehicle Types in the Technical Assessment Analysis

\begin{tabular}{|c|c|c|c|c|}
\hline $\begin{array}{c}\text { Utility } \\
\text { Class \# }\end{array}$ & Utility Class & $\begin{array}{l}\text { Vehicle } \\
\text { Use }^{1}\end{array}$ & $\begin{array}{l}\text { Footprint } \\
\text { Criteria }\end{array}$ & $\begin{array}{c}\text { Structure } \\
\text { Criteria }\end{array}$ \\
\hline 1 & $\begin{array}{l}\text { Subcompact } \\
\text { Auto }\end{array}$ & Car & Footprint $<43$ & -- \\
\hline 2 & $\begin{array}{c}\text { Compact } \\
\text { Auto }\end{array}$ & Car & $43<=$ Footprint $<46$ & -- \\
\hline 3 & $\begin{array}{c}\text { Mid Size } \\
\text { Auto }\end{array}$ & Car & $46<=$ Footprint $<53$ & -- \\
\hline 4 & Large Auto & Car & $56<=$ Footprint & -- \\
\hline 5 & Small SUV & SUV & $43<=$ Footprint $<46$ & -- \\
\hline 6 & Large SUV & SUV & $46<=$ Footprint & -- \\
\hline
\end{tabular}




\begin{tabular}{|c|c|c|c|c|}
\hline 7 & Small Pickup & Pickup & Footprint $<50$ & -- \\
\hline 8 & Large Pickup & Pickup & $50<=$ Footprint & -- \\
\hline 9 & Cargo Van & Van & -- & $\begin{array}{c}\text { Ladder } \\
\text { Frame }\end{array}$ \\
\hline 10 & Minivan & Van & -- & Unibody \\
\hline
\end{tabular}

1. Vehicle use type is based upon analysis of EPA certification data.

F1.5.2 Accounting for Technology already on the Vehicles

The market data input file utilized by OMEGA, which characterizes the vehicle fleet, is designed to account for the fact that the 2008 model year vehicles which comprise our baseline fleet may already be equipped with one or more of the technologies available in general to reduce $\mathrm{CO} 2$ emissions. As described in Appendix B, EPA decided to apply technologies in packages, as opposed to one at a time. However, 2008 vehicles were equipped with a wide range of technology combinations, many of which cut across the packages. Thus, EPA developed a method to account for the presence of the combinations of applied technologies in terms of their proportion of the EPA packages described in Chapter 3.

This analysis can be broken down into four steps

The first step in the updated process is to breakdown the available GHG control technologies into five groups: 1) engine-related, 2) transmission-related, 3) hybridization, 4) weight reduction and 5) other. Within each group we gave each individual technology a ranking which generally followed the degree of complexity, cost and effectiveness of the technologies within each group. More specifically, the ranking is based on the premise that a technology on a 2008 baseline vehicle with a lower ranking would be replaced by one with a higher ranking which was contained in one of the technology packages which we included in our OMEGA modeling. The corollary of this premise is that a technology on a 2008 baseline vehicle with a higher ranking would be not be replaced by one with an equal or lower ranking which was contained in one of the technology packages which we chose to include in our OMEGA modeling. This ranking scheme can be seen in the TEB/CEB calculation macro, available in the docket.

In the second step of the process, we used these rankings to estimate the complete list of technologies which would be present on each baseline vehicle after the application of each technology package. We then used the EPA lumped 
parameter model to estimate the total percentage $\mathrm{CO} 2$ emission reduction associated with the technology present on the baseline vehicle (termed package 0 ), as well as the total percentage reduction after application of each package. This process was repeated to determine the total cost of all of the technology present on the baseline vehicle and after the application of each applicable technology package.

The third step in this process is to determine the degree of each technology package's incremental effectiveness and incremental cost is affected by the technology already present on the baseline vehicle. The degree to which a technology package's incremental effectiveness is reduced by technology already present on the baseline vehicle is termed the technology effectiveness basis, or TEB, in the OMEGA model. The value of each vehicle's TEB for each applicable technology package is determined as follows:

$$
T E B_{i}=\frac{1-\left(\frac{\text { TotalEffec }_{v, i-1}}{1-\text { TotalEffec }_{v, i}}\right) \times\left(\frac{1-\text { TotalEffec }_{p, i}}{1-\text { TotalEffec }_{p, i-1}}\right)}{\left(1-\frac{1-\text { TotalEffec }_{p, i}}{1-\text { TotalEffec }_{p, i-1}}\right)}
$$

Where

TotalEffect $v, i=$ Total effectiveness of all of the technologies present on the baseline vehicle after application of technology package $i$

TotalEffect $v, i-1=$ Total effectiveness of all of the technologies present on the baseline vehicle after application of technology package i1

TotalEffect $\mathrm{p}, \mathrm{i}=$ Total effectiveness of all of the technologies

included in technology package $\mathrm{i}$

TotalEffect $p_{, i-1}=$ Total effectiveness of all of the technologies included in technology package i-1 Equation 1.5-1 - TEB

\section{calculation}

The degree to which a technology package's incremental cost is reduced by technology already present on the baseline vehicle is termed the cost effectiveness basis, or CEB, in the OMEGA model. The value of each vehicle's CEB for each applicable technology package is determined as follows:

$$
\mathrm{CEB}_{\mathrm{i}}=1-\left(\text { TotalCost }_{\mathrm{v}, \mathrm{i}}-\text { TotalCost }_{\mathrm{v}, \mathrm{i}-1}\right) /\left(\text { TotalCost }_{\mathrm{p}, \mathrm{i}}-\text { Total Cost }_{\mathrm{p}, \mathrm{i}}\right.
$$

1) 


\author{
Where \\ TotalCost $=$ total cost of all of the technology present on \\ the vehicle after addition of package i or i-1 \\ to baseline vehicle $\mathrm{v}$ \\ TotalCost $\mathrm{p}_{\mathrm{p}} \quad$ total cost of all of the technology \\ included in package $\mathrm{i}$ or $\mathrm{i}-1 \mathrm{i}=$ the technology \\ package being evaluated $\mathrm{i}-1=$ the previous \\ technology package
}

\title{
Equation 1.5-2 - CEB calculation
}

The values of CEB and TEB are capped at 1.0 or less, since a vehicle cannot have more than the entire package already present on it. In other words, the addition of a technology package cannot increase emissions nor reduce costs. (A value of 1.0 causes the OMEGA model to not change either the cost or $\mathrm{CO} 2$ emissions of a vehicle when that technology package is added.) The value of a specific TEB or CEB can be negative, however. This implies that the incremental effectiveness or the incremental cost of adding a package can be greater than that when adding the packages in sequence to a vehicle with no baseline technology.

An example of this is a baseline vehicle with a 6 speed manual transmission. All of our technology package effectiveness and cost estimates are estimated for specified baseline vehicles, all of which have 4 speed automatic transmissions. Our technology packages improve this transmission, sometimes to a 6 speed automatic transmission and then a dual clutch transmission and sometimes directly to a dual clutch transmission. Subsequent packages may then strongly hybridize the vehicle. If a baseline vehicle has a 6 speed manual transmission, this transmission is unaffected by the technology packages which include either a 6 speed automatic transmission or a dual clutch transmission, since the manual transmission is both cheaper and/or more efficient than these other transmissions. However, when the vehicle is hybridized, this manual transmission is replaced. The incremental cost of changing this vehicle to a power-split hybrid design, for example, is greater than that for a vehicle with a dual clutch transmission, since the credit for removing the manual transmission is less than that for the dual clutch transmission. The negative CEB causes the OMEGA model to apply a cost for this power-split package which is slightly higher than that for the typical baseline vehicle. 
The fourth step is to combine the fractions of the cost and effectiveness of each technology package already present on the individual 2008 vehicles models for each vehicle type. For cost, percentages of each package already present are combined using a simple sales-weighting procedure, since the cost of each package is the same for each vehicle in a vehicle type. For effectiveness, the individual percentages are combined by weighting them by both sales and base $\mathrm{CO}_{2}$ emission level. This appropriately weights vehicle models with either higher sales or $\mathrm{CO}_{2}$ emissions within a vehicle type. Once again, this process prevents the model from adding technology which is already present on vehicles, and thus ensures that the model does not double count technology effectiveness and cost associated with complying with the reference standards or the $\mathrm{CO}_{2}$ control scenarios.

For this analysis, we automated the process through a visual basic macro that both operates the lumped parameter model and calculates the TEBs and CEBs. This macroenabled excel file is available in the docket.

\section{F1.6 Post-processing OMEGA}

\section{F1.6.1 A/C Credits}

As noted above, $\mathrm{A} / \mathrm{C}$ credits were simply subtracted off the OMEGA results for both the reference and control cases. A/C system costs were added into both cases. As a result, the delta between reference and control cases, both in terms of costs and environmental impact, did not change.

\section{F1.6.2 Calculating Technology Penetrations}

Technology penetrations were calculated using the new -techpacksales $\|$ output file of the OMEGA model. This output provides, for each of the approximately 60 vehicle platforms, the distribution of sales among the tech packs. In a postprocessing step, this distribution is applied back to the 1130 individual vehicles of the disaggregate baseline fleet projection so that we have the tech pack distribution of each vehicle. As discussed in the description of TEB/CEB calculations, we have already produced a file which contains the specific technologies on each vehicles with every possible technology package. By applying the technology pack distributions from the 60 vehicle platforms back against the 1130 vehicles in dissagregated fleet, we are able to determine the specific technologies on each vehicle in each scenario and tech pathway. As an example, this file would show what technologies are actually on a Ford F150 with 
technology package 1, 2, 3 etc. This file is combined with OMEGA's technology pack distribution output to determine the penetration of each tracked technology.

\section{F1.6.3 Impacts Calculations}

Liquid fuel consumption, electricity consumption and emission impacts were calculated in a modified version of the post-processor spreadsheet that was used in the MY 2012-2016 final rule. This spreadsheet, available in the downloadable material accompanying this technical assessment report, is the repository for the inputs discussed in Appendix E. The impacts calculations sequentially calculate light duty vehicle stock, VMT, and impacts for each MY and CY from 2010 through 2050. Outputs are available on either calendar year or model year basis. For this Technical Assessment Report, the VMT algorithm was integrated into the benefits calculations, electricity calculations were added, and the inputs and outputs were restructured. Provided the same inputs, the current benefits spreadsheet would still provide the same outputs as the version used in the MY 2012-2016 Final Rule.

A detailed discussion of the benefits calculations algorithms is available in the MY 2012-2016 Final Rule RIA chapter 5 and in the OMEGA users guide.

We note that the current analysis did not rely upon many of the outputs of the OMEGA benefits post-processor. These outputs, such as co-pollutant impacts, monetized emission impacts, the benefits of additional travel time, and damages due to noise, accidents, and congestion, may not produce accurate results in the context of the numerous input changes, and should not be used. 


\section{Samenvetting}

De algemene kwaliteit van milieu-indicatoren in de Europese Unie en het bijbehorende succes van milieubeleid worden in de hele wereld met jaloezie bekeken. De Unie heeft de weg geleid voor strikt maar marktvriendelijk Milieubeleid, en laat zich voorstaan op haar rol als milieu-rentmeester in de wereld, door hogere standaarden te propageren en door het goede voorbeeld te geven. De strikte regelgeving geeft de regio ook een economisch concurrentievoordeel dat het bepalende verschil zou kunnen worden in de wereldhandel van de 21e eeuw.

Die voorsprong blijft echter niet eeuwig gegarandeerd. Aan de ene kant hebben de financiële crisis vanaf 2008, de daaropvolgende recessie in de Eurozone, en een soevereine schuldencrisis de beleidsruimte door de hele Unie heen drastisch beperkt. Aan de andere kant hebben opkomende economieën met bloeiende industrieën te maken met meer fiscale flexibiliteit en een maatschappelijke roep om beleidshervormingen. In de kern richt dit onderzoek zich op manieren om Europa's voorsprong op het gebied van milieubeleid vast te houden, in het bijzonder door te innoveren met beleidsanalyse, en met aanvullende maatregelen om mogelijkheden te benutten zoals enkel een leider dat kan.

Zelfs op minder gefragmenteerde en gecompliceerde beleidsgebieden dan milieubeleid, is het extreem moeilijk om aan te tonen dat een beleidsoptie beter is dan alle andere opties op tafel. Ook als het minder ingewikkeld is, hoeft namelijk niet iedereen aan tafel overtuigd te raken. Omdat alle tijd en moeite die wordt gestoken in het maken van beleidskeuzes wordt betaald door belastingbetalers, zijn de beschikbare tijd en moeite voor het doel beperkt. De kosten van een echt "rationele-allesomvattende" keuze zijn niet te betalen. Het aantal soorten beleidsinstrumenten stijgt ook, zowel in de praktijk als op de plank.

Economische analyse zit in de kern van alle keuzes. Planten en dieren wegen kosten en baten zorgvuldig af, zelfs als dit uit instinct, en niet vrijwillig of bewust gebeurt. Het blijft immers de eenvoudigste vorm van een rationele keuze. En dat is het sterkte argument voor het gebruiken en het voortdurend verbeteren ervan. Wanneer iemand van zo'n methode gebruik maakt, begrijpen alle anderen gemakkelijk de beweegredenen. Of ze het eens zijn met alle gebruikte parameters, of niet, is een andere vraag, maar ze begrijpen de gekozen methode. Juist omdat ze de elementaire logica begrijpen, zullen velen in staat zijn om scherpzinnige bezwaren over de kleinere details in te brengen. Dat is het lot van economische 
analyse van openbaar beleid, en misschien in grotere mate van milieubeleid in het bijzonder. Hoewel er meerdere vormen van beleidsevaluatie bestaan, nemen evaluaties op het gebied van milieubeleid bijna altijd economische vorm aan, vaak in de vorm van een kosten-batenanalyse (KBA), of haar broertje, kosteneffectiviteitsanalyse (KEA).

Het doel in het eerste deel van dit onderzoek is het voorstellen van een specifieke analytische innovatie en het uitleggen en bestuderen hiervan. De nieuwe methode maakt een categorisch onderzoek en vergelijking van kosten van milieubeleidsinstrumenten mogelijk binnen een goed gedefinieerd referentiekader. Meer specifiek onderzoeken we de keuze van het referentiekader voor KEA, geïnspireerd door een andere populaire vorm van milieu-analyse, LifeCycle-analyse (LCA), waarin veel belang wordt gehecht aan referentiekaders.

De innovatie dient meerdere doelen. Allereerst wordt het mogelijk om een uitgesplitste vergelijking te maken van bijbehorende kosten, wat op haar beurt een schat aan onmisbare informatie levert voor het kritische ontwerp van beleidsinstrumenten op het niveau van de analist. In de Europese Unie maakt de voorgestelde methode het bij het omzetten van regulatie mogelijk om kosten te vergelijken met inachtneming van contextuele verschillen tussen lidstaten. Een goede vergelijking van bepaalde categorieën aan kosten, zoals administratieve kosten, zou ook een vorm van governance-analyse mogelijk maken. Ook helpt het bij het bestuderen van interactie-effecten met kosten van beleid dat tegelijkertijd in andere sectoren wordt gevoerd. Het kostenvraagstuk is ook een belangrijk aandachtspunt bij het operationaliseren van het voorzorgsprincipe, en de keuze voor een analytisch referentiekader zou helpen bij het oplossen van een aantal problemen rondom vermeende onevenredige kosten.

Het proefschrift begint met de geschiedenis van economische analyse en een overzicht van relevante literatuur in hoofdstuk twee. Het behandelt de huidige praktijk op het gebied van milieubeleid en geeft een breed overzicht van zowel oude als nieuwe problemen met KBA, de meestgebruikte methode voor zulke analyses, en waarvan KEA kan worden gezien als een subset. De literatuurstudie is nodig om de beperkingen en de bescheiden reikwijdte van dit proefschrift met betrekking tot het oplossen van openstaande vraagstukken af te kaderen, terwijl tegelijkertijd de belangrijkste vraagstukken worden erkend. Die reikwijdte wordt aan het begin van het volgende hoofdstuk, hoofdstuk 3, afgekaderd door de onderzoeksvragen. In dat hoofdstuk worden ook de methodologische keuzes in de verschillende onderdelen van dit werk onderbouwd. 
Het volgende hoofdstuk gaat over de redenen achter het innoveren met KEA en presenteert de voorgestelde aanpassing. Het behandelt de gedachte achter het idee, introduceert LCA, en legt de aanpassing uit die wordt gemaakt aan de economische analyse van instrumenten voor milieubeleid. Ter illustratie zijn enkele voorbeelden opgenomen.

Hoofdstuk vijf is, in de vorm van kwantitatieve case studies, gewijd aan de analytische tests van de aangepaste methode. Elke case gebruikt een ander computergebaseerd model dat in werkelijkheid wordt gebruikt bij beleidsvorming door overheden, en biedt op deze manier een test met data en parameters uit de praktijk. Het doel is om te laten zien hoe de resultaten van een gebruikelijke KEA veranderen, als extra informatie over de context in het keuzekader zou worden opgenomen door gebruik te maken van de voorgestelde aanpassing. Ook is een poging gedaan om de omkering van keuzes te illustreren, louter om de potentiële impact op beleidsbeslissingen te benadrukken.

Dit wordt gevolgd door een gesprek met de uiteindelijke klanten van dit onderzoek, namelijk beleidsanalisten, in hoofdstuk zes, gebruikmakend van Key Informant Interviews. De discussie probeert informatie te ontdekken over zaken variërend van de aard en mate van het gebruik van economische analyse in de praktijk, tot de typische educatieve achtergrond van de analisten en hun collega's, en de uitdagingen die zij in hun werk treffen.

Een terugkerende bevinding in dat hoofdstuk betreft problemen met de beschikbaarheid van data. Het volgende hoofdstuk zoekt daarom naar oplossingen voor het gebrek aan data in het licht van mogelijkheden die de huidige technologie- en mediatrends bieden. Het hoofdstuk biedt een overzicht van de huidige buzz rond de belofte van Big Data, en doet een empirisch onderzoek naar de potentie van die belofte op dit specifieke gebied. Het afsluitende hoofdstuk, het achtste, stelt vast in hoeverre het onderzoek voldoet aan de vooraf opgestelde doelen, en geeft een kritische beschouwing van de verdere waarde die het onderzoek biedt. Dit hoofdstuk behandelt ook de beperkingen van het onderzoek, en stelt richtingen voor om beperkingen te overwinnen en voor toekomstig onderzoek rondom de centrale ideeën. 


\section{MGSoG Dissertation Series}

Irina Burlacu

An Evaluation of Tax Benefit Systems Impact on the Welfare of Frontier Workers

The Case of Luxembourg and Belgium

MGSoG Dissertation Series, nr 51 (2014)

Özge Bilgili

Simultaneity in Transnational Migration Research:

Links Between Migrants' Host and Home Country Orientation

MGSoG Dissertation Series, nr 50 (2014)

Yulia Krieger

Reshaping the Big Agenda: Transnational Politics and Domestic Resistance

Financial crisis and social protection reform in Bosnia and Herzegovina

MGSoG Dissertation Series, nr 49 (2014)

Marieke van Houte

Moving Back or Moving Forward?

Return migration after conflict

MGSoG Dissertation Series, nr 48 (2014)

Oxana Slobozhan

Global Governance in the Management of Natural Resources:

The Case of the Extractive Industries Transparency Initiative (EITI)

MGSoG Dissertation Series, nr 47 (2014)

Luis Bernardo Mejia Guinand

The Changing Role of the Central Planning Offices in Latin America:

A Comparative Historical Analysis Perspective (1950-2013)

MGSoG Dissertation Series, nr 46 (2014)

Cheng Boon Ong

Ethnic Segregation in Housing, Schools and Neighbourhoods in the Netherlands

MGSoG Dissertation Series, nr 45 (2014)

Luciana V. Cingolani

Bureaucracies for Development: Oxymoron or Reality?

Studies on State Capacity in Challenging Governance Contexts

MGSoG Dissertation Series, nr 44 (2014) 
Carlos Cadena Gaitán

Green Politics in Latin American Cities - Sustainable Transport Agendas

MGSoG Dissertation Series, nr 43 (2014)

Katie Kuschminder

Female Return Migration and Reintegration Strategies in Ethiopia

MGSoG Dissertation Series, nr 42 (2014)

Metka Hercog

Highly-Skilled Migration and New Destination Countries

MGSoG Dissertation Series, nr 41 (2014)

Margaret Agaba Rugadya

Can Remittances Influence the Tenure and Quality of Housing in Uganda?

MGSoG Dissertation Series, nr 40 (2014)

Ilire Agimi

New Governance Under Limited Statehood

The Case of Local Government Reform in Kosovo

MGSoG Dissertation Series, nr 39 (2014)

Kristine Farla

Empirical Studies on Institutions, Policies and Economic Development

MGSoG Dissertation Series, nr 38 (2013)

Marina Petrovic

Social Assistance and Activation in the Pursuit of Happiness:

Shedding New Light on Old Policy Solutions to Social Exclusion

MGSoG Dissertation Series, nr 37 (2013)

Laura Torvinen

Assessing Governance Assessments; The Case of Mozambique

Governance Assessments in the Context of Aid Effectiveness Discourse

MGSoG Dissertation Series, nr 36 (2013)

Biniam Egu Bedasso

Institutional Change in the Long Shadow of Elites

Essays on Institutions, Human Capital and Ethnicity in Developing Countries

MGSoG Dissertation Series, nr 35 (2013) 
Sepideh Yousefzadeh Faal Deghati

Childhoods Embargoed

Constructing and Reconstructing Multidimensional Child Poverty in Iran 1984-2009

MGSoG Dissertation Series, nr 34 (2013)

Robert Bauchmüller

Investing in Early Childhood Care and Education:

The Impact of Quality on Inequality

MGSoG Dissertation Series, nr 33 (2013)

Martin Rehm

Unified Yet Separated

Empirical Study on the Impact of Hierarchical Positions within Communities of Learning MGSoG Dissertation Series, nr 32 (2013)

Dorcas Mbuvi

Utility Reforms and Performance of the Urban Water Sector in Africa

MGSoG Dissertation Series, nr 31 (2012)

Lina Salanauskaite

Distributional Impacts of Public Policies:

Essays in Ex-Ante and Ex-Post Evaluation

MGSoG Dissertation Series, nr 30 (2012)

Esther Schüring

To Condition or not - is that the Question?

An Analysis of the Effectiveness of Ex-Ante and Ex-Post Conditionality in Social Cash

Transfer Programs

MGSoG Dissertation Series, nr 29 (2012)

Joe Abah

Strong Organisations in Weak States

Atypical Public Sector Performance in Dysfunctional Environments

MGSoG Dissertation Series, nr 28 (2012)

Zina Samih Nimeh

Social Citizenship Rights: Inequality and Exclusion

MGSoG Dissertation Series, nr 27 (2012)

Lenka Eisenhamerová

Legitimacy of 'Humanitarian Military Intervention'

MGSoG Dissertation Series, nr 26 (2011) 
Sonila Tomini

Informal Payments for Health Care Services in Albania

MGSoG Dissertation Series, nr 25 (2011)

Jinjing Li

Dynamic Microsimulation in Public Policy Evaluation

MGSoG Dissertation Series, nr 24 (2011)

Aziz Atamanov

Rural Nonfarm Employment and International Migration as Alternatives to Agricultural

Employment:

The Case of Kyrgyzstan

MGSoG Dissertation Series, nr 23 (2011)

Frieda Vandeninden

Poverty Alleviation: Aid and Social Pensions

MGSoG Dissertation Series, nr 22 (2011)

Juliana Nyasha Tirivayi

The Welfare Effects of Integrating AIDS Treatment with Food Transfers:

Evidence from Zambia

MGSoG Dissertation Series, nr 21 (2011)

Agnieska Ewa Sowa

Who's Left Behind? Social Dimensions of Health Transition and Utilization of Medical Care in Poland

MGSoG Dissertation Series, nr 20 (2011)

Emmanaouil Sfakianakis

The Role of Private Actors in the Provision of Public Goods with Applications to Infrastructure and Financial Stability

MGSoG Dissertation Series, nr 19 (2011)

Siu Hing Lo

White Collars Green Sleeves

An Interonganizational Comparison of Determinants of Energy-Related Behaviors among Office Workers

MGSoG Dissertation Series, nr 18 (2011) 


\section{Treena $\mathrm{Wu}$}

Constraints to Human Capital Investment in Developing Countries:

Using the Asian Financial Crisis in Indonesia as a Natural Experiment

MGSoG Dissertation Series, nr 17 (2011)

\section{Henry Espinoza Peña}

Impact Evaluation of a Job-Training Programme for Disadvantaged Youths:

The Case of Projoven

MGSoG Dissertation Series, nr 16 (2011)

Florian Tomini

Between Family and Friends

Understanding the Interdependency of Private Transfers

MGSoG Dissertation Series, nr 15 (2010)

Michał Polalowski

The Institutional Transformation of Social Policy in East Central Europe:

Poland and Hungary in comparative and historical perspective

MGSoG Dissertation Series, nr 14 (2010)

Maha Ahmed

Defining, Measuring and Addressing Vulnerability:

The Case of Post Conflict Environments

MGSoG Dissertation Series, nr 13 (2010)

\section{Pascal Beckers}

Local Space and Economic Success

The role of spatial segregation of migrants in the Netherlands

MGSoG Dissertation Series, nr 12 (2010)

Victor Cebotari

Conplicting Demands in Ethnically Diverse Societies

Ethnopolitical Contention and Identity Values in Europe

MGSoG Dissertation Series, nr 11 (2010)

Dennis Gyllensporre

Competing and Complementary Perspectives on the EU as a Crisis Management Actor:

An Examination of the Common Security and Defence Policy through the Lenses of

Idealism and Realism

MGSoG Dissertation Series, nr 10 (2010) 
Judit Vall Castello

Business Cycle and Policy Effects on Labour Market Transitions of Older and Disabled Workers in Spain

MGSoG Dissertation Series, nr. 9 (2010)

Keetie Roelen

False Positives or Hidden Dimensions: the definition and measurement of child poverty MGSoG Dissertation Series, nr. 8 (2010)

Denisa Maria Sologon

Earning Dynamics in Europe

MGSoG Dissertation Series, nr. 7 (2010)

Melissa Siegel

Money and Mobility: Migration and Remittances

MGSoG Dissertation Series, nr. 6 (2010)

Jessica S. Hagen-Zanker

Modest Expectations: Causes and effects of migration on migrant households in source countries

MGSoG Dissertation Series, nr. 5 (2010)

Mirtha R. Muniz Castillo

Human Development and Autonomy in Project Aid: Experiences from four bilateral projects in Nicaragua and El Salvador

MGSoG Dissertation Series, nr. 4 (2009)

Christiane Arndt

Governance Indicators

MGSoG Dissertation Series, nr. 3 (2009)

Britta Augsburg

Microfinance - Greater Good or Lesser Evil?

MGSoG Dissertation Series, nr. 2 (2009)

Geranda Notten

Measuring and Managing Poverty Risks

MGSoG Dissertation Series, nr. 1 (2008) 
अयं निज: परो वेति गणना लघुचेतसाम् । उदारचरितानां तु वसुधैव कुटुम्बकम्॥ 